\title{
Disuse and physical deconditioning in chronic low back pain
}

Citation for published version (APA):

Verbunt, J. A. M. C. F. (2003). Disuse and physical deconditioning in chronic low back pain. [Doctoral Thesis, Maastricht University]. Universiteit Maastricht. https://doi.org/10.26481/dis.20040116jv

Document status and date:

Published: 01/01/2003

DOI:

10.26481/dis.20040116jv

Document Version:

Publisher's PDF, also known as Version of record

\section{Please check the document version of this publication:}

- A submitted manuscript is the version of the article upon submission and before peer-review. There can be important differences between the submitted version and the official published version of record.

People interested in the research are advised to contact the author for the final version of the publication, or visit the DOI to the publisher's website.

- The final author version and the galley proof are versions of the publication after peer review.

- The final published version features the final layout of the paper including the volume, issue and page numbers.

Link to publication

\footnotetext{
General rights rights.

- You may freely distribute the URL identifying the publication in the public portal. please follow below link for the End User Agreement:

www.umlib.nl/taverne-license

Take down policy

If you believe that this document breaches copyright please contact us at:

repository@maastrichtuniversity.nl

providing details and we will investigate your claim.
}

Copyright and moral rights for the publications made accessible in the public portal are retained by the authors and/or other copyright owners and it is a condition of accessing publications that users recognise and abide by the legal requirements associated with these

- Users may download and print one copy of any publication from the public portal for the purpose of private study or research.

- You may not further distribute the material or use it for any profit-making activity or commercial gain

If the publication is distributed under the terms of Article $25 \mathrm{fa}$ of the Dutch Copyright Act, indicated by the "Taverne" license above, 


\title{
DISUSE AND PHYSICAL DECONDITIONING
} IN CHRONIC LOW BACK PAIN

\author{
Jeanine Verbunt
}


Painting: Equinox by Sylvia Goebel, Germany. Reprinted with permission.

Cover design and layour: Ingrid Schreibers, SRL, Hoensbrock

Printed by: Drukkerij Schrijen-Huntjens, Voerendaal

The printing of this thesis is financially supported by the Institute for Rehabilitation Research (iRv), the Rehabilitation Foundation Limburg (SRL), the University of Maastricht, the Laurentius Hospital Roermond and Allergan BV.

All rights are reserved. No part of this publication may be reproduced or transmitted in any form or by any means, without permission in writing form of the copyright owner.

Disuse and physical deconditioning in chronic low back pain/ Jeanine A. Verbunt- Thesis University Maastricht- With references-With summary in Dutch

ISBN 90-9017422-2

(C) 2003 Jeanine A. Verbunt, Maastricht, The Netherlands 


\section{DISUSE AND PHYSICAL DECONDITIONING IN CHRONIC LOW BACK PAIN}

\section{PROEFSCHRIFT}

ter verkrijging van de graad van doctor aan de Universiteit Maastricht, op gezag van de Rector Magnificus, Prof. mr. G.P.M.F. Mols volgens het besluit van het College van Decanen, in het openbaar te verdedigen op vrijdag 16 januari 2004 om 14.00 uur

door

Jeanine (Adriana, Maria, Christina, Francisca) Verbunt

geboren op 9 augustus 1969

te Breda 


\section{Promotor}

Prof. dr. J.A. Knottnerus

Co-promotores

Dr. G. van der Heijden (Juliuscentrum, Universiteit Utrecht)

Dr. J.W.S. Vlaeyen

Beoordelingscommissie

Prof. dr. H. Kuijpers

(voorzitter)

Prof, dr. L. Goeken

(Rijksuniversiteit Groningen)

Dr. M. Peters

Prof. dr. P. Watson (University of Leicester, UK)

Prof. dr. D. Wade $\quad$ (Oxford Centre for Enablement, Oxford, UK;

Universiteit Maastricht)

The studies in this thesis are supported by grants from the Council for Medical and Health Research of the Netherlands (NWO-MW, nr. 904-65-090), Zorgonderzoek Nederland (ZON, nr. 96-06-006) and the foundation "De Drie Lichten". 


\section{CONTENTS}

Page

Chapter one

Introduction

Chapter two

Disuse and deconditioning in chronic low back pain:

concepts and hypotheses on contributing mechanisms.

Chapter three

Physical activity in daily life in patients with chronic

low back pain.

Chapter four

Fear of injury and physical deconditioning in patients with chronic low back pain.

Chapter five

Pain-related factors contributing to muscle inhibition in patients with chronic low back pain;

An experimental investigation based on superimposed electrical stimulation.

Chapter six

Decline in physical activity, disability and pain related fear in sub-acute low back pain.

Chapter seven

General discussion

Chapter eight

Summary/Samenvatting

About the author

Dankwoord 
ำ 
Chapter one

INTRODUCTION 


\section{THE IMPACT OF THE PROBLEM OF LOW BACK PAIN}

Acute low back pain (LBP) is a common health problem in industrialised western countries (Andersson, 1999). Epidemiological studies in western countries have reported an annual LBP incidence of about $5 \%$ (Frymoyer JW and Cats-Baril WL, 1991) and a life time incidence ranging from 48.8 to 69.9 (Andersson, 1999). A study in the Netherlands reported a 12 month period prevalence of 44 to $55 \%$ (Picavet et al, 1999). For the majority of low back pain patients the pathogenetic mechanism of low back pain is unknown (Waddell and Turk, 2001). Most of the time, however, back pain is like a self limiting disease. 75 to $90 \%$ of patients with acute low back pain recover within four to six weeks (Frymoyer, 1988). A minority (lower than $10 \%$ ) of patients who have acute pain without a known specific cause, eventually develops chronic low back pain (CLBP). However, this group accounts for $75 \%$ to $90 \%$ of the societal costs of back pain (Nachemson, 1992). The psychological, social and financial consequences of the problem of CLBP underscores the relevance of finding out the reasons why low back pain becomes chronic in this subgroup of patients.

The main question is: What makes this subgroup of patients more vulnerable for developing pain-related disability compared to other patients? To answer this question over the years much research has been concentrated on the explanation and prediction of chronicity in low back pain. Already in the seventeenth century, the French philosopher Rene Descartes was one of the first to present his Cartesian model of specific pain pathways, which has been extremely influential in the research on pain. Even today, a lot of pain treatments are based on his assumptions. According to Descartes, pain was a reflex of the mind upon nociceptive stimulation of the body. Pain treatment was therefore based on the localization of the underlying pathology and successively removal of the pathology with appropriate remedy or cure. In the absence of bodily damage, according to Descartes, a psychic pathology was inferred. (Descartes, 1664; as translated by Foster, 1901). In the explanation of disability in chronic pain, however, no consistent and sufficiently strong relation between biomedical findings and pain has been found to explain disability in back pain patients solely according the Cartesian model (Burton et al, 1989; Waddell et al, 1992; Gronblad et al, 1997). To deal with the shortcomings of this biomedical oriented model, Melzack and Wall introduced in 1965 the gate control theory. Instead of concentrating on biomedical findings, the gate control theory focuses on an interaction of neurophysiological and psychological activity that was hypothesized to modulate pain and help explain the complexity of clinical pain. A major contribution of the gate control theory was that it highlighted the central nervous system as an essential component in the pain processes and perception. It changed the way of thinking about pain perception. However, although the gate control theory provided a physical basis for the role of psychological 
factors in pain, it does not address the nature of participating psychological factors in depth. A new era in thinking about chronic pain began with Fordyce's description of the role of operant factors in chronic pain (1976). The basis of his contribution was the assumption that factors maintaining the pain problem were not necessarily the same as those initiating pain. This resulted in a new clinical model of pain: the biopsychosocial model, in which biomedical, psychological, interpersonal and social factors together explain the course of back pain. This model stands in sharp contrast to the traditional biomedical perspective, which conceptualises illness in terms of more narrowly defined psycho medical dimensions.

According to Fordyce, the focus of treatment for chronic pain should be directed to "pain behaviour", which refers to observable signs of pain and suffering. Although pain can originally arise from neurophysiological stimuli originating in the back in case of tissue damage (which is called nociception), its eventual clinical presentation involves other aspects than only physical factors. Pain behaviour reflects the severity of the physical problem, but its final expression may depend more on psychological rather then the underlying physical problem. Beliefs about pain, coping strategies and psychological distress influence the way a patient behaves as a reaction to pain. Pain, but especially pain behaviour is an important factor in communication (verbal and non-verbal) concerning pain with the patient's environment, including communication with health professionals. Therefore in the interpretation of a patient's current level of pain and disability biomedical, psychological, behavioural and social factors have to be taken in account together.

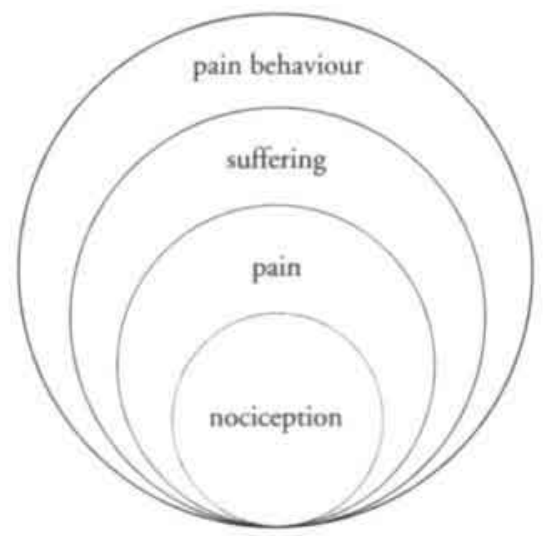

Figure 1: A bio-psychosocial model of components of chronic pain (Loeser et al, 1980). 
Over time, based on the biopsychosocial model, various more specified behavioural and pain related factors have been introduced as contributors to the explanation of disability in low back pain. In 1983, Turk et al emphasized the role of attribution, efficacy expectations, personal control and problem solving within the cognitive behaviour perspective on chronic pain. In recent years, fear of injury, has been introduced as one of the hypothesized contributing factors for disability in chronic pain (Vlacyen, 1995). In figure 2 the biopsychosocial model on the role of pain-related fear in chronic low back pain is presented.

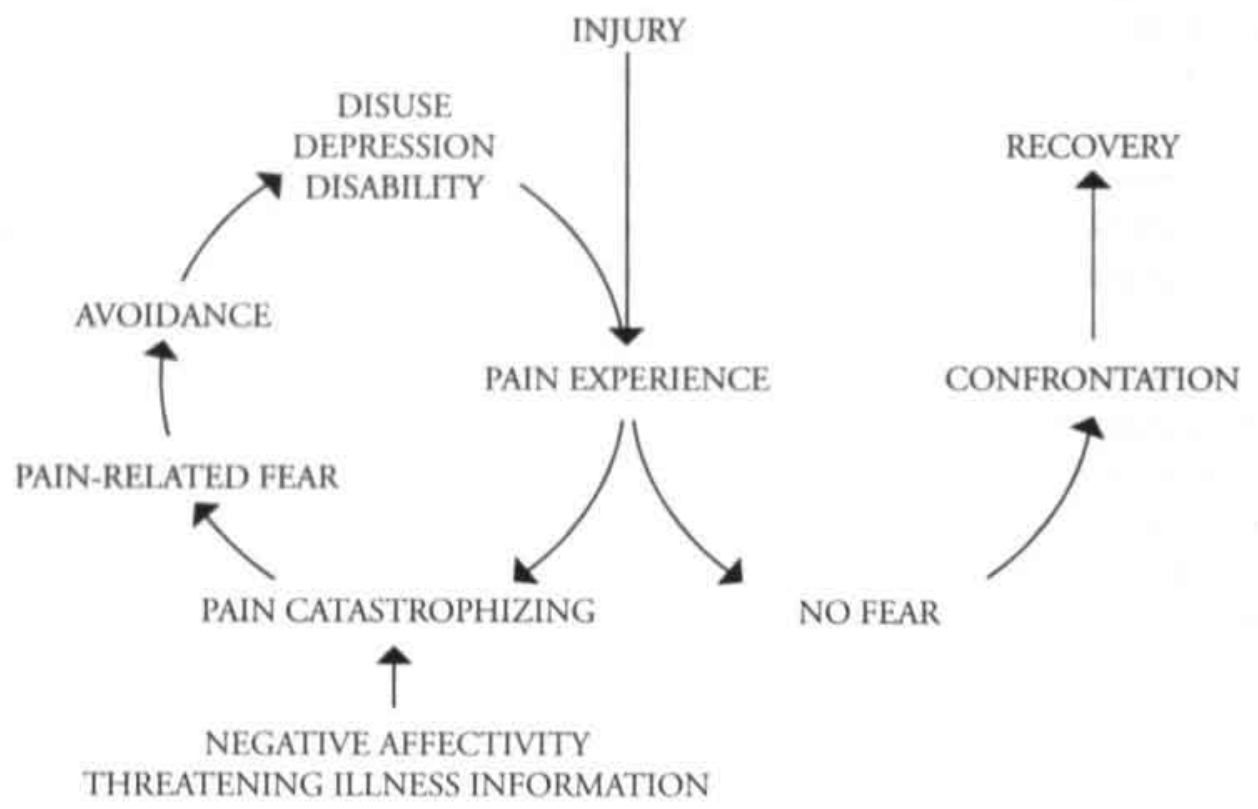

Figure 2: Fear of movement/(ne)injury as a determinant of pain disability (Vlacyen and Linton, 2000).

According to this fear-avoidance model, there are two opposing behavioural responses as a reaction to a pain-related injury: confrontation and avoidance. The "confronters" are patients who, although they have pain, persist in performing their daily activities and therefore will continue to participate in daily life situations without many implications. In contrast, for "avoiders" the impact of pain on life will be more explicit. These patients fear an increase of pain or even (re)injury. Negative thoughts about pain and its consequences, i.e. pain catastrophizing, can be a potential precursor for painrelated fear. Negative affectivity and wrongful interpretation of medical information can mediate the problem of pain catastrophizing. The resulting pain-related fear is characterized by escape and avoidance behaviour, of which the immediate consequences are that daily activities, that are expected to cause pain, are not accomplished anymore. Avoidance behaviour occurs in anticipation to pain rather than 
as a response to pain. This way of behaviour may persist for a long time because there are not many opportunities to correct these incorrect expectations and beliefs about pain. In the long run, avoidance behaviour can result in a combination of negative health consequences: disability, depression and disuse. The latter may be defined as a decreased level of physical activities in daily life, in the long term leading to physical deconditioning. Depression and long term inactivity are even thought to be associated with a decreased pain tolerance, which will even worsen the pain problem, leading to a downward spiral of the impact of the pain problem on a patient's life.

In contrast to the influence of fear on the perceived disability level, which has been confirmed frequently (Riley et al, 1988; Waddell et al, 1993; Vlacyen et al, 1995, Klenerman et al, 1995; Mc Cracken et al, 1996; Crombez et al, 1999) the presumed negative influence of fear on the level of physical activity in daily life (in the model presented as disuse) and accompanying physical deconditioning has been studied less. Nevertheless, the assumption that physical deconditioning in chronic low back pain has its role in the chronicity of back pain has been present in the choice for the composition of treatment programmes for years. A lot of rehabilitation programmes for non-specific CLBP focus on reconditioning. However, evidence to prove the assumption of a lower level of physical activity in daily life and a fitness deficit associated with CLBP is still inconclusive.

In this thesis the role of physical deconditioning in CLBP is investigated. Aims for research in this thesis are consecutively: An extensive review of the literature concerning the role of physical activity and physical fitness in CLBP; An evaluation of physical activity in daily life and physical fitness in patients with CLBP; The identification of interfering factors in physical performance of patients with CLBP; The identification of prognostic factors for disability and physical deconditioning related problem in patients with CLBP. 


\section{OUTLINE OF THIS THESIS}

In chapter $\mathbf{2}$ an overview is presented as to the literature concerning physical deconditioning and chronic low back pain. Terms like 'disuse', 'physical deconditioning' and 'disuse syndrome' are defined. Possible mechanisms that contribute to the development of physical deconditioning in CLBP, such as avoidance behaviour and suppressive behaviour, are discussed, as are the presence of physiological changes associated with deconditioning and functional changes due to deconditioning in patients with CLBP. Results of studies regarding the level of physical activities in daily life (PAL) and the level of physical fitness in patients with CLBP compared to healthy controls are reviewed.

In chapter 3 PAL in patients with CLBP is investigated. In a cross-sectional case control study the level of physical activity in daily life of patients with CLBP is compared to activity levels in age and sex matched healthy controls, in order to evaluate the presence of disuse in the former population. Furthermore, the validity of accelerometry as a method to assess physical activity in daily life in patients with chronic low back pain is discussed.

Chapter 4 focuses on physical fitness in patients with CLBP. This multidimensional phenomenon of physical fitness includes important parameters like aerobic fitness, muscle strength, muscle endurance, muscle power and joint flexibility. Of all fitnessrelated parameters aerobic fitness in healthy subjects is best related to a person's physical activity level in daily life. In case of a lower level of physical activity in CLBP, changes in aerobic fitness, representing physical deconditioning, have to be expected. In a crosssectional study design the assumption that fear of injury leads to disability and physical deconditioning, as presented in the fear avoidance model on patients with CLBP, is tested. Furthermore the relation between disability and physical deconditioning in CLBP is discussed.

In chapter 5 muscle strength, another parameter of physical fitness, is investigated. The hypothesis that patients with CLBP have a lower level of physical fitness compared to healthy controls is tested. Physical deconditioning, expressed as a decrease in muscle strength in patients with CLBP as compared to healthy age and gender matched controls, is evaluated in a case control study with a cross-sectional design. Furthermore, the complexity of using performance tests, such as strength tests, as a measure for physical changes of the human body in CLBP is addressed. The central activation ratio is used as a representation of the performance level during strength testing. The contribution of cognitive behavioural and pain-related factors to the performance level of patients with CLBP is discussed. 
Chapter 6 focuses on patients with subacute low back pain (SL.BP; i.e. 4 to 7 weeks after a non-specific back pain complaint). In this study the hypothesis is tested whether a decline in the level of physical activities due to the pain episode is more disabling than the actual level of activities. Furthermore the role of an activity decline in the association fear and disability is investigated. Do fearful patients indeed experience an activity decline, which successively leads to disability? And is this disabling role of a decline in activities also present for catastrophizing patients? Further unravelling will test the hypothesis whether the disabling influence of a decline in activities differs between patients who had an active lifestyle before their back pain started and formerly sedentary persons.

Finally chapter 7 provides a critical appraisal of the results of the different studies presented in this thesis and their interdependency. Furthermore, this chapter includes a general discussion regarding the role of fear avoidance on physical activity and physical fitness in CLBP. The relation between both physical activity and physical fitness with disability in patients with CLBP will be discussed. Practical consequences for rehabilitation care are addressed. Finally this chapter provides recommendations for further research on the subject of physical activity and physical fitness in patients with CLBP. 


\section{REFERENCES}

- Andersson GB. Epidemiological features of chronic low back pain. Lancet 1999;354:581-585.

- Burton AK, Tillotson KM, Troup JDG. Variation in lumbar sagittal mobility with low back trouble. Spine 1989;14:584-590.

- Crombez G, Vlaeyen JWS, Heuts PHTG, Lysens R. Fear of pain is more disabling than pain itself. Evidence on the role of pain-related fear in chronic back pain disability. Pain 1999;80:329-340.

- Fordyce WE. Behavioural methods for chronic pain and illness. St Louis, Mosby, 1976.

- Foster M. Lectures on the history of physiology during the sixteenth, seventeenth and eighteenth centuries. Cambridge University Press, Cambridge (translated from Descartes R 1664 L'homme).

- Frymoyer JW, Back pain and sciatica. N Engl J Med 1988;318(5):291-300.

- Frymoyer JW, Cats-Baril WL. An overview of the incidence and costs of low back pain. Orthop Clin N Am 1991;22:263-271.

- Gronblad M, Hurri H, Kouri JP. Relationships between spinal mobility, physical performance tests, pain intensity and disability assessments in chronic low back pain patients. Scan J Rehabil Med 1997:29;17-24.

- Klenerman L, Slade PD, Stanley M, Pennie B, Reilly JP. The prediction of chronicity in patients with an acute attack of low back pain in a general practice setting. Spine 1995;20:478-484.

- Loeser JD. Perspectives on pain. In: Turner P. Clinical pharmacy and therapeutics. Macmillan, London, 1980;313-316.

- McCracken LM, Gross RT, Aikens J, Carnkike JCLM. The assessment of anxiety and fear in persons with chronic pain: a comparison of instruments. Beh Res Ther 1996:34:927- 933 .

- Melzack R and Wall PD. Pain mechanisms: a new theory. Science 1965;150(699):971-979.

- Nachemson AL. Newest knowledge of low back pain. A critical look. Clin Orthop 1992;279:8-20.

- Picavet HS, Schouten JS, Smit HA. Prevalence and consequences of low back problems in The Netherlands, working versus non-working population, the MORGEN-Study. Monitoring Project on Risk Factors for Chronic Disease. Public Health 1999;113(2):73-7.

- Pope MH, Rosen JC, Wilder DG, Frymoyer JW. The relation between biomechanical and psychological factors in patients with low-back pain. Spine 1979;5:173-178. 
- Riley JF, Ahern DK, Follick MJ. Chronic pain and functional impairment: assessing beliefs about their relationship. Arch Phys Med Rehabil 1988;69:579-582.

- Turk DC, Meichenbaum D, Genest M. Pain and behavioral medicine. A cognitivebehavioral perspective. New York. Guilford Press, 1983.

- Vlaeyen JWS, Kole-Snijders AM, Rotteveel AR, Ruesink R, Heuts PH. The role of fear of movement/(re)injury in pain disability. J Occup Rehabil 1995;5(4):235-52.

- Vlacyen JWS, Linton SJ. Fear-avoidance and its consequences in chronic musculoskeletal pain: a state of the art. Pain 2000;85:317-332.

- Waddell G, Bircher M, Finlayson D, Main CJ. Symptoms and signs: physical disease or illness behavior? BMJ 1984;289:739-741.

- Waddell G. Volvo award in clinical sciences. A new model for the treatment of lowback pain. Spine 1987;12(7):632-644.

- Waddell G, Sommerville D, Henderson I, Newton M. Objective clinical evaluation of physical impairments in chronic low back pain. Spine 1992;17:617-628.

- Waddel G and Turk DC. Clinical assessment in low back pain. In: Turk D and Melzack R, Handbook of pain assessment. Second edition. New York, The Guilford Press, 2001.

- Waddell G, Newton M, Henderson I, Somerville D, Main C. A Fear-Avoidance Beliefs Questionnaire (FABQ) and the role of fear-avoidance beliefs in chronic low back pain and disability. Pain 1993;52:157-168. 
$\frac{8}{8}$ 
Chapter Two

DISUSE AND DECONDITIONING IN CHRONIC LOW BACK PAIN: CONCEPTS AND HYPOTHESES ON CONTRIBUTING MECHANISMS

Jeanine A. Verbunt, Henk A. Seelen, Johan W. Vlaeyen, Geert J. van der Heijden, Peter H. Heuts, Kees Pons, J. André Knottnerus

Published as:

J. Verbunt, H. Seelen, J. Vlaeyen, G. van der Heijden, P. Heuts, K. Pons and A. Knottnerus. Disuse and deconditioning in chronic low back pain: concepts and hypotheses on contriburing mechanisms.

Eur J Pain 2003;7:9-21. Reprinted with permission from Elsevier Science Ltd. 


\section{Abstract}

For years enhancement of a patient's level of physical fitness has been an important goal in rehabilitation treatment in chronic low back pain (CLBP), based on the hypothesis that physical deconditioning contributes to the chronicity of low back pain. However, whether this hypothesis in CLBP holds is not clear. In this article, possible mechanisms that contribute to the development of physical deconditioning in CLBP, such as avoidance behaviour and suppressive behaviour, are discussed. The presence of both deconditioning-related physiological changes, such as muscle atrophy, changes in metabolism, osteoporosis and obesity as well as deconditioning related functional changes, such as a decrease in cardiovascular capacity, a decrease in muscle strength and impaired motor control in patients with CLBP are discussed. Results of studies on the level of physical activities in daily life (PAL) and the level of physical fitness in patients with CLBP compared to healthy controls were reviewed. In studies on PAL results that were either lower or comparable to healthy subjects were found. The presence of disuse (i.e. a decrease in the level of physical activities in daily life) in patients with CLBP was not confirmed. The inconclusive findings in the papers reviewed may partly be explained by different measurement methods used in research on PAL in chronic pain. The level of physical fitness of CLBP patients also appeared to be lower or comparable to the fitness level of healchy persons. A discriminating factor between fit and unfit patients with back pain may be the fact that fit persons more frequently are still employed, and as such may be involved more in physical activity. Lastly some suggestions are made for further research in the field of disuse and deconditioning in CLBP. 


\section{INTRODUCTION}

Pain in the musculoskeletal system is a major health problem in the industrialised countries. In 1991, 12.5\% of the Dutch population consulted a health care professional for musculoskeletal pain problems, of which low back pain was the most prevalent problem (Tulder et al, 1995). Specific back pain occurs in no more than approximately $2 \%$ of all patients with back complaints (Spizzer et al, 1987). For the majority of low back pain patients the pathogenetic mechanism of low back pain is unknown. A relatively small percentage (up to $10 \%$ ) of patients who have acute pain without a specific cause, eventually develops chronic pain. However, this group accounts for $75 \%$ to $90 \%$ of the societal costs of back pain (Nachemson, 1992). It is therefore important to find the reasons why low back pain becomes chronic in this subgroup of parients.

In recent years, physical disuse has been presented as one of the perpetuating factors for chronicity in theoretical research models on pain (Hasenbring et al, 1994: Vlacyen et al, 1995a). Disuse, or a decreased level of physical activity in daily life, could lead to physical deconditioning or an extremely low level of physical fitness. For several decades, physical reconditioning has been proposed in clinical practice as a goal in the treatment of patients with chronic pain, resulting in a variety of rehabilitation programs based on reconditioning. However, inactivity has not only become a topic in chronic pain management, but also in general medicine. In 1993-1997, a large descriptive study on the physical activities in daily life of the Dutch population aged 20 to 64 years, showed that $21 \%$ of all participants led an inactive lifestyle (i.e. were active in moderate activities for less than half an hour five times a week. Schuit et al, 1999). This may give rise to the question whether the deconditioning problem in chronic pain exceeds its presence in the general population. The extent of the problem of deconditioning in chronic pain and its specific perpetuating role in chronicity are still unclear. Is physical deconditioning only a result of a decreased physical activity level in pain and is it reversible when pain disappears? Or has deconditioning a perpetuating role for pain itself?

In this article literature on disuse and deconditioning in CLBP will be reviewed. Firstly, the available data on the concepts of disuse and deconditioning, as presented in literature, will be discussed. Secondly, the level of physical activity in daily life (PAL) in patients with CLBP will be reviewed. Thirdly, the available data on the level of physical fitness is discussed in patients with CLBP. And finally, future goals in research will be addressed. 


\section{Defining Disuse, Deconditioning and the Disuse syndrome}

As early as $1199 \mathrm{AD}$, Maimonides warned of the danger of physical inactivity: "Anyone who lives a sedentary life and does not exercise, even if he eats good foods and takes care of himself according to proper medical principles, all his days will be painful ones and his strength shall wane." (from Buschbacher, 1996). In the twentieth century, the term "disuse" was introduced. In 1946 Young published "The effects of use and disuse on nerve and muscle", presenting his observations on the inactive human body. He referred to disuse as the process of "not using the musculoskeletal system" in times of physical immobility. The changes of the human body that are the result of long-term immobility are often referred to as deconditioning. There is a wealth of physiology literature on deconditioning. Over time, the term "disuse" was also introduced in a different context. There, disuse refers to the inappropriate use of the musculoskeletal system that merely results in a change in the quality of movement. In the case of chronic pain, for example, muscles are not optimally co-ordinated during movement, which leads to inefficient usage or an asymmetrical gait. Main and Watson (1996) introduced the term "guarded movement": abnormalities in muscle action in CLBP patients during physical activity.

In 1984, the "disuse syndrome" is mentioned in literature for the first time. Bortz (1984) focused on the consequences of long-term inactivity and proposed to consider disuse as a syndrome, rather than a symptom. The identifying characteristics of the disuse syndrome, as quoted by Bortz, were multidimensional: cardiovascular vulnerability, obesity, musculoskeletal fragility, depression and premature ageing. The focus was on the physical consequences of inactivity. The psychological consequences were considered to be caused mainly by social deprivation.

In Bortz's concept of the disuse syndrome, the reason for inactive behaviour was not considered. He wrote his paper from a physiological point of view. The main theme of his article was: What will happen to healthy persons if they are extremely inactive? In clinical practice, however, a disuse syndrome will seldom appear as a separate condition. There is nearly always a specific reason for depriving oneself from social and physical activities. The causes for such inactive behaviour can be of a somatic or a psychological nature. For most people, it is probably a health problem with a great impact on their wellbeing. Especially the psychological consequences of this health problem will confound those of inactivity. Evaluating aspects of the disuse syndrome in healthy persons in an experimental setting is much easier than evaluating the syndrome in patients suffering from chronic pain. In patients with chronic pain, inactivity can indeed result in psychological problems, according to Bortz's concept. But above all, the impact of pain and the problems in coping with pain in daily life of CLBP patients 
seem more likely to provoke psychological distress than inactivity. It is difficult to distinguish the disuse syndrome, as presented by Bortz, from the chronic low back pain syndrome.

In contrast to Bortz's view on the disuse syndrome, which focuses on human (in)activity in general and does not specifically address CLBP patients, Mayer and Gatchel (1988) focused in particular on the consequences of long-term inactivity in patients with musculoskeletal pain. They introduced the term "deconditioning syndrome" for patients with pain who also suffer from both physiological and psychological loss of physical fitness (1988). Among the components of physiological deconditioning they also included muscle atrophy, decreased cardiovascular endurance, decreased neuromuscular co-ordination, and a decreased ability to perform complicated repetitive tasks. They referred to psychological deconditioning as a set of behavioural and psychological problems that occur in response to chronic pain and the patient's attempt to cope with that pain. According to Mayer and Gatchel, psychological deconditioning included the response to both pain and inactivity. In the final stage, a deconditioning syndrome is the result of the interaction between physical and psychological deconditioning.

The discrepancy between the concepts of Bortz on the one hand and Mayer and Gatchel on the other, is most prominent in the psychological consequences of inactivity. Bortz described the psychological consequences in the syndrome as a result of inactivity, whereas Mayer and Gatchel described psychological deconditioning as a reaction to both pain and inactivity and not as solely the result of inactivity. In the concept of Mayer and Gatchel, the deconditioning syndrome in chronic pain covers almost the entire concept of the chronic pain syndrome as described by Pinsky and Crue (1984). Pinsky and Crue defined the three main aspects of the chronic pain syndrome as follows: no causality between pain and pathophysiological or pathoanatomical processes, a history of unsuccessful medical interventions, and a disturbance in the patient's psychosocial functioning in combination with pain.

Clear definitions are a prerequisite for understanding the role of long-term physical inactivity in chronic pain. In this article, three different constructs are proposed: "disuse", "deconditioning" and "disuse syndrome". The expression "disuse" can be read as "performing at a reduced level of physical activity in daily life". Disuse refers to a behavioural component leading to physical inactivity. The construct of "physical deconditioning" can best be described as "a decreased level of physical fitness with an emphasis on the physical consequences of physical inactivity for the human body". And 
lastly, the "disuse syndrome" is defined as "a result of long-term disuse, which is characterised by both physical and psychosocial effects of inactivity". In this definition, psychosocial consequences of inactivity are reactive to disuse and not reactive to pain itself. Figure 1 represents the different constructs and their relations.
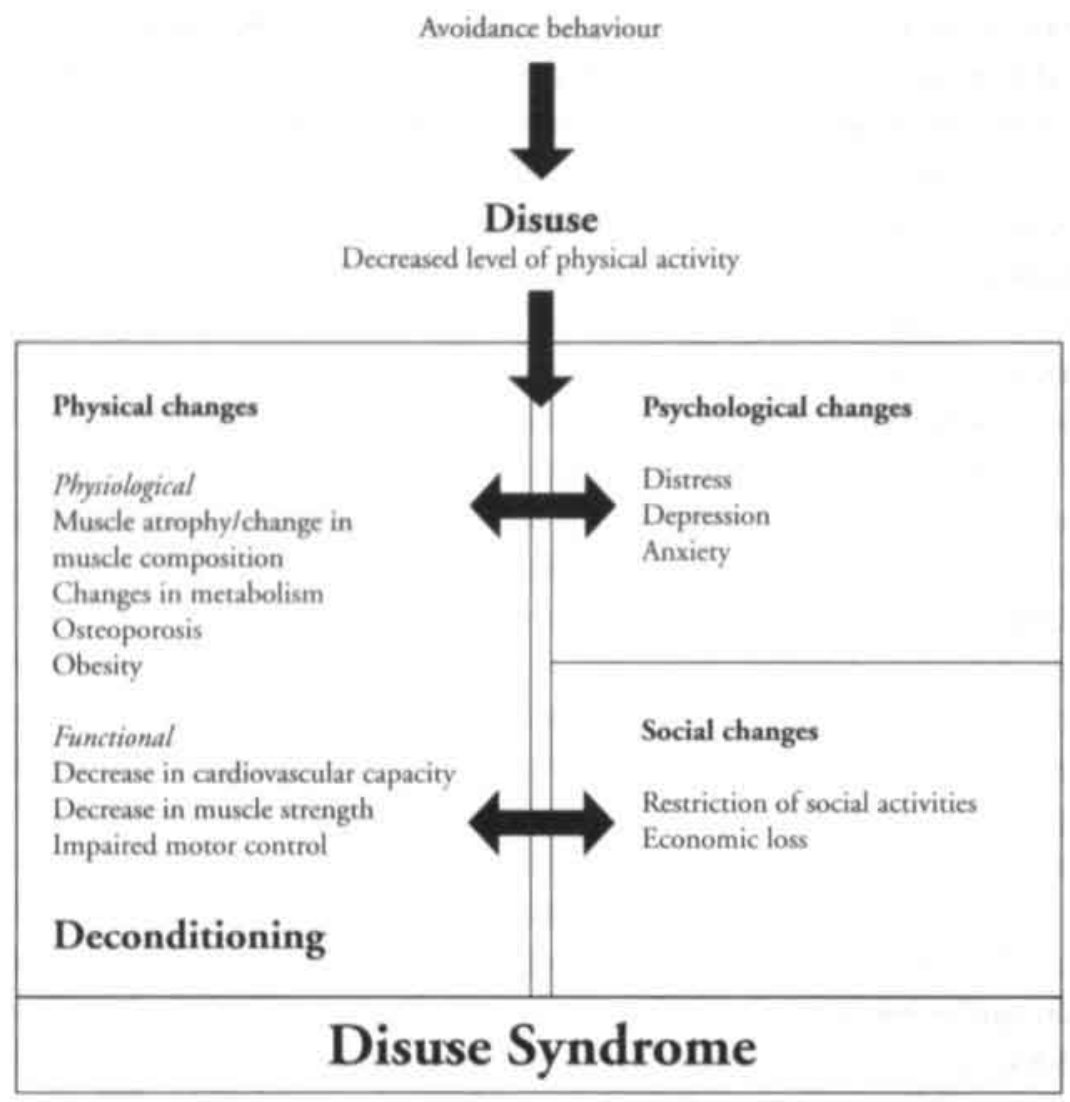

Figure 1: Disuse syndrome: consequences of long-term inactivity.

Although in the disuse syndrome, physical and psychosocial consequences are both important, we focus on the physical consequences in CLBP in this review. In a situation of chronic pain, psychosocial consequences, as referred to in the disuse syndrome, can hardly be distinguished from psychosocial consequences in the chronic pain syndrome. It is beyond the scope of this article to discuss psychosocial problems in CLBP. We will, however, discuss the psychosocial consequences of inactivity in a general population. 


\section{MODELS OF DISUSE IN CLBP}

Why is it so difficult for patients with back pain to return to a normal level of activity after an acute attack of pain? And what explains the fact that not every patient with back pain eventually becomes inactive and that only a subgroup of patients develops disuse-related deconditioning? In recent years, explanatory models were presented on this topic (Hasenbring et al, 1994; Vlaeyen et al, 1995a). They assume that different strategies in coping with pain play a role in changes in a patient's activity level. Two behavioural coping strategies in particular are mentioned: avoidance behaviour and suppressive behaviour.

\section{Avoidance behaviour}

According to Vlacyen's fear-avoidance model (as presented in Vlacyen and Linton, 2000), a subgroup of CLBP patients is afraid of increasing their physical activity level because they fear a reactive increase of their pain or even (re)injury (presented in Figure 2).

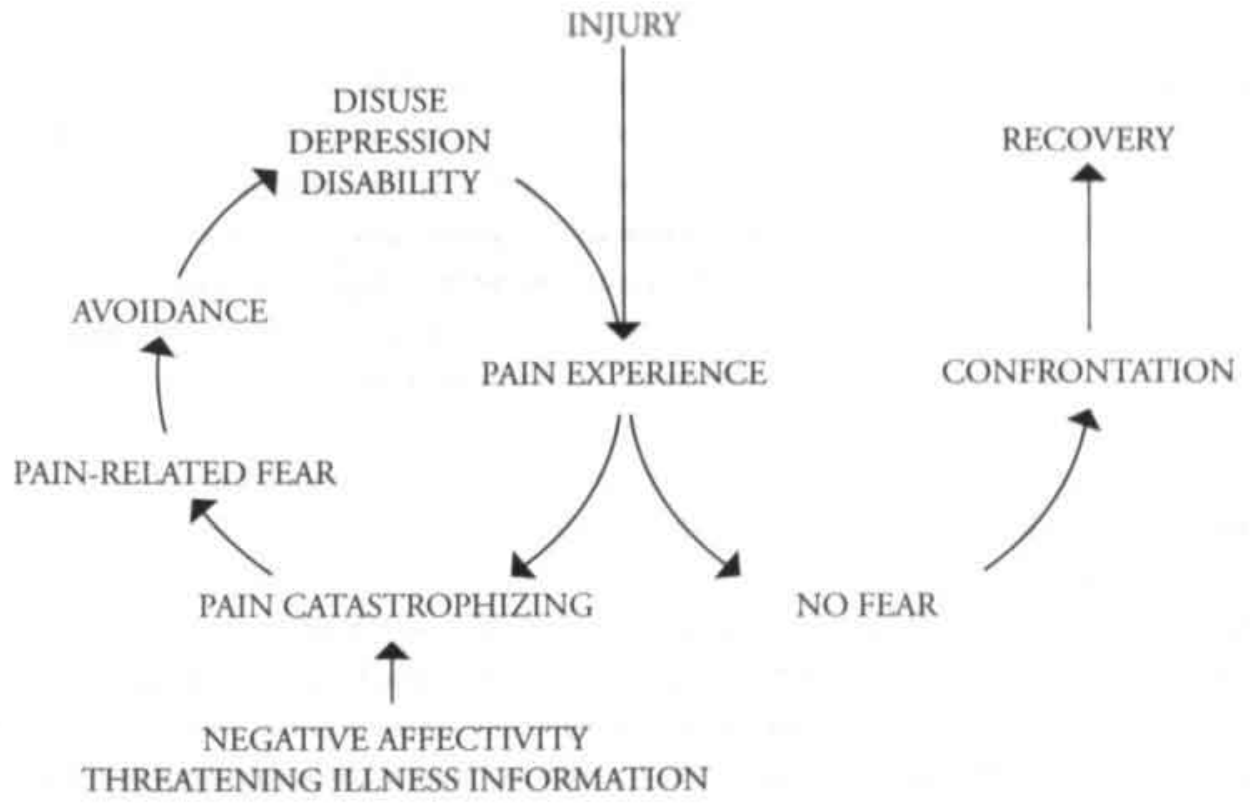

Figure 2: Fear of movement/(re)injury as a determinant of pain disability (Vlaeyen and Linton, 2000$).$ 
Their high degree of fear of pain or their expectation of other adverse consequences of increasing movements may be the motivation to restrict movement (Pope et al, 1979). In the most extreme situation, the expression 'kinesiophobia' is used, referring to an excessive, irrational and debilitating fear of physical movement and activity resulting from a feeling of vulnerability to painful injury or re-injury (Kori et al, 1990; Vlaeyen et al, 1995b; Crombez et al, 1998). According to this model, a state of chronic inactivity, induced by fear of (re)injury, will make it more difficult to return to a normal activity level due to physiological changes of the body system, apart from back pain problems. The physiological changes in this extreme situation of disuse may be equivalent to the deconditioning changes in the disuse syndrome mentioned above. This means that, if the fear avoidance model is applicable in the theoretical explanation for the disability in chronic pain for a subgroup of patients, these patients have a low physical activity level in daily life and deconditioning-related changes of their body will appear.

Fear of movement may result not only in a low activity level, but also in changes in movement patterns. Main and Watson (1996) found a strong relation between fear avoidance and guarded movement. Guarded movement is the adaptation of posture in response to pain, which may give a patient short-term alleviation of pain and thus enable him or her to participate in normal activities of daily life. But after some time, adaptation of posture may result in abnormal motion and a prolonged abnormal transfer of loads to other structures of the musculoskeletal system, with further restricting motion. The subject, conditioned through pain as a reaction to movement, may eventually develop a learned association between the two. Eventually this learned pain is no longer related to the initial cause of the acute pain sensation, but may have the same qualities and location. This may contribute to exaggerated illness behaviour, of which overt muscle guarding on movement is a feature. Guarded movements can in the long run contribute to the development of disuse and deconditioning.

\section{Suppressive behaviour}

Hasenbring et al (1994) presented an avoidance-endurance model of pain chronicity. In accordance with the fear-avoidance model, she refers to a subgroup of patients with low back pain who avoid activities and develop deconditioning and chronic low back pain. But, in addition to this subgroup of patients with avoidance strategies as a coping mechanism, she also identified a second subgroup of patients who have a tendency to cope with pain using endurance strategies. These patients appear to ignore the pain and, by their suppressive behaviour, overload their muscles (overuse), which leads to muscular hyperactivity. Long-term muscular hyperactivity can eventually cause chronic low back pain. According to Hasenbring, both disuse and overuse lead to one-sided and 
false straining of the muscles, thus enhancing chronification of pain.

The two different ways of coping (i.e. avoidance and suppression) in the subacute phase have different effects on the PAL of daily life. According to the theoretical models, patients who cope using avoidance strategies report a low PAL. Patients who apply endurance strategies are likely to report a physical activity level that fluctuates dramatically over time in reaction to pain. They are likely to persevere until increasing pain prevents further activity, then rest completely until the pain subsides or frustration over inactivity stimulates resumption of activity. Subsequently, they persevere again until increasing pain hinders further activity (Harding, 1998). Murphy et al (1997) referred to this as "all or nothing" behaviour, representing the so-called "overactivity/under-activity" cycle, which has been observed in many chronic pain patients. Adequate registration of PAL over time could provide insight in the way in which a patient tries to cope with the limitations in daily life (Edwards, 1986). In the long run. however, both coping strategies will, theoretically, result in a low level of physical activity leading to a situation as presented in the disuse syndrome. Also, this low level of physical activity in daily life and its consequences should be measurable in CLBP patients.

\section{Disuse in CLBP}

Little information exists on the level of physical activity in daily life of CLBP patients. The results on the physical activity level (PAL) in CLBP available are inconclusive. Nielens and Plaghki (2001) found a significantly lower PAL in CLBP, which was most pronounced in occupational activities. In recent studies by Protas (1999) and Verbunt et al (2001), a PAL was found that was comparable with a PAL of healthy individuals. A remarkable difference concerned the percentage of persons with paid jobs in the studies. In Nielens' study, only $20-34 \%$ of the participants had a paid job, whereas in Verbunt's study $72 \%$ of patients had a paid job. These different levels of participation in occupational activities could explain the different results of the studies. Persons with CLBP who are still working will have at least a PAL that is sufficient to meet the physical demands of their jobs. This could result in a higher PAL, compared to the PAL in a situation in which activities are influenced by pain. It is also important to realise that different assessment methods for PAL were used in the studies. In the studies by Nielens and Protas, the assessment of PAL was based on self-report, whereas assessment in the study by Verbunt was based on physiological measurements. To date, the validity of assessment of PAL in CLBP by self-report is unclear. A self-report can reflect a difference between how patients function and how they believe they function, resulting in a differently reported PAL compared to the actually observed active behaviour 
(Fordyce et al, 1984). The validity of self-report on PAL will be negatively influenced by this. This discrepancy in reported functioning and actual functioning has been observed before in CLBP patients. Kremer et al (1981) compared PAL as reported by CLBP patients and as reported by their therapists simultaneously. Patients significantly underestimated their level of activity. In line with this finding, Schmidt (1986) found that CLBP patients have difficulty in judging their own performance in an experimental setting. Patients were less capable of estimating their physiological level of exertion during a performance test situation than healthy controls. In 1985 Linton found a relationship between PAL and pain intensity in global interview self-reports, but this relationship gradually disappeared when the measure of PAL became more overt and objective. This may imply that a patient's perception of his activities is biased by other pain-related factors, which will influence the validity of his self-report. Apart from these comments with respect to content, it is surprising that only a few studies on PAL in CLBP have been performed. The information available does not allow a conclusive statement on the presence of disuse in CLBP. We need new studies on PAL in CLBP that make use of valid assessment methods.

In summary, behavioural factors such as avoidance and suppressive behaviour, are assumed to play a role in provoking disuse in CLBP. At this moment, however, insufficient evidence is available that either supports or rejects the presence or absence of disuse in CLBP. An important component of PAL appears to be work status, which therefore needs to be considered in further research. There are many assessment methods for PAL, with psychometric properties tested on healthy subjects. But the validity of these assessment methods in CLBP patients must be evaluated carefully. In the following sections, we will review various assessment methods on PAL.

\section{Physical activity in daily life: Methods for Measurement}

Just as in healthy persons, the registration of physical activity in CLBP patients must reflect a mean activity level over more than one day in order to represent normal daily life. The influence of extraneous factors and daily patterns, such as differences between the activities during the weekend and during the week, can be great. According Gretebeck and Motoye, all methods measuring PAL need at least 5 or 6 days of registration to minimise intra-individual variance (1992). Both weekdays and weekend days must be included in the period of measurement. Most methods measuring PAL have been extensively evaluated regarding validity and reproducibility in a healthy population. However, their psychometric properties in a population of CLBP patients are still unknown. In this section, we will discuss different methods for measuring PAL and evaluate their applicability in a population of chronic pain. 
Self-report measures, such as questionnaires or diaries, are easy to administer, require little time, and are inexpensive. This makes these measures popular in epidemiological studies featuring large sample studies. Kriska and Caspersen et al (1997) made a compilation of physical activity questionnaires for health-related research, in which they summarised the validity, reliability and feasibility of the questionnaires. However, as stated in the previous section, it is conceivable that psychometric properties of questionnaires on PAL are influenced by extraneous factors in a population of CLBP patients. Unfortunately, little information on this topic in CLBP is available, and a difference in discriminative validity has to be considered. With questionnaires on PAL designed for a healthy population, the lack of discriminative validity occurs especially in low physical activity levels, which may result in a so-called "floor effect" in a population of chronic pain patients. Modified questionnaires, especially designed for sedentary people, deal with this "floor effect". In general, however, the available modified questionnaires are validated for a healthy older population and concentrate on habitual activities of this specific age group. This means that occupation-oriented questions are often absent. Nevertheless, these activities are of special interest in a population of chronic pain patients. This limits the usefulness of a modified activity questionnaire designed for older persons in CL.BP. Protas (1999) suggested that questionnaires used in a population with CLBP should contain both occupational and leisure time activities, since many individuals with low back pain are still working. An example of a questionnaire that fulfils these criteria is the Baecke questionnaire (Baecke, 1982). Its test-retest reliability in CLBP is comparable to that in healthy controls (Jacob et al, 2001), while it is easy to administer, cheap, and takes little time to analyse.

\section{Observation}

A second technique to evaluate PAL is by observation. This may encompass registration of a subject's activities by an observer or by video recording, followed by an interpretation. Observational techniques are generally considered reliable (Bussmann and Stam, 1998a), but their administration is costly and time-consuming and therefore probably only useful in daily life on a time-sample basis.

\section{Movement registration}

A third possibility is the registration of PAL with ambulatory systems, using motion sensors. A variety of systems exist, ranging from pedometers, designed to count steps, to three-dimensional activity monitors giving more specific data on postures and activities during movement. Most of the motion sensors are small, can register at least for one day up to four weeks, and hardly interfere with daily life. In CLBP, research has been done using accelerometry. In a previous study we compared the registration of 
PAL of a tri-axial accelerometer with a registration of PAL with physiological assessment (Verbunt et al, 2001). The validity of the registration of PAL during a period of 2 weeks was satisfactory with a correlation coefficient of 0.72 . Bussmann et al (1998b) reported a good validity of a tri-axial motion sensor, which is based on a combination of accelerometers, in the quantification of behaviour (e.g. duration of activities and number of movement transitions) of patients after failed back surgery. Accelerometry makes it possible to measure changes in the quantity of activities and changes in the pattern of physical activities over days. The registration of PAL with a tri-axial accelerometer seems applicable for measuring PAL in CLBP.

\section{Physiological measurement}

A fourth possibility is the measurement of physiological markers, which is based on the indirect measurement of physiologic responses of the body to exercise. A simple physiology-related method is a 24 -hour heart rate registration. Heart rate registration hardly interferes with the patient's daily life and its costs are moderate. However, in stress reactions the registration of heart rate as a representation of physical activity can be biased by an increase of the heart rate as a reaction to stress (Raskell et al, 1993). Another disadvantage of heart rate registration is the inaccuracy in low-level physical activity (Gretebeck et al, 1991). In CLBP patients, PAL is probably limited and stressrelated problems can be present in coping with pain. Heart rate registration therefore seems to be a less than ideal method to measure PAL in CLBP. Another physiological rechnique for PAL, based on energy expenditure, is the doubly labelled water technique (Westerterp et al, 1995). In a healthy population, this technique is generally accepted as the 'gold standard' for physical activity assessment in daily life (Bouten et al, 1996). It determines the average daily metabolic rate and, together with an estimate of basal energy expenditure, it provides a reliable measure of energy expenditure associated with PAL during one to three weeks. However, the double labelled water technique is expensive and therefore only usable in small population studies.

\section{DECONDITIONING IN CHRONIC LOW BACK PAIN}

Disuse leads to deconditioning or a low level of physical fitness. Physical fitness is a multidimensional term, which includes a combination of physical parameters such as muscle strength, muscle endurance, muscle power, flexibility, cardiovascular capacity, motor control and body composition. As shown in Figure 1, these parameters are negatively affected by a continuous low level of PAL. If this change in physical parameters is also present in CLBP patients, it would be an indirect sign of the presence of disuse. It seems therefore worthwhile to consider a change in physical parameters presented in the disuse model in a population of CLBP patients. In the next section, 
we will discuss research findings that support the physical findings in the model on CLBP. We will successively discuss reported bodily changes due to inactivity in healthy persons and observed changes in CLBP patients.

\section{Physiological changes}

\section{Muscle atrophy/ changes in muscle composition}

Inactivity causes changes in all tissues, the most obvious of which are changes in muscle characteristics, such as a decrease in muscle mass (muscle atrophy) and changes in muscle composition. In micro-gravity simulation models, postural muscles that normally counteract the effects of gravity have been reported to become atrophic to a greater extent than fast contracting locomotor muscles (St.-Pierre and Gardiner, 1987). This implies that muscles situated on the trunk and lower extremities are affected most by deconditioning. This finding was confirmed in healthy persons in several studies (Berry et al, 1993; Greenleaf, 1997). In CLBP patients, muscle atrophy was found by Gibbons et al (1997). In patients with more frequent low back pain in the previous year, magnetic resonance imaging (MRI) studies showed a slightly smaller crosssectional area of the paraspinal muscles and greater signal intensities, possibly due to muscle atrophy.

In healthy subjects, changes in muscle composition have been reported (Musacchia, 1988 ) besides a decrease in muscle mass. A human muscle contains different muscle fibres, of which fast twitch (FT) fibres and slow twitch (ST) fibres are the most prevailing. FT fibres can contract fast and are rapidly fatigued, whereas ST fibres contract slowly and are metabolically inexpensive, which means that they can therefore act much longer. In healthy subjects, cessation of normal repetitive low-level activity patterns is supposed to result in transformation of the muscle towards a faster, more fatigable type (St.-Pierre and Gardiner, 1987; Mannion, 1999). In addition to microscopic effects, long-term immobilisation can introduce macroscopic anatomic complications such as, for example, a limited range of motion or muscle contractures (Halar and Bel, 1988). As a result of infrequent use of the total range of motion a joint, changes in the connective tissue occur, leading to increased stiffness and contractures. In inactivity, in contrast to immobility, it is hypothesised that contractures may not play such an evident role. The regularly use of the arthrogenic range of motion in case of inactivity is supposed to prevent the complication of contractures.

\section{Changes in metabolism}

Changes in metabolism result in serious negative effects such as orthostatic 
hypotension, reduction of plasma blood volume leading to dehydration and development of thromboembolic complications. After 30 days of complete bed rest, healthy young men had a decrease in plasma blood volume and red cell volume of $14 \%$ and $10 \%$ respectively (Greenleaf, 1997). Average orthostatic tolerance (during a fast upright movement) decreased in this population by $19-43 \%$. Since metabolic changes are merely a result of immobility and not of inactivity, their role in CLBP seems limited.

\section{Osteoporosis}

Another problem of deconditioning in immobility is osteoporosis. In a situation of immobility, a lack of muscle pull and gravity on especially the trunk and lower extremity bones results in a loss of calcium from the bones leading to osteoporosis (Dittmer and Teasell, 1993). Osteoporosis is progressive in time and may show little or no outward sign of its progression until pathological fractures of bone occur. The skeletal calcium loss causes an increased urinary calcium loss. This urinary calcium loss increases already in the first week of bed rest and may continue for months, even after resumption of physical activity (Halar and Bel, 1988). Skeletal calcium loss may already occur in a situation of decreased physical activity alone, without actual confinement to bed (Uhthoff, 1978). Long-standing disuse osteoporosis is not easily reversed. In a study of primates, immobilised for 7 months, normal bone formation was not seen until 6 months after resumption of activity (Young, 1986).

\section{Obesity}

Deconditioning affects the composition of the body. Lean body mass (i.e. body mass without the mass of fat) decreases during 30 days bed rest, whereas body weight does not change (Greenleaf, 1997). This finding suggests that the percentage of body fat will increase as the percentage of muscle mass decreases. Sothmann et al (1991) confirmed this inverse relationship during reconditioning. In a cross-sectional study with three different groups of aerobic fitness levels there was a significant decrease in the percentage of body fat and body weight. In female CLBP patients, the percentage of body fat was higher compared to healthy age and gender matched controls (Toda et al, 2000). This difference was not present in men. In a previous study in our laboratory, the body fat percentage of patients was comparable to the percentage of healthy controls (Verbunt et al, 2001). However, both studies had a cross-sectional design, which makes it impossible to provide evidence that an increased body fat percentage is the result of deconditioning in CLBP. It is conceivable that obesity may contribute to the occurrence of back pain and was already present before back pain started. 


\section{Functional changes}

\section{Candiovascular capacity}

The most general parameter of physical fitness is cardiovascular capacity, expressed as the maximum oxygen uptake (VO2max). In healthy individuals confined to bed. VO2max decreased by $21 \%$ after 30 days of bed rest (Greenleaf, 1997). The gold standard for determining absolute VO2max is by direct calorimetry at a maximum heart rate of at least $90 \%$ of the age-predicted maximum (i.e. 220-age) during the test. This procedure needs sophisticated equipment to analyse oxygen and carbon dioxide gas, which is usually not available in a clinical setting. Therefore in healthy subjects submaximal test protocols are developed in which $\mathrm{VO} 2 \mathrm{max}$ can be predicted on the basis of the measured heart rate in a steady state. This heart rate in a steady state is extrapolated to the maximum heart rate on the basis of the known linear increase of heart rate with the increase in oxygen uptake (Astrand and Rohdahl 1977). Table 1 contains a summary of studies comparing the cardiovascular capacity of CLBP patients and healthy controls.

The results from these studies are not unequivocal. Schmidt (1985b, 1986), Davis et al (1992), Brennan et al (1987), and Van der Velde and Mierau (2000) found a significantly lower cardiovascular capacity in patients, whereas Battie et al (1989), Hurri et al (1991), Kellet et al (1991), and Wittink et al (2000) found comparable levels for patients and controls. Nielens and Plaghki $(1991,1994,2001)$ reported a lower cardiovascular capacity for men, but not for women. All other studies presented in table 1 were based on submaximal exercise testing, but the decision to end the test was not the same in all studies. In the studies by Schmidt, this decision was made by participants, whereas in other studies the observer ended the test when a situation of steady state was reached. The main subject of study for Schmidt was the behaviour of CLBP patients during an exercise test instead of their cardiovascular capacity. Patients had to decide when to end the test due to pain or fatigue and the total testing time was recorded. In his study in 1985, a comparison of physiological parameters, such as heart rate and respiratory quotient, was reported for patients and controls on a total average testing time for both groups at the moment just before patients ended the test. No differences were found in physiological parameters between the groups. Therefore Schmidt concluded that psychological rather than physiological limitations explained the decreased performance level in this study. For the interpretation of cardiovascular capacity, it is better to evaluate the physiological parameters. Davis (1992) used the direct measurement of VO2 -exchange as an outcome measure. The aerobic capacity of patients was assessed before they entered a rehabilitation programme. The reference population (derived from the literature) comprised a working population and their fitness level was significantly different from the patients. After the rehabilitation 


\begin{tabular}{|c|c|c|c|c|c|}
\hline Author & Pauent populanous & $\begin{array}{l}\text { Work natus padencs } \\
\text { (\% with a paid job) }\end{array}$ & Controls & Extrcive tal procedare & $\begin{array}{l}\text { Cardiovascular capacity of } \\
\text { patients compared to conimals }\end{array}$ \\
\hline Schmide (1985) & $\begin{array}{l}39 \text { patients referred by an orthopacdic clinic } \\
\text { ( } \% \text { male unknown) }\end{array}$ & unknown & $\begin{array}{l}39 \text { males recrited from } \\
\text { a general population } \\
\text { gender and age matched }\end{array}$ & Treadmill test & $\begin{array}{l}\text { sign: lower toul testing time. } \\
\text { no difference in hearr rate and. } \\
\text { resperatory quotient }\end{array}$ \\
\hline Schmidt (1986) & $\begin{array}{l}41 \text { persons with CL.BP reacted on } \\
\text { announcement in local newsaper (100\% male) }\end{array}$ & unknown & $\begin{array}{l}39 \text { imales recruiced from } \\
2 \text { general population }\end{array}$ & Treadmill-test & sign. lower total testing time \\
\hline Brenaan et al (1987) & $\begin{array}{l}40 \text { putients with intervertebral herniated diak } \\
\text { (1) male unknown) }\end{array}$ & & $\begin{array}{l}40 \text { persons, matched } \\
\text { on age and gender }\end{array}$ & $\begin{array}{l}\text { Bicycle-ergotneter-test } \\
\text { (according to Astrand } \\
\text { Ryhiming) }\end{array}$ & $\begin{array}{l}\text { sign. lawer predicted VO2max } \\
\text { for males and female }\end{array}$ \\
\hline Hanic ot al (1989) & $\begin{array}{l}690 \text { morkers with velf reponted current of } \\
\text { previous back pain, rouruited from their } \\
\text { company ( } 809 \% \text { male) }\end{array}$ & $\begin{array}{l}100 \% \\
\text { blue collar workers. }\end{array}$ & $\begin{array}{l}1744 \text { workers without } \\
\text { back pain complaints } \\
\text { (80\% male) }\end{array}$ & Treadmill-test & $\begin{array}{l}\text { no cugn. difference in predicted } \\
\text { VO2-max for males and females }\end{array}$ \\
\hline $\begin{array}{l}\text { Nielens and } \\
\text { Plaghiki (1991) }\end{array}$ & $\begin{array}{l}56 \text { patients referred by chronk pain care unit } \\
\text { ( } 48 \% \text { male) }\end{array}$ & $\begin{array}{l}\text { male: } 26 \% \text { : femule: } 17 \% \text {, } \\
\text { (6o\%t had no pain jab } \\
\text { before the pain started })\end{array}$ & $\begin{array}{l}42 \text { members of the } \\
\text { tardical staff ( } 50^{\circ} \text { male) }\end{array}$ & $\begin{array}{l}\text { 1. Step-test } \\
\text { 2. Bicycle-ergometet-teat }\end{array}$ & $\begin{array}{l}\text { males: sign. lower } \\
\text { femsles: no sign. difference }\end{array}$ \\
\hline Kellet et al (1991) & $\begin{array}{l}111 \text { workets wich self reported cutrent of } \\
\text { pervious back pain, recristed from their } \\
\text { company (\% male unknown) }\end{array}$ & $\begin{array}{l}10096 \\
\text { blue collat worken }\end{array}$ & $\begin{array}{l}\text { derived from literature on } \\
\text { a normative poputation }\end{array}$ & $\begin{array}{l}\text { Bicydo-tess } \\
\text { (according to Autrand } \\
\text { Ryhuming) }\end{array}$ & $\begin{array}{l}\text { no significant difference in } \\
\text { VO2-max }\end{array}$ \\
\hline Hurri el al (1091) & 245 patients & $\begin{array}{l}\text { J00\% } \\
\text { blue collar worken }\end{array}$ & $\begin{array}{l}\text { derived from literature } \\
\text { on normative population }\end{array}$ & Bicycle-ergometer-tat & $\begin{array}{l}\text { no sign. difference } \\
\text { in prodicted } \mathrm{VOZ} \text { mas }\end{array}$ \\
\hline Davis a al (1992) & 46 parients ( $599 \mathrm{~m}$ male) & uniknown & $\begin{array}{l}\text { derived from litersture on } \\
\text { a working normative } \\
\text { popularion }\end{array}$ & Bicycle-etgorneter-teit & $\begin{array}{l}\text { man and wornen: level of } \\
\text { sedentary individuals }\end{array}$ \\
\hline $\begin{array}{l}\text { Nielams and } \\
\text { Plaghki (199-6) }\end{array}$ & $\begin{array}{l}42 \text { parients referrod by dhronic pain care unit } \\
\text { (55\% male) }\end{array}$ & unknown & $\begin{array}{l}34 \text { memben of the } \\
\text { medical seaff ( } 509 \text { male) }\end{array}$ & Bicycle-ergometer-test & $\begin{array}{l}\text { males: sugn. lowet } \\
\text { females no vign diffetence }\end{array}$ \\
\hline $\begin{array}{l}\text { Velde van der and } \\
\text { Mierau (2000) }\end{array}$ & $\begin{array}{l}258 \text { parients, referred fos cxercise treatment } \\
\text { (50\% male) }\end{array}$ & unknown & $\begin{array}{l}1001 \text { perwons withour } \\
\text { back pain, who entered } \\
\text { an oxercise-program } \\
\text { (\%male unknown) }\end{array}$ & Step test & $\begin{array}{l}\text { sign. difference for both } \\
\text { mala and fernales }\end{array}$ \\
\hline Wittink et al $(2000)$ & 50 patients ( $44 \%$ male) & $54 \%$ & $\begin{array}{l}\text { denved from fiecrature on } \\
\text { a normative population }\end{array}$ & $\begin{array}{l}\text { Treadmill test } \\
\text { Gacconding to Bruce) }\end{array}$ & $\begin{array}{l}\text { males level of healthy } \\
\text { sedentary men } \\
\text { females level of healtity } \\
\text { accive women }\end{array}$ \\
\hline $\begin{array}{l}\text { Nielens and } \\
\text { Plaghki (2001) }\end{array}$ & $\begin{array}{l}55 \text { patients refierrod by chronic puin care unis } \\
\text { (36\% mule) }\end{array}$ & malez:200s ticmatic $54 \mathrm{~s}$ & $\begin{array}{l}\text { derived from literanare on } \\
\text { a normatise population }\end{array}$ & Bicyde-crgoneter-ter & $\begin{array}{l}\text { males iqpi. lower WCI } \\
\text { fernalex no wign. difference in WCI }\end{array}$ \\
\hline
\end{tabular}

Table 1: Summary of studios comparring candionuscular capacioy of chronic low back pain patrients and bealthy controls. 
programme, parients had significantly improved their cardiovascular capacity, but their level of performance did still not reach the mean level of the reference population. The reference population in this study consisted only of persons with a paid job and is therefore probably not fully comparable to a general population as was used in other studies.

\section{The role of work status in cardiovascular capacity}

As can be seen in Table 1, Nielens and Plaghki (1991, 1994, 2001) reported a difference in cardiovascular capacity for men, but not for women in three studies. They assumed that a reason for this gender discrepancy could be work status. It could be more common for men to lose their jobs as a result of CLBP, leading to a loss of their occupational activities. Jobs of men are probably physically more strenuous, resulting in a more explicit change in activity level after job loss compared to women. Since in healthy young men a positive relation was found between heavy physical work and a high level of physical fitness (Tammelin et al, 2002), the loss of this work-related activity level in patients will probably result in a more substantial decrease in their physical fitness level. Women, with or without a paid job, on the other hand are probably more active at home in household tasks and child care, which contributes to keeping them at an activity level that may be considered almost equivalent to that of healthy females in most cases. Again, similar to the interpretation of the activity level, work status is an important factor in interpreting the cardiovascular capacity in CLBP patients. Unfortunately information on work status is not available in all studies. Of the studies that do present the work status, it is remarkable that in most studies in which no difference in cardiovascular capacity was reported, all persons are still working. Hazard et al (1989) compared the cardiovascular capacity of CLBP patients who were working and of patients who were not working. They found that patients with a paid job had a better cardiovascular capacity than patients without a job. This underlines the importance of the loss of occupational activities in deconditioning in CLBP.

\section{Muscle strength}

Immobility is reported to lead to a decrease in muscle strength and endurance, especially in the postural muscles (Gogia et al, 1988; Dittmer et al, 1993). In healthy persons confined to bed for 4 to 5 weeks, the maximum isometric peak torque for the m. quadriceps decreased by 10.3-21\%. (Gogia, 1988; Dudley et al, 1989; Germain et al, 1995). Hultman et al (1993) in a cross-sectional design compared endurance of the lumbar muscles in CLBP patients and healthy volunteers. The healthy group had significantly longer trunk muscle endurance times than the group with CLBP. Cassisi et al (1993) confirmed this finding of decreased lumbar strength in CLBP. Most research on muscle strength in CLBP is focused on the lumbar muscles. In the concept 
of disuse, postural muscles, such as trunk and leg muscles, are also important. Lee et al (1995) reported in their study a decrease in trunk strength combined with a decrease in strength of the knee extensors for CLBP patients. This finding implies that muscle weakness in CLBP is not just a local problem of the trunk, but a generalised problem, probably due to a lower PAL. Again, work status could play a role, since only $31 \%$ of the patients and $59 \%$ of the controls reported a job with a heavy physical load, while $28 \%$ of the patients and $63 \%$ of the controls regularly participated in sports activities (Lee et al, 1995).

\section{Motor control}

Motor control is also reported to be affected after a period of bed rest. Immobility decreases co-ordination and balance (Haines, 1974). The impairment of balance appears to be due not so much to muscle weakness, but rather to impaired neural control. Maintaining a high degree of co-ordination requires frequent performance of an activity under conditions in which the sensory perception of the motor performance can be checked for accuracy and errors may be corrected (Kottke, 1966; Dustman et al, 1984). Bed rest decreases the amount of proprioceptive stimuli, which are responsible for regulating neuromuscular performance. In CLBP, motor control can be affected too. As mentioned above, guarded movements lead to a change in movement patterns. In a laboratory setting, patients with low back pain had less trunk motion during a specific dynamic task than healthy persons (Rudy et al, 1995). The recruitment of stabilising trunk muscles during motion of the upper limbs appeared to be different in persons with and without back pain. CLBP patients showed a delayed onset of contraction of especially the abdominal muscles, which can be hypothesised to result in inefficient muscular stabilisation of the spine (Hodges and Richardson, 1996, 1999). The role of pain severity in altered motor control in CLBP must be considered. In a standardised reach task, postural control in patients with severe pain was poorer than in patients with moderate pain (Luoto et al, 1996). With impaired motor control, the problem can either be caused by pain or result from inactivity.

In the measurement of physical fitness, physical performance tests, such as strength measurement or exercise testing, are used. To decide whether patients are deconditioned, however, we need information about a patient's functional capacity rather than his or her physical performance. In sports it is assumed that physical fitness is only one factor influencing performance and that fatigue and pain thresholds must be crossed to reach optimal performance (St-Pierre and Gardiner, 1987). The extent to which one is willing to tolerate feelings of pain or exhaustion also determines performance. In assessing physical fitness in CLBP patients, physical performance is probably modified to a larger extent by motivational and cognitive factors than in healthy persons. Watson (1999) mentioned the importance of evaluating non-physical 
contributing factors during performance tests in CLBP. According to Watson, physical assessment measures should be regarded as representing a steady psycho-physiological state. To interpret changes in outcome during repeated measurement, it is important to consider a change in these non-physical factors as well. Only then does one have the opportunity to interpret a change in physical capacity during a performance test. In CLBP, research has been done to identify non-physiological factors in performance testing. Pain-related variables such as pre-test pain level (Schmidt, 1986, Estlander, 1994), pain level on exertion (Keller et al, 1999), pain threshold (Pope et al, 1979) and pain expectancy (Crombez et al, 1996) were correlated to the final test result of the different cross-sectional studies. These non-physiological factors can thus influence performance assessment indicating that the validity of the test could be biased by these pain-related variables.

Over time, tests have been developed with the purpose of minimising nonphysiological factors, such as Functional Capacity Evaluation (FCE). The purpose of FCE is to test a person's physical abilities to the maximum in order to produce objective documentation regarding work and activities of daily life. FCE has become part of the accepted practice in work injury prevention and rehabilitation (King et al, 1998). During a FCE, the patient has to complete a standard protocol of physical tasks while a trained observer records the performance and limitations. Practical data on the use of FCEs to determine an individual's physical capacities have been available for over a decade, but research to justify the use of FCEs is still lacking. Although the term 'capacity' is included in its name, FCE is a performance test rather then a capacity test. FCE is not fully objective since an observer has to decide if a patient performed maximally or sub-maximally during the test. The influence of psychological factors is also assumed to be present in FCE but cannot be measured. In general, the interpretation of results on deconditioning requires a critical look at the assessment methods that were used.

\section{Psychosocial changes}

Distress, depression and anxiery - the psychosocial variables mentioned in the deconditioning model - are studied extensively in CLBP. It is beyond the scope of this article to review the literature on distress, depression and anxiety in chronic pain. Their presence in CLBP patients is probably the result of pain rather than the result of a decreased level of physical activities, or at least a combination of both effects. It is, however, striking that in research findings on persons without pain, these variables seems to be correlated to PAL. Most research on psychosocial consequences (in persons without (CLBP) in deconditioning is done in inactive people instead of in persons 
during immobility. Thirlaway and Benton (1992) found in 246 healthy men and women that higher levels of physical activity were associated with a better mood. Inactive, but fit people reported a poorer mood than inactive and unfit people. They concluded that the positive relation between physical activity and mental mood was less mediated by improved physical fitness but more by participation in performance of physical activity as a social event. Martinson (1990) found that physical work capacity was reduced in depressed people. Crews and Landers (1987), in a review of 34 studies on the relation between physical fitness and stress response, found that aerobically fit people had reduced psychosocial stress responses. In a group of 100 young and healthy police officers after an aerobic training period, which improved physical fitness, Norris (1990) found that self-reported stress was reduced and scores for subjective health and wellbeing were increased. The results of these studies suggest that inactivity is strongly associated with increased distress. Petruzello et al (1991) conducted a meta-analysis on the anxiety-reducing effects of exercise and found that aerobic, but not anaerobic, exercise was associated with lower anxiety levels. Since deconditioning especially affects the aerobic energy capacity, anxiety may play a role. Social consequences of long-term immobility can change the person's role in society. Job loss, related economic loss and restriction of social activities may occur and may have their effects on a person's mood (Waddell, 1991).

In summary, there are more studies available on deconditioning than on disuse in CLBP. Most studies on deconditioning in CLBP assess the cardiovascular capacity. Again, work status seems an important variable to differentiate between levels of deconditioning. In most studies, it appeared that patients that fully participate in occupational activities have a fitness level comparable to healthy controls. It is important to realise that physical fitness is tested using a test of physical performance instead of physical capacity. In CLBP patients, pain-related non-physiological factors may influence the test to a greater extent than in healthy controls.

\section{CONCLUSION AND SUGGESTIONS FOR FURTHER RESEARCH}

In the literature on physical activity and physical fitness in chronic pain, Bortz's disuse syndrome is cited frequently. In the studies on CLBP in which a cross-sectional comparison was made between fitness related parameters in patients and healthy controls, however, results were inconclusive. It is important to realise that disuse as described in the physiological literature is referred to in a context of immobility, whereas in chronic pain disuse is already referred to as in a state of inactivity. And as we cannot judge the magnitude of the decline in fitness-related parameters in CLBP because of the cross-sectional design of most of these studies, a situation of immobility 
for CLBP patients probably rarely occurs. Some complications of immobility, such as contractures and dramatic changes in metabolism, are prevented by any activity and will therefore not appear in a state of inactivity. It is therefore at least questionable if the disuse syndrome, to the extent as reported by Bortz, is applicable as a separate identity in the chronic pain syndrome.

Although disuse is not based on immobility, inactivity can still play an important role. It remains important to objectify PAL, or its change in patients with low back pain, since the assumption that physical activity decreases with the occurrence of back pain is still the basis of most reconditioning programmes. It is remarkable that in several studies presented in this review no difference could be found between patients and healthy controls in their levels of PAL or physical fitness. Work status is presented as a possible discriminating variable between fit and unfit persons with CLBP. However, this is not exclusively found in persons with back pain. In a large study of the Dutch population, involving people aged 20 to 64 years, $36 \%$ of the unemployed persons and $16 \%$ of the working persons had an inactive lifestyle (i.e. less than half an hour five times a week of moderate activities) (Schuit et al, 1999). It could be that disuse or deconditioning is more related to the time when patients leave their paid jobs, especially in men, than to the time when back pain appears.

In the evaluation of a decrease in PAL, the measurement of intra-individual changes over time in a longitudinal design is preferable. All studies in this review were based on a cross-sectional design, in which the level of physical activity and physical fitness of patients was compared to controls. In future research, a longitudinal design in the study of physical activity is preferred. It also seems important in future research to evaluate a change in work status and its relation to a change in physical fitness. If we evaluate physical fitness over time and possible causes of changes in activity levels, such as pain intensity over time and occupational and sport-related changes, more will be known about their relation.

In assessing physical fitness, the validity of performance tests that measure physical fitness in CLBP has to be taken into account. A multidimensional approach that includes physiological and physical factors influencing the outcome of an exercise test, is favoured in future research on chronic low back pain. A recently developed method that shows the influence of psychological factors during strength testing, is the twitch interpolation technique (Edwards, 1986; Vollestadt, 1997). The twitch interpolation technique is based on the registration of a twitch contraction elicited by a supramaximal electrical stimulus delivered to the muscle or nerve during a maximal voluntary contraction. The force increment in response to this stimulus reflects the muscle force reserve or the difference between the maximum force that can be 
generated by the muscle and the maximum voluntary contraction force, in which nonphysiological factors play a role. This method can be used to make the role of nonphysiological factors during strength testing more transparent.

In conclusion, the presence of deconditioning and disuse in CLBP as factors contributing to chronicity in chronic pain is not confirmed by the literature presented in this review. In the evaluation of deconditioning and disuse in chronic pain, it is also important to consider the psychometric properties of the assessment methods on both PAL and physical fitness. In future research, it may be possible to confirm the assumed relation between fitness and pain as presented in theoretical models on the development of CLBP. 


\section{REFERENCES}

- Astrand P and Rodahl K. Textbook of work physiology, physiology bases of exercise. 2nd ed. New York: McGraw-Hill, 1977;333-365.

- Baecke JAH, Burema J, Frijters JER. A short questionnaire for the measurement of habitual physical activity in epidemiological studies. Am J Nutr 1982;36:936-941.

- Battie M, Bigos SJ, Fisher LD, Hansson TH, Nachemson AL, Spengler DM, Wortley MD, Zeh J. A prospective study of the role of cardiovascular risk factors and fitness in industrial back pain complaints. Spine 1989;14:141-147.

- Berry P, Berry MD, Manelfe MD. Magnetic Resonance imaging evaluation of lower limb muscles during bedrest: a micro gravity simulation model. Aviat Space Environ Med 1993:212-218.

- Bortz WM. The disuse syndrome. West J Med 1984;141:691-694.

- Bouten CV, Verboeket-van de Venne WR, Westerterp KR, Verduin M, Janssen JD. Daily physical activity assessment: comparison between movement registration and doubly labelled water. J Appl Physiol 1996;81:1019-1026.

- Brennan GP, Ruhling RO, Hood RS et al. Physical characteristics of patients with herniared intervertebral lumbar discs. Spine 1987;12:699-702.

- Buschbacher RM. Deconditioning, conditioning and the benefits of exercise. In: Braddom, R.L., Physical Medicine and Rehabilitation, Philadelphia, W.B. Saunders Company, 1996:687- 708.

- Bussmann JBJ and Stam HJ. Techniques for measurement and assessment of mobility in rehabilitation: a theoretical approach. Clin Rehabil 1998a;12:455-464.

- Bussmann JBJ, Van de Laar YM, Neeleman MP, Stam HJ. Ambulatory accelerometry to quantify motor behaviour in patients after failed back surgery: a validation study. Pain 1998b;74:153-161.

- Cassisi JE, Robinson ME, O'Conner P, MacMillan M. Trunk strength and lumbar paraspinal muscle activity during isometric exercise in chronic low-back pain patients and controls. Spine 1993;18:245-251.

- Crews DJ, Landers DM. A meta-analytic review of aerobic fitness and reactivity to psychosocial stressors. Med Sci Sports Exerc 1987;19:S114-S120.

- Crombez G, Vervaet L, Baeyens F, Lysens R, Eelen P. Do pain expectancies cause pain in chronic low back patients? A clinical investigation. Behav Res ther 1996;34:919925.

- Crombez G, Vervaet L, Lysens R, Baeyens F, Eelen P. Avoidance and confrontation of painful, back straining movements in chronic back pain patients. Behav Modif 1998;22:62-77.

- Davis VP, Fillingin RB, Doleys DM, Davis MP. Assessment of aerobic power in chronic pain patients before and after a multi-disciplinary treatment program. Arch Phys Med Rehabil 1992;73:726-729. 
- Dittmer DK and Teasell R. Complications of immobilization and bed rest; part 1: musculoskeletal and cardiovascular complications. Can Fam Physician 1993;39:1428-1437.

- Dudley GA, Gollnick PD, Convertino VA, Buchanan P. Changes of muscle function and size with bedrest. Physiologist 1989;1:S65-S66.

- Dustman RE, Ruhling RO, Russell EM, Shearer DE, Bonekat HW, Shigeoka JW, Wood JS, Bradford DC. Aerobic exercise training and improved neuropsychological function of older individuals. Neurobiol Aging 1984;5:35-42.

- Edwards RHT. Muscle fatigue and pain. Acta Med Scand 1986;711:S179-S188.

- Estlander A, Vanharanta H, Moneta GB, Kaivonto K. Anthropometric variables, selfefficacy beliefs, and pain and disability ratings on the isokinetic performance of low back pain patients. Spine 1994;19(8): 941-947.

- Fordyce WE, Lansky D, Calsyn DA, Shelton JL, Stolov WC, Rock DL. Pain measurement and pain behaviour. Pain 1984;18:53-69.

- Germain P, Guell A, Marini JE. Muscle strength during bedrest with and without exercise as a countermeasure. Eur J Appl Physiol 1995;71:342-348.

- Gibbons LE, Videman T, Crites Battié M. Isokinetic and psychophysical lifting strength, static back muscle endurance, and magneric resonance imaging of the paraspinal muscles as predictors of low back pain in men. Scan J Rehabil Med 1997;29:187-191.

- Gogia PP, Schneider VS, LeBlanc AD, Krebs J, Kasson C, Pientok C. Bed rest effect on extremity muscle torque in healthy men. Arch Phys Med Rehabil 1988;69:10291032 .

- Greenleaf JE. Intensive exercise training during bed rest attenuates deconditioning. Med Sci Sports Exerc 1997;29:207-215.

- Gretebeck RJ, Montoye HJ, Ballor D, Montoye AP. Comments on heart rate recording in field studies. J Sports Med Phys Fitness 1991;31-4:629-631.

- Gretebeck RJ and Montoye HJ. Variability of some objective measures of physical activity. Med Sci Sports Exerc 1992;24:1167-1172.

- Haines RJ. Effect of bed rest and exercise on body balance. J Appl Physiol 1974; 36:323-327.

- Halar EM and Bel KR. Contracture and other deleterious effects of immobility. In: Rehabilitation Medicine Principles and Practice, Philadelphia: J.B. Lippincott, 1988: 448-462.

- Harding VR and Williams AC. Activities Training: Integrating behavioural and cognitive methods with physiotherapy in pain management. J Occup Rehabil 1998:8(1):47-61.

- Hasenbring M, Marienfeld G, Kuhlendahl D, Soyka D. Risk factors of chronicity in lumbar disc patients. A prospective investigation of biologic, psychological, and social predictors of therapy outcome. Spine 1994;19-24:2759-2765. 
- Hazard RG, Fenwick JW, Kalisch SM, Redmond J, Reeves V, Reid S, Frymoyer JW. Functional restoration with behavioral support: a one year prospective study of patients with chronic low back pain. Spine 1989;14:157-165.

- Hodges P and Richardson C. Inefficient muscular stabilization of the lumbar spine associated with low back pain. A motor control evaluation of transversus abdominus. Spine 1996;21:2640-2650.

- Hodges P and Richardson C. Altered trunk muscle recruitment in people with low back pain with upper limb movement at different speeds. Arch Phys Med Rehabil 1999;80:1005-1012.

- Hultman G, Nordin M, Saraste H, Ohlsen H. Body composition, endurance, strength, cross sectional area and density of MM Erector spinae in men with and without low back pain. J Spinal Disord 1993;6:114-123.

- Hurri H, Mellin G, Korhonen O, Harjula R, Harkapaa K, Luamo J. Aerobic capacity among chronic low back pain patients. J spinal Disord 1991:4:34-38.

- Jacob T, Baras M, Zeev A, Epstein L. Low back pain: reliability on a set of pain measurement tools. Arch Phys Med Rehabil 2001;82:735-742.

- Keller A, Johansen JG, Hellesnes J, Brox JI. Predictors of isokinetic back muscle strength in patients with low back pain. Spine 1999:24-3:275-280.

- Kellett KM, Kellett DA, Nordholm LA. Effects of an exercise program on sick leave due to back pain. Phys Ther 1991;71:283-290.

- King PM, Tuckwell N, Barrett TE. A critical Review of functional capacity evaluations. Phys Ther 1998:78(8):852-866.

- Kori SH, Miller RP, Todd DD. Kinesiophobia: a new view of chronic pain behavior, Pain Management 1990:35-43.

- Kottke FJ. The effects of limitation of activity upon the human body. JAMA 1966;196:117-122.

- Kremer EF, Block A, Gaylor M. Behavioral approaches to treatment of chronic pain: The inaccuracy of patient self-report measures. Arch Phys Med Rehab 1981;62:188191.

- Kriska AM and Caspersen CJ. A collection of physical activity questionnaire for health-related research. Med Sci Sports Exerc 1997;29(6)S3-S201.

- Lee JH, Ooi Y, Nakamura. Measurement of muscle strength of the trunk and the lower extremities in subjects with history of low back. Spine 1995;20(18):19941996.

- Linton SJ. The relationship between activity and chronic back pain. Pain 1985;21:289-294.

- Luoto S, Taimela S, Hurri H, Aalto H, Pyykko I, Alaranta H. Psychomotor speed and postural control in chronic low back pain patients. A controlled follow-up study. Spine 1996;15:2621-2627. 
- Main CJ and Watson PJ. Guarded movements: development of chronicity. J Musculoskeletal Pain 1996;4:163-170.

- Mannion AF. Fibre type characteristics and function of the human paraspinal muscles: normal values and changes in association with low back pain. J Electromyogr Kinesiol 1999:363-377.

- Martinsen EW. Benefits of exercise for the treatment of depression. Sports Med 1990;9(6)380-389.

- Mayer TG and Gatchel RJ. Functional Restoration for spinal disorders: the sports medicine approach. Philadelphia: Lea \& Febiger, 1988:8-9.

- Murphy D, Lindsay S, Williams A. Chronic low back pain: predictions of pain and relationship to anxiety and avoidance. Behav Res Ther 1997;35:231-238.

- Musacchia XJ. Disuse atrophy of skeletal muscle animal models. Exerc Sports Sci Rev 1988;16:61- 87 .

- Nachemson AL. Newest knowledge of low back pain. A critical look. Clin Orthop 1992;279:8-20.

- Nielens $\mathrm{H}$ and Plaghki L. Evaluation of physical adaptation to exercise of chronic pain patients by steptest procedure. The Pain Clinic 1991;4:21-25.

- Nielens $\mathrm{H}$ and Plaghki L. Perception of pain and exertion during exercise on a cycle ergometer in chronic pain patients. Clin J Pain 1994;10:204-209.

- Nielens $\mathrm{H}$ and Plaghki L. Cardiorespiratory fitness, physical activity level, and chronic pain: are men more affected than women? Clin J Pain 2001;17:129-137.

- Norris R, Carroll D, Cochrane R. The effects of aerobic and anaerobic training on fitness, blood pressure, and psychological stress and well-being. J Psychosom Res 1990;34(4):367-75.

- Petruzello SJ, Landers DM, Hatfield BD, Kubitz KA, Salazar W. A meta-analysis on the anxiery-reducing effects of acute and chronic exercise Sports Med 1991;11:143182.

- Pinsky J and Crue DL. Intensive Group Psychotherapy, In: Wall PD and Melzack R, Textbook on Pain, Edinburgh: Churchill Livingstone 1984.

- Pope MH, Rosen JC, Wilder DG, Frymoyer JW. The Relation between biomechanical and psychological factors in patients with low-back pain. Spine 1979;5:173-178.

- Protas EJ. Physical activity and low back pain, In Mitchell, M. et al., Pain 1999 an updated review; refresher course syllabus 9th World Congress on Pain, Seattle: IASP press, 1999:145-152.

- Raskell WL, Yee MC, Evans A, Irby PJ. Simultaneous measurement of heart rate and body motion to quantitate physical activity. Med Sci Sports Exerc 1993;25:109-115.

- Rudy TE, Boston JR, Lieber SJ, Kubinski JA, Delitto A. Body motion patterns during repetitive wheel rotation task. A comparative study of healthy subjects and patients with low back pain. Spine 1995;20(23):2547-2554. 
- Schmidt AJ. Cognitive factors in the performance level of chronic low back pain patients. J Psychosom Res 1985a;29(2):183-189.

- Schmidt AJ. Performance level of chronic low back pain patients in different treadmill test conditions. J Psychosom Res 1985b;29:639-645.

- Schmidt AJ. Persistence behaviour of chronic low back pain patients in treadmill test with false and adequate feedback. Thesis 1986.

- Schuit AJ, Feskens EJM, Seidell JC. Lichamelijke activiteit in samenhang met sociaal-demografische determinanten en gezondheidskenmerken bij volwassen mannen en vrouwen in Amsterdam, Doetichem en Maastricht. Ned Tijdschr Geneesk 1999;143(30):1559-1564.

- Sothmann MS, Bam H, Horn TS. Plasma catecholamine response to acute psychological stress in humans: relation to aerobic fitness and exercise training. Med Sci Sports Exerc 1991;23: 860-867.

- Spitzer WO, Leblanc FE, Dupuis M. Scientific approach to the assessment and management of activity-related spinal disorders: report of the Quebec task Force on spinal disorders 1987;12(\$7) S1-S59.

- St.-Pierre D and Gardiner PF. The effect of immobilization and exercise on muscle function: a review. Phys Canada 1987;39:24-36.

- Tammelin T, Nayha S, Rintamaki H, Zitting P. Occupational physical activity is related to physical fitness in young workers. Med Sci Sports Exerc 2002;34(1):158165.

- Thirlaway K and Benton D. Participation in physical activity and cardiovascular fitness have different effects on mental health and mood. J psychol Res $1992 ; 36: 657-665$.

- Toda Y, Segal N, Toda T, Morimoto T, Ogawa R. Lean body mass and body fat distribution in participants with chronic low back pain. Arch Intern Med 2000;160:3265-3269.

- Tulder MW, Koes BW, Bouter LM. A cost-of-illness study of back pain in the Netherlands. Pain 1995;62:233-240.

- Uhthoff HK and Jaworski ZFG. Bone loss in response to long-term immobilization. J Bone Joint Surg 1978;60:420-429.

- Velde G van der and Mierau D. The effect of exercise on percentile rank aerobic capacity, pain, and self-rated disability in patients with chronic low back pain: a retrospective chart review. Arch Phys Med Rehabil 2000;81:1457-1463.

- Verbunt JA, Westerterp KR, Van der Heijden GJ, Seelen HA, Vlacyen JW, Knottnerus JA. Physical activity in daily life in patients with chronic low back pain. Arch Phys Med Rehab 2001;82: 726-730.

- Vlaeyen JWS, Kole-Snijders AMJ, Boeren RGB, Van Eek H. Fear of movement/ (re)injury in chronic low back pain and its relation to behavioral performance. Pain 1995a;62:363-372. 
- Vlacyen JWS, Kole-Snijders AMJ, Rotteveel A, Ruesink R, Heuts PHTG. The role of fear of movement/(re)injury in pain disability. J Occup Rehabil 1995b;5:235-252.

- Vlaeyen JWS and Linton SJ. Fear-avoidance and its consequences in chronic musculoskeletal pain: a state of the art. Pain 2000;85:317-332.

- Vollestadt NK. Measurement of human fatigue. J Neurosci Methods 1997;74:219227.

- Waddell G. Low back Disability, A syndrome of Western Civilization. Neurosurg Clin N Am 1991;4:719-738.

- Watson PJ. Non-psychological determinants of physical performance in musculoskeletal pain, In Mitchell M et al. Pain 1999 an updated review; refresher course syllabus 9th World Congress on Pain, Seattle: IASP press 1999:153-158.

- Westerterp KR, Wouters L, Van Marken Lichtenbelt WD. The Maastricht Protocol for the Measurement of Body Composition and Energy Expenditure with labeled water. Obes Res 1995:3:49-57.

- Wittink H, Hoskins Michel T, Wagner A, Sukiennik A, Rogers W. Deconditioning in patients with chronic low back pain. Fact or fiction? Spine 2000;25(17)22212228.

- Young JZ. Effects of use and disuse on nerve and muscle. The Lancet 1946:109-113.

- Young DR, Niklowitz WJ, Jee WSS. Immobilization associated osteoporosis in primates. Bone 1986:7:109-117. 
춘 
Physical aCtivity in DAILY LifE IN PATIENTS WiTH CHRONIC LOW BACK PAIN

Jeanine A. Verbunt, Klaas R. Westerterp, Geert J. van der Heijden, Henk A. Seelen, Johan W. Vlaeyen, J. André Knottnerus

Published as:

J. Verbunt, K. Westerterp, G. van der Heijden, H. Seelen, J. Vlacyen and A. Knottnerus. Physical activity in daily life in patients with chronic low back pain. Arch Phys Med Rehabil 2001; 726-730. Reprinted with permission from W.B. Saunders Company 


\section{ABSTRACT}

\section{Objective:}

The first objective is the evaluation of the presence of disuse, i.e. a decreased daily physical activity level, in patients with chronic low back pain compared to healthy controls. The second objective is the evaluation of the construct validity of accelerometry as a measurement method for physical activity in daily life.

\section{Design:}

Case control study in a cross-sectional design; comparison of accelerometry to the criterion standard doubly labelled water.

\section{Setting:}

Normal daily living (unrestricted by the measurement-devices).

\section{Patients:}

Thirteen patients with chronic non-specific low back pain and age and sex matched healthy controls.

\section{Main outcome measures:}

Physical activity in daily life, firstly expressed as whole body acceleration measured by means of a triaxial accelerometer (Tracmor) and secondly expressed as the ratio between average daily metabolic rate (ADMR) measured by the doubly labeled water technique and resting metabolic rate (RMR) measured by the ventilated hood. Both techniques were used simultaneously during fourteen days.

Results:

Mean physical activity level in patients and controls was not significantly different. The correlation between the Tracmor and ADMR/RMR was $0.72(p<0.01)$.

\section{Conclusions:}

The presence of disuse in this sample of chronic low back pain patients was not confirmed. The Tracmor is a valid instrument for measuring daily activity in patients with chronic low back pain. 


\section{INTRODUCTION}

In clinical practice activity intolerance is a problem which is often reported by patients with chronic low back pain (CLBP). As a result of their back pain problems, patients report a forced reduction in their level of physical activity. A prolonged reduced level of physical activity in daily life can result in physiological changes of the human body such as a decrease in muscle mass, increase in body weight and percentage of body fat, and a decrease in resting metabolic rate (Pratley et al, 1994; Convertino et al, 1997). Altogether these physiological changes often referred to as disuse, complicate the initial health problem of low back pain. As in other chronic disabilities, disuse can play an additional role in developing a chronic low back pain syndrome after an acute back problem. Therefore it is important to evaluate whether in patients with CL.BP the level of physical activity is decreased.

Different methods for the evaluation of physical activity in daily life are available, varying from simple patient reports to sophisticated technical oriented ambulatory monitoring (Bussmann and Stam, 1998). Selection of an appropriate evaluation method is primarily based on the perspective of interest concerning physical activity, methodological quality and practical feasibility. The most appropriate assessment method for measuring the level of physical activity to evaluate related physiological changes is an objective method that can be used under normal daily living conditions over a prolonged period of time with minimal discomfort to the patient.

In the physiology literature, physical activity is often described in terms of energy expenditure (Ainsworth et al, 1993). The perspective of interest is energy expenditure associated with physical activity. Two available techniques for measuring this are the doubly labelled water technique and accelerometry. The doubly labelled water technique is generally accepted as the 'gold standard' for physical activity assessment in daily living (Bouten et al, 1996). This technique determines the average daily metabolic rate (ADMR) and, together with an estimate of basal energy expenditure, provides a reliable measure of energy expenditure associated with physical activity during one to three weeks (Schoeller, 1988). Schoeller and Hnilicka, in a summary of studies describing repeated measurements of energy expenditure by doubly labeled water in various subgroups, reported an average coefficient of variation (CV) of $8,0 \%$ (Schoeller and Hnilicka, 1996). Different subgroups were: young men (CV:8.5\%); young women (CV:7.8\%); obese women (CV:8.8\%); children (CV:7.1\%) and man on hypercaloric diet (CV:2.9\%). In contrast to the fact that this method is feasible, the high costs and the need for sophisticated analyses limit the applicability of the doubly labelled water technique. 
Accelerometry, the other above-mentioned technique for measuring physical activity, is based on movement registration with accelerometers fixed to the body. Research in ergonomics has demonstrated a relationship between the integral of the absolute value of body acceleration and oxygen consumption or energy expenditure (Cotes and Meade, 1960). As an improvement of the unidirectional accelerometers, which have already been in use for several years, tri-axial accelerometers are now available. Measurement in three directions instead of one direction improved the prediction of energy expenditure using accelerometry (Chen and Sun, 1997). Data sampling with a one-minute interval is possible during a measurement period of fourteen days, giving the opportunity to measure the daily pattern of physical activities (Bouten et al, 1994). Meijer et al (1991a) tested the reliability of a triaxial accelerometer (Tracmor) in young adults during a treadmill test. Reproducibility of the signal was 76,85 and $95 \%$ at 3 , 5 , and $7 \mathrm{~km} / \mathrm{h}$ respectively. Kochenberger et al (1996) studied the reproducibility of a triaxial accelerometer in an elderly population (mean age $=71$ years) and found an average ICC (intraclass correlation coefficient) of 0.81 (range $0.77-0.88$ ). It is important to emphasize that reliability in measurement of energy expenditure in daily life, as presented here with accelerometry and doubly labeled water, is also a function of physiologic variation in total energy expenditure and not just analytic error. In healthy persons accelerometry compared to indirect calorimetry showed a strong relationship between accelerometer output and energy expenditure in both an experimental setting $(r=0.95)$ and in daily life $(r=0.73)$ (Bouten et al, 1994 and 1996; Chen and Sun, 1997; Westerterp, 1999) suggesting that accelerometry is a valid measurement method for physical activity.

As in healthy persons, accelerometry may be a promising instrument for measuring physical activity in patients with CLBP. However, it is possible that the instrument's validity may be biased by a different body motion pattern in CLBP patients in comparison to healthy persons. It is imaginable that persons with CLBP may have a different body motion pattern compared to healthy persons to avoid worsening of their back pain. In a laboratory setting, patients with low back pain had less trunk motion during a specific dynamic task than healthy persons (Rudy et al, 1995). Since the accelerometer is fixed around the trunk, measurement of physical activity in daily life in patients with CLBP by accelerometry could be influenced as a result of decreased trunk motion. This may result in a different correlation between energy expenditure and accelerometer output as compared to healthy persons. Before using the accelerometer in research as method to evaluate physical activity in daily life in CLBP patients the validity of the instrument has to be proven in this group.

The purpose of the present study was threefold: A) Accelerometry was compared to the doubly labelled water technique to evaluate the construct validity of accelerometry in 
measuring physical activity in daily life in patients with low back pain. B) The presence of disuse in CLBP was evaluated, by comparing the level of physical activity, body mass and percentage of body fat in CLBP patients, to a sample of matched healthy persons. C) Furthermore, the relationship between the physical activity level and perceived disability in chronic low back pain was evaluated.

\section{METHODS}

\section{Subjects}

\section{Patients:}

Thirteen patients, nine males and four females, participated in the study. The mean age was 45 years (sd $3 \mathrm{yr}$ ). All patients had non-specific low back pain with a mean duration of 12 years (sd 7 yr.). 10 patients ( $77 \%$ ) had a paid job, of which were two patients (15\%) on sick leave because of their back pain. Two patients (15\%) had a disability payment because of back pain problems. Inclusion criteria were: non-specific low back pain during a period of at least three months and age between 18 and 60 years. Exclusion criteria were lumbar disc herniation with neurological complications, major structural back abnormality, evidence of inflammatory, systemic or neoplastic disease, major psychiatric illness and pregnancy. Patients entered the study in two ways: Firstly, patients were referred by the medical specialists of the departments of rheumatology, orthopaedies and rehabilitation medicine of the University Hospital of Maastricht and the Rehabilitation Centre of Hoensbroek. Secondly, patients, who participated in a study of low back pain some years earlier and still had back pain complaints, were invited to participate (Beurskens et al, 1995). All patients gave their written informed consent to participate in the study. The experimental protocol was approved by the Ethics Committee of the Maastricht University and the Rehabilitation Foundation Limburg.

\section{Controls:}

To compare the level of physical activity, body mass and percentage body fat of patients and healthy volunteers, data from healthy volunteers were used derived from a database of the Department Human Biology of the Maastricht University. Data from persons, individually matched for sex and age to a patient, were derived anonymously. Mean age was 45.7 years (sd $2.93 \mathrm{yr}$ ). The doubly labelled water technique for assessing physical activity in daily living and hydrostatic weighing for assessing percentage of body fat were used uniformly for both the patients and the healthy volunteers. 


\section{Protocol}

\section{Protocol:}

Measurements included resting metabolic rate (RMR), average daily metabolic rate (ADMR), physical activity assessed by accelerometry, body mass, body composition and patient reports of disability, pain intensity and fear of movement. In the Department of Human Biology of the Maastricht University measurements were performed in the summer, from June to August 1998. Physical activity in daily life was measured simultaneously with the doubly labelled water technique and an accelerometer over a period of two weeks.

\section{Resting metabolic rate:}

On the first day RMR was determined in all subjects in standard conditions by an open-circuit ventilated hood system (Oxycon Beta, Mijnhardt, The Netherlands.) The patients arrived by car at the university between 7:30 and 8:15 AM, having fasted for 12 hours, to approach basal metabolic rate. After a period of ten minutes of bed rest, RMR was measured during 20 minutes while the patients were watching television in a lying position.

\section{Body composition:}

Body mass was obtained before consuming any food or drink with an electronic balance. The percentage of body fat was measured by hydrodensitometry (Meijer et al, 1991b). In hydrodensitometry body volume is computed as the difference between body mass measured in air and body weight measured during water submersion. Residual lung volume was measured simultaneously with helium dilution. Percent body fat was calculated according the equation of Siri (1956).

\section{Average daily metabolic nate:}

ADMR was measured using the doubly labelled water technique according to Westerterp and co-workers (Westerterp et al, 1995). This method is based on the concept that oxygen in expired carbon dioxide is in isotopic equilibrium with the oxygen in body fluid. A dose of water containing the isotope deuterium and the stable isotope ${ }^{18} \mathrm{O}$ is ingested and allowed to equilibrate with the total body water. Over time, water lost from the body during normal physiological activity contains the two isotopic labels in proportion to their concentrations in the body fluids. The disappearance rate of the two stable isotopes can be detected by taking several urine samples during the period of measurement. Therefore, on the evening before day 1 the patient drank a weighed amount of ${ }^{15} \mathrm{O}$ and ${ }^{2} \mathrm{H}$, after a baseline urine sample was collected. Urine samples were collected also on day 1,8 and 15. Isotope abundance in the urine samples was measured with an isotope ratio mass spectrometer (Aqua Sira, VG Isogas, 
Middlewich, UK). A maximum difference of ten percent between the two weeks of an observation interval of fourteen days was accepted, analogous to criteria of Westerterp and co-workers (1995). The energy estimates RMR and ADMR were used to reflect the metabolic cost of successively rest and average daily activity. PAL or physical activity level is the ratio of ADMR/RMR and indicates the overall level of physical activity relative to the rest metabolic rate. A higher PAL indicates a higher level of daily activity.

\section{Physical activity:}

A triaxial accelerometer (Tracmor; dimensions: $7 \times 2 \times 0,8 \mathrm{~cm}$; weight: $30 \mathrm{gr}$.) consisting of three uniaxial piezoresistive accelerometers was used to record the amount of body movement. The accelerometer was attached to the lower back of the subject. Acceleration signals from the three measurement directions (the posterior, the mediolateral and the longitudinal axes of the trunk) were amplified and filtered according to Bouten et al (1996). The rectified and integrated acceleration from all three directions over a time-period of one minute was calculated. The number of occasions on which this signal exceeded a predefined threshold was calculated. The data is the output of the accelerometer and is expressed in counts per minute (in this paper this output is referred to as Tracmor output). Data-collection continued uninterrupted for fourteen days. Output was stored in a data-memory chip within the accelerometer and read out by a computer after fourteen days. Patients attached the Tracmor with an elastic belt around the waist. They were instructed to wear the Tracmor during waking hours, for 14 days except during bathing, taking a shower or swimming. In addition, they recorded in a diary the moment of attaching the Tracmor to the body in the morning and the moment of taking it off in the evening. In case they had to remove the Tracmor during the day, the reason and the exact time-period had to be registered also. Physical activity in daily life was expressed as the total sum of counts registered during waking hours in fourteen days.

\section{Patient reports:}

To score the perceived level of distress and current pain the patients filled out questionnaires: i.e. A: the Dutch version of the Roland Disability Questionnaire scoring low back disability (Gommans et al, 1997), B: the Dutch version of the Tampa scale for kinesiophobia scoring fear of movement (Vlacyen et al, 1995) and current pain intensity was rated on a visual analogue scale with extremes of 0 , i.e., no pain and 100, i.e. unbearable pain (Bolton, 1999).

\section{Statistics:}

Results were expressed as means and standard deviation. Comparisons between the two groups were performed using the Mann-Whitney $U$ test for unpaired observations $(\alpha=0.05)$. Bivariate correlations between the doubly labeled water technique and the 
accelerometer were performed by Spearman's rank order correlation ( $\left.\mathbf{r}_{\mathbf{r}}\right)$.

\section{RESUlts}

The test result of the doubly labelled water-technique of one patient showed an inconsistency between the first and the second week and was therefore excluded of further analysis, as stated in the method section.

Physical activity level: chronic low back pain patients compared to healthy controls. PAL measured by the doubly labelled water technique did not differ significantly between the patients and healthy controls (table 1).

\begin{tabular}{lcccc}
\hline & \multicolumn{2}{c}{ Patients } & \multicolumn{2}{c}{ Controls } \\
& Male $(\mathrm{n}=8)$ & Female $(\mathrm{n}=4)$ & Male $(\mathrm{n}=8)$ & Female $(\mathrm{n}=4)$ \\
& & & & \\
\hline PAL. & $1.66 \pm 0.30$ & $1.77 \pm 0.21$ & $1.77 \pm 0.32$ & $1.73 \pm 0.22$ \\
Body mass, kg & $82.9 \pm 16.0$ & $70.0 \pm 18.3$ & $82.1 \pm 10.9$ & $76.6 \pm 13.1$ \\
Body fat, \% & $27.2 \pm 6.6$ & $40.7 \pm 8.0$ & $24.6 \pm 6.7$ & $40.7 \pm 6.2$ \\
Resting metabolic rate, & $7.3 \pm 1.3$ & $5.7 \pm 0.7$ & $8.1 \pm 1.3$ & $6.4 \pm 0.7$ \\
Myldary & & & & \\
\hline
\end{tabular}

•Physical activity level: average daily metabolic ratel resting metabolic rate.

A PAL-score below 1,60 is considered as a low activity level, between 1.60 and 1.85 is considered as a moderate activity level and above 1.85 is considered as a high activity level (according to Bouten et al, 1996)

Values are means * SD

Table 1: physiological parameters concerning physical activity.

There were no significant differences in the physiological parameters 'body mass' and 'percentage of bodyfat'. Mean resting metabolic rate seemed lower in both male and female patients compared to their healthy controls, although the difference did not reach the significant level set prior. 
Tracmor versus doubly labelled water technique

The correlation between measurement of physical activity in chronic low back pain patients with the doubly labelled water technique, expressed in PAL and the accelerometer was 0.72 ( $\mathrm{p}<0.01)$. When energy expenditure was expressed as ADMRRMR corrected for body mass the correlation was 0.63 ( $p<0.05$ ).

\section{Patients reports and physical activity}

The mean score for subjective disability on the Roland Disability Questionnaire was 12.5 (sd 7.4). Mean score of fear of movement on the Tampa-scale for kinesiophobia was 42.8 (sd 9.3). Mean pain-intensity, scored on a VAS scale was 33.7 (sd 27.2). As shown in table 2, no significant correlations were found between physical activity in daily life measured with both the doubly labelled water technique and the accelerometer and subjective disability, measured by RDQ. Furthermore fear of movement, measured by the TSK and current pain intensity measured by a VAS-scale showed no significant correlation with physical activity in daily life (table 2).

\section{Physical Activity}

Accelerometer

PAL.

\begin{tabular}{|c|c|c|c|}
\hline \multirow{3}{*}{ Patient reports } & RDQ* & $0.10(0.76)$ & $-0.06(0.74)$ \\
\hline & Tampa scale & $0.10(0.77)$ & $-0.28(0.53)$ \\
\hline & Pain intensity & $-0.06(0.86)$ & $0.25(0.44)$ \\
\hline
\end{tabular}

-Roland Disability Questionnaire

Values are Spearman Rank Correlations:; 0 are p-values

Table 2: Correlation of daily physical activity and patient neports. 


\section{DISCUSSION}

For statistical analysis the non-parametric Mann - Whitney $U$ test, a non-parametric statistical test was used, since the data were clearly skewed. They did not satisfy the Gaussian distribution assumptions, which is likely the result of the criteria and procedure of patient selection, combined with the small number of included patients. Bivariate correlations between the doubly labeled water technique and the accelerometer were also performed by a non-parametric statistical test (Spearman's rank order correlation.) Although, non-parametric statistical tests provide more conservative results, the demonstrated correlation coefficient was sufficiently large and was statistically significant.

The first purpose of the study was to investigate the relationship berween physical activity in daily life measured by the accelerometer and the doubly labelled water technique in patients with chronic low back pain. The correlation found in patients with CLBP was in good agreement with the correlation found in healthy populations (Meijer et al, (1991a); Bouten et al, 1994 and 1996; Chen and Sun, 1997). The results showed that in this group of patients with CLBP the correlation was not negatively affected by a different body movement pattern of patients with chronic low back pain in comparison with healthy persons. In other words: The energy expenditure during physical activity in chronic low back pain patients is comparable to the energy expenditure in healthy persons. These results imply that accelerometry correlates with energy expenditure in patients with CLBP as in healthy persons and the construct validity of the accelerometer for measuring the physical activity level appears to be sufficient in patients with CLBP.

In both patients and healthy volunteers, no perfect match was found between the different measurement methods of physical activity in daily life. Two aspects have to be taken in account: The influence of diet-induced thermogenesis on energy expenditure and the influence of static exercise on accelerometry. Diet induced thermogenesis is energy metabolism stimulated by the ingestion of food and it involves about $10 \%$ of ADMR (Mc Ardle et al, 1996). Since this process influences the outcome of energy expenditure with doubly labelled water and does not effect assessment of body acceleration, a discrepancy between both methods can be introduced. In the present study, and the related study in healthy persons, the influence of diet-induced thermogenesis was not accounted for and therefore it may be possible that the reported correlation is an underestimation of the true correlation. Secondly, energy expenditure during static exercise has to be taken in account. Static exercise results in an increase in energy expenditure without any body movement and therefore can create a discrepancy between outcomes of the two methods assessing physical activity. However, in contrast 
to energy used by diet induced thermogenesis, the contribution of static exercise to daily physical activity is almost negligible (Saris and Binkhorst, 1977). Therefore the influence of static exercise is not a serious limitation in measuring energy expenditure over a prolonged period of time. Given the comparable correlation in chronic low back pain patients and a healthy population, it is suggested that the accelerometer can be used as a valid assessment-method for physical activity in a population of patients with chronic low back pain.

The second purpose of the present study was the investigation of the presence of disuse in CLBP parients compared to healthy controls. The mean level of daily physical activity in the patients with CLBP did not differ from the level of physical activity of their sex and age-matched healthy controls. The PAL measured in both the patients with CLBP and the healthy controls was in good agreement with PAL-criteria of the World Health Organization (WHO, 1985). RMR seemed to show a decreased level in the patient-group compared to the controls but this failed to attain significance. No difference between the two groups was found in the physical activity related parameters 'percentage of body fat' and 'body mass', what is in agreement with the findings of Hultman et al (1993). In interpreting differences in RMR and percentage of body fat the reliability of the measurement methods has to be taken into account. Leff et al found in young healthy adults an ICC of RMR measured by ventilated hood measurement ranging from 0.70 to 0.98 (Leff et al, 1987). The largest variability was found in the beginning of the measurement period, which can be explained by time necessary for the patient to adapt to the calorimetry equipment. For this reason in our study measurement was started after an initial period of 10 minutes in which the patient could adapt to the measurement conditons. Furthermore reliability of body composition measured by hydrodensitometry was high in a study reported by Katch et al, with a test-retest reliability coefficient of 0.94 (Katch et al, 1967). Given the comparable mean level of physical activity in daily life in both groups, no differences were to be expected in the physiological parameters since they reflect the physiological consequence of a long term level of physical activity in daily life.

There is however a possibility that the patients participating in this study were in a relatively better physical condition compared to other patients with CLBP. As shown in the result section, $77 \%$ of the included patients was still able to work despite their back problems. Although patients could be referred to the study by medical specialists in a university hospital and a rehabilitation centre, no patients of the rehabilitation centre entered the study. Patients of the rehabilitation centre matched one of the exclusion criteria and were excluded for participation or they did not want to 
participate. In patients, who need tertiary care for CLBP as given in a rehabilitation centre, physiological changes caused by a worse physical condition could be different from the patients in this study. The postulated presence of disuse in patients with CLBP could not be confirmed in the group of patients, who participated in this study. But further investigation seems warranted.

It is remarkable that although patients felt disabled because of their back problem, as shown in their RDQ-scores, their level of physical activity was not decreased in comparison to the level of physical activity in the healthy controls. The RDQ-scores of the patients in this study were even above the mean RDQ-scores $(9.5, \mathrm{sd}=5.8)$ in a comparable population of 338 persons with chronic low back pain (Gommans et al, 1997). No correlation was found between subjective disability, as measured by the RDQ, and physical activity, measured by both accelerometry or doubly labelled water. There was also no correlation between pain intensity and physical activity level. These findings are in line with previous research. For example Vendrig and Lousberg (1997) reported within-subject correlations between pain intensity, mood and activity level. Pain intensity was significantly associated with mood, but not with physical activity. Linton did find a relationship between physical activity and pain intensity in global interview reports (Linton, 1985), but this relationship gradually disappeared, as the measure of physical activity became more overt and objective. Schmidt found that patients with chronic low back pain were less capable of estimating their physiological level of exertion in a performance test situation compared to healthy controls (Schmidt, 1985). In generally, patient reports, as used in dairies and questionnaires, reflect the patients' perception and cognitive evaluation of the variable of interest. For instance changes in perception of being disabled may be considered in the reported outcome. In measurement of physical activity this can result in a totally different patient report about the activities in daily living as compared to his actual behaviour, expressed in physiological parameters. This finding stresses the need to use objective methods to measure physical activity and to avoid self-report of physical activity if physiological factors instead of behavioural factors are of interest.

In this study we could not confirm the postulated presence of disuse in patients with chronic low back pain. As stated before it is important to include patients referred to tertiary care in further research. It is also noticeable that in a cross-sectional study as presented here, no data can be obtained of the changes in physical activity within a person. An alternative approach to the within person changes is made by comparing the patient group to a group of healthy controls, assuming that the patients acted as the controls before the back pain started. However to monitor the process of disuse, it is more appropriate to measure within person changes in physical activity level and 
related parameters as percentage of body fat and body weight. For this reason a study in a longitudinal design is preferred.

We conclude that, the tri-axial accelerometer is a valid instrument for measuring daily activity in patients with chronic low back pain. The mean level of physical activity was not different in chronic low back pain patients compared to a healthy population and the presence of disuse in chronic low back pain was not confirmed. The discrepancy between measured physical activity and patient reports stresses the need to use objective measurement if physiological factors are of interest.

Acknouledgements: The authors thank Peter Heuts and Kees Pons for their contribution to the study. 


\section{REFERENCES}

- Ainsworth BE, Haskell WL, Leo AS, Jacobs DR, Montoye HJ, Sallis JF et al Compendium of physical activities: classification of energy costs of human physical activities. Med Sci Sports Exerc 1993;25;71-80.

- Beurskens A, de Vet HC, Koke AJ, Lindeman E, Regtop W, van der Heijden GJ, Knipschild PG. Efficacy of traction for non-specific low back pain: a randomised clinical trial. The Lancet 1995;346:1596-600.

- Bolton JE. Accuracy of recall of usual pain intensity in back pain parients. Pain 1999; 533-9.

- Bouten CV, Westerterp KR, Verduin M, Janssen JD. Assessment of energy expenditure for physical activity using a triaxial accelerometer. Med Sci Sports Exerc 1994:26:1516-23.

- Bouten CV, Verboeket-van de Venne WP, Westerterp KR, Verduin M, Janssen JD. Daily physical activity assessment: comparison between movement registration and doubly labeled water. J Appl Physiol 1996; 81(2):1019-26.

- Bussmann JB, Stam HJ. Techniques for measurement and assessment of mobility in rehabilitation medicine: a theoretical approach. Clin Rehab 1998; 12:513-22.

- Chen KY, Sun M. Improving energy expenditure estimation by using a triaxial accelerometer. J Appl Physiol 1997;83(6): 2112-22.

- Convertino VA, Bloomfield SA, Greenleaf JF. An overview of the issues: physiological effects of bed rest and restricted activity. Med Sci Sports Exerc 1997;29:187-90.

- Cotes JE, Meade F. The energy expenditure and mechanical energy demand of walking. Ergonomics 1960;3:97-119.

- Gommans JH, Koes BW, Tulder MW van. Validiteit en responsiviteit Nederlandstalige Roland Disability Questionnaire. Vragenlijst naar functionele status bij patienten met lage rugpijn. Ned T fysiotherapie 1997;107(2):28-33.

- Hultman G, Nordin M, Saraste H, Ohlsen H. Body composition, endurance, strength, cross-sectional area, and density of $\mathrm{mm}$ erector spinea in men with and without low back pain. J Spinal Disord 1993;6(2):114-26.

- Katch et al. Estimation of body volume by underwater weighing: discription of a simple method. J Appl Physiol 1967;23:811.

- Kochensberger G, McConneell E, Kuchibhatla M, Pieper C.The reliability, validity and stability of measure of physical activity in the elderly. Arch Phys Med Rehabil 1996; 77; 793-5.

- Leff ML, Hill JO, Allison AY, Cotson GA, Heymsfield SB. Resting metabolic rate: measurement reliability. J Parent Enteral Nutr 1987;11:354-9.

- Linton SJ. The relationship between activity and chronic back pain. Pain 1985:21:289-94. 
- Mc. Ardle WD, Katch FI, KatchVL. Exercise physiology. Energy, nutrition and human performance. 4nd ed, Baltimore (USA): Williams and Wilkins; 1996.

- Meijer GA, Westerterp KR, Verhoeven FM, Koper HB, de Hoor F. Mechods to assess physical activity with special reference to motion sensors and accelerometers. IEEE Trans Biomed Eng (1991a); 38: 221-229.

- Meijer GA. Westerterp KR, Seyts GH, Janssen GM, SarisWH, Hoor F ten . Body composition and sleeping metabolic rate in response to a 5-month endurance training programme in adults. Eur J Appl Physiol (1991b);62:18-21.

- Pratley R et al. Strength training increases resting metabolic rate and norepinephrine level in healthy 50-to 65-yr-old men. J Appl Physiol 1994;73:133.

- Rudy TE, Boston JR, Lieber SJ, Kubinski JA, Delitto A. Body motion patterns during repetitive wheel rotation task. A comparative study of healthy subjects and patients with low back pain. Spine 1995;20(23):2547-54.

- Saris WH, Binkhorst RA. The use of the pedometer and actometer in studying daily physical activity in man. Part II: validity of the pedometer and actometer in measuring the daily physical activity. Eur J Appl Physiol 1977;37:229-35.

- Schmidr AJ. Cognitive factors in the performance level of chronic low back pain patients, J Psychosom Res 1985;29(2):183-9.

- Schoeller DA. Measurement of energy expenditure in free living humans by using doubly labelled water. J Nutr 1988;118:1278-89.

- Schoeller DA, Hnilicka JM. Reliability of the doubly labeled water method for the measurement of daily energy expenditure in tree living subjects. J Nutr 1996;126:348S-354S.

- Siri WE. Gross composition of the body. In: Lawrence JH, Tobias CA, editors. Advances in biological and medical physics. New York: Ac. Press 1956.

- Vendrig AA, Lousberg R. Within-person relationships among pain intensity, mood and physical activity in chronic pain: a naturalistic approach. Pain 1997:73:71-6.

- Vlaeyen JW, Kole-Snijders AM, Rotteveel AR, Ruesink R, Heuts PH, The role of fear of movement/(re)injury in pain disability. J Occup Rehab 1995;5(4): 235-52.

- Westerterp KR, Wouters L, Marken Lichtenbelt van WD. The Maastricht protocol for the measurement of body composition and energy expenditure with labeled water. Obes Res 1995;3:49-57.

- Westerterp KR. Physical activity assessment with accelerometers. Int J Obes Relat Metab Disord 1999;23 suppl 3:45-9.

- World Health Organization. Energy and protein requirements, report of a joint FAO/WHO/UNO expert consultation. Geneva: WHO,1985.(Technical report series 724) 


\section{Chapter four}

FEAR OF INJURY AND PHYSICAL DECONDITIONING IN PATIENTS WITH CHRONIC LOW BACK PAIN

Jeanine A. Verbunt, Henk A. Seelen, Johan W. Vlacyen, Geert J. van der Heijden, J. André Knottnerus

Published as:

J. Verbunt, H. Seelen, J. Vlaeyen, G. van der Heijden, A. Knottnerus. Fear of injury and physical deconditioning in patients with chronic low back pain. Arch Phys Med Rehabil 2003:84:1227-1232. Reprinted with permission from W.B. Saunders Company 


\section{Abstract}

\section{Objective:}

To test the assumption that fear of injury leads to disability and physical deconditioning in patients with chronic low back pain (CLBP). To evaluate the relation between disability and physical deconditioning.

\section{Design:}

Survey in a cross-sectional design.

\section{Setting:}

A rehabilitation centre.

Patients:

40 Patients with chronic non-specific LBP.

\section{Main Outcome measures:}

Fear of injury was measured with the Tampa Scale of Kinesiophobia. Physical fitness was expressed in aerobic fitness measured as predicted VO2max derived in a submaximal exercise test according the protocol of Siconolfi. Disability was measured with the Roland Disability Questionnaire. The association between fear of injury on the one hand and physical fitness or disability on the other hand was examined using correlational and multiple linear regression analyses.

\section{Results:}

Fear of injury was significantly correlated to disability ( $r=0.44)$, but was not significantly correlated to acrobic fitness. There was no statistically significant association between disability and aerobic fitness. Multiple regression analysis revealed that aerobic fitness was predicted by gender only.

\section{Conclusions:}

Fear of injury appears to be more strongly associated with perceived disability than with aerobic fitness. The assumption that fear of injury leads to physical deconditioning is not confirmed in this sample of patients with CLBP. 


\section{INTRODUCTION}

According to the fear-avoidance model (figure 1), a subgroup of patients can, after an acute back pain problem, interpret their pain as threatening (or, in other words, catastrophize about their pain) (Vlacyen and Linton, 2000). Their pain and their assumption that this pain is caused by a serious injury can result in pain-related fear, of which fear of movement/(re)injury is most salient in these chronic low back pain parients. Both this fear and the expectation of adverse consequences of increasing activities may be the reason to avoid physical activities (Pope et al, 1979), In the long run, avoidance behaviour can result in a combination of negative health consequences: disability, depression and disuse, the latter of which may be defined as a decreased level of physical activities in daily life. The theoretical pathway for these three negative health consequences in chronic low back pain (CLBP) is hypothesised to be similar to the pathway as depicted in the quadrangle in figure 1 . However, the scientific basis for disability, depression and disuse as a consequence of fear in patients with CLBP is not well-founded for all three variables. In contrast to the frequently reported effect of pain-related fear at the level of disability and depression of patients with CLBP (Riley et al, 1988; Waddell et al, 1993; Vlaeyen et al, 1995; Klenerman et al, 1995; McCracken et al,1996; Crombez et al, 1999), the presence of disuse in patients with CLBP has been studied less.

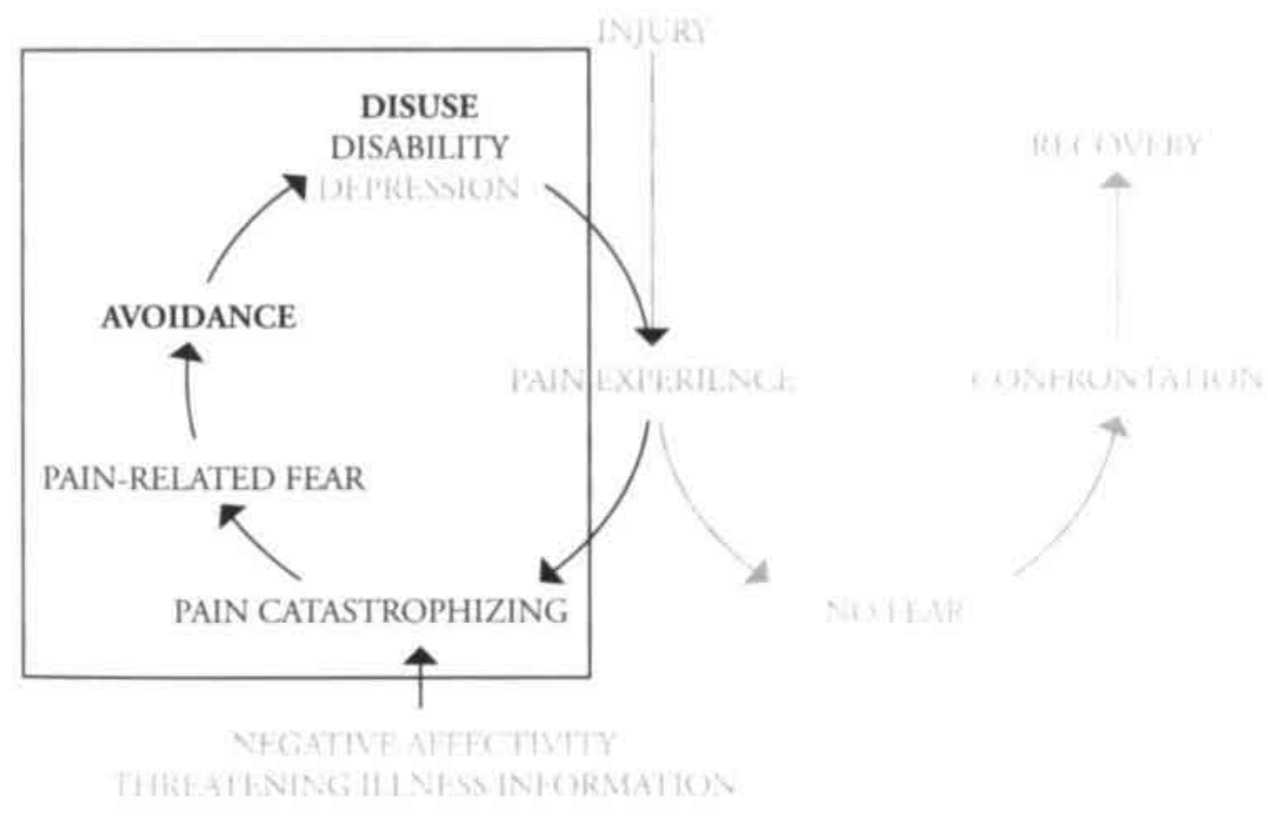

Figure 1: Fear of movement/(re)injury as a determinamt of chronic pain disability. In the quadnangle the focus of the present study is indicated. 
According to the principles of exercise physiology, disuse will, eventually, result in physical deconditioning, i.e. in a decrease in the level of physical fitness. As physical fitness can be seen as a multidimensional phenomenon, including muscle strength, muscle endurance, muscle power, joint flexibility, aerobic fitness, speed, reaction time, balance and body composition (Park, 1989), one or more of these physical domains may be affected by disuse. In contrast to other domains of physical fitness, muscle strength has been evaluated as to its relation to fear of injury. The latter was negatively related to muscle strength during a maximal voluntary contraction (Crombez et al, 1996; Al-Obaidi et al, 2000) and in a test based on muscle endurance (Vlaeyen et al, 1995). Of all physical fitness- related domains, aerobic fitness is most clearly and directly related to a person's physical activity level in daily life in healthy subjects (McArdle et al, 1996). For that reason the largest consequences of disuse are to be expected in a person's level of aerobic fitness. Therefore this domain of physical fitness, in contrast to muscle strength, seems the appropriate variable to assess physical deconditioning.

Little research is available on the relation between fear of injury and catastrophizing on the one hand and aerobic fitness on the other hand. Also the assumed link between aerobic fitness and the two other health consequences, i.e. disability and depression in the model (fig, 1), which is based on a collective pathway, is not well documented. Wittink (1998) found a moderate association between disability and aerobic fitness, which was not confirmed by Hurri et al (1991), who found that depression and aerobic fitness were not significantly correlated in a population with CLBP (McQuade et al, 1988).

In view of the above mentioned lack of clarity about the role of disuse and physical deconditioning in CLBP, in this study three research questions, based on the hypothesised relation depicted in the quadrangle of figure 1, will be addressed:

1. Do CLBP patients with more fear of injury and/or a higher level of catastrophizing have a lower level of aerobic fitness?

2. Do CLBP patients with more fear of injury and/or a higher level of catastrophizing have a higher level of disability?

3. Is a patient's disability level inversely related to his level of aerobic fitness? 


\section{MeTHODS}

\section{Patients}

Forty patients entered the study. Thirteen patients participated in a study at our laboratory in 1998 (Verbunt, 2001), in which exercise testing was a part of the study protocol. These patients were referred by the medical specialists of the departments of rheumatology, orthopaedics and rehabilitation medicine of the University Hospital in Maastricht. In an additional study period in 2000, 27 patients who were referred by physiatrists of the rehabilitation department of the Atrium Medical Centre Heerien (hospital) and the Hoensbroeck Rehabilitation Centre in Hoensbroek entered the study. These patients were on a waiting list for rehabilitation treatment. Inclusion criteria for all patients were: non-specific low back pain during a period of at least three months directly prior to participation in this study as well as age between 18 and 65 years. Exclusion criteria were: lumbar disc herniation with neurological complications; major structural back abnormality; evidence of inflammatory, systemic or neoplastic disease; major psychiatric, cardiac and/or pulmonary conditions; pregnancy and the use of medication that might influence heart rate and/or blood pressure. All patients gave their written informed consent to participate in the study. The experimental protocol was approved by the Medical Ethics Committee of the Rehabilitation Foundation Limburg and the Institute for Rehabilitation Research.

\section{Test procedure}

The test protocol contained items focused on a patient's physical and psychosocial condition. As a representation of the psychosocial condition fear of injury and perceived disability were measured for all patients. For the 27 patients that entered the study in 2000 questionnaires on depression and catastrophizing were added to the protocol.

\section{Psychosocial factors}

\section{Perceived disability}

The Dutch version of the Roland Disability Questionnaire (RDQ) scores perceived low back disability. This questionnaire consists of 24 items. The RDQ has been demonstrated to be a valid measure of physical disability in patients with CLBP (Gommans et al, 1997). 


\section{Fear of movement}

The Dutch version of the Tampa scale for kinesiophobia (TSK) scores fear of movement. This questionnaire contains 17 items and is aimed at the assessment of fear of (re)injury due to movement. The TSK appeared to be sufficiently reliable and valid (Vlaeyen et al, 1995; Goubert et al, 2000).

\section{Depression}

The Dutch version of the Beck Depression Inventory (BDI) scores depression. It is a 21-item self-report questionnaire designed to measure the severity of depression and was proposed by the Dutch Committee for the Standardization of Depression Questionnaires (Beck et al, 1979; Zitman et al, 1989).

\section{Catastrophizing}

The Pain Catastrophizing Scale (PCS) scores catastrophizing. The PCS consists of three subscales focused on rumination, magnification and helplessness. The psychometric properties of the PCS, as tested in a population of patients with CLBP, appeared to be good (Osman et al, 2000; van Damme et al, 2000).

\section{Physical factors}

\section{Physical activities}

Questions were asked regarding sport participation and the intensity of regular daily activities such as walking and cycling. (Example: "How many minutes per day do you cycle or walk to your work, the school, a shop etc?" Multiple choice answers were: less then 5 minutes, 5 to 15 minutes, 15 to 30 minutes, 30 to 45 minutes and more than 45 minutes)

\section{Aerobic fitness}

For the measurement of aerobic fitness a submaximal exercise test, based on the protocol of Siconolfi, was used to predict VO2max based on heart rate. In research on the evaluation of rehabilitation treatment in CLBP submaximal exercise protocols are commonly used (Battie et al, 1989; Hurri et al, 1991; Kellett et al, 1991). Especially since maximal endurance testing is almost impossible in patients with CLBP, because patients tend to stop due to pain before the maximal test-intensity is reached. The most widely used submaximal exercise test is the Astrand Ryhming test (Astrand and Rodahl, 1986), which was designed for healthy persons to predict VO2max based on heart rate recording during submaximal cycling exercise. However, Wittink (1999) found that, in patients with CLBP, predicted VO2max based on the Astrand method was overestimated for $17 \%$ compared to $\mathrm{VO} 2 \mathrm{max}$ derived from direct measurement of 
$\mathrm{VO} 2$ using calorimetry. Although the Astrand test is submaximal, its intensive increase in load can still be problematic for patients with CLBP. On the other hand in the Siconolfi protocol, which is especially designed to assess aerobic performance in inactive persons, load is increased more gradually and the initial load is lower compared to the Astrand test. For a population of healthy inactive persons the Siconolfi method was more accurate in predicting VO2max as measured during a maximal exercise test than the prediction based on the Astrand equation (Siconolfi et al, 1982). Since parients with CLBP are supposed to have a lower fitness level (according to the fear avoidance model) compared to healthy controls and since the gradually increase of load in the Siconolfi protocol seems more appropriate to use in these patients, in this study we decided to measure aerobic performance using the Siconolfi protocol.

All patients performed a cycle ergometer test according the Siconolfi protocol (1982). During the test, heart rate was recorded every minute by a heart rate monitor positioned on the chest. For men of 35 years and older and for women of all ages the initial load of 25 Watts was increased by 25 Watts every two minutes until the subject achieved a target heart rate, which was $70 \%$ of the predicted maximal heart rate (calculated as 220-age). For men under the age of 35, the initial exercise load of 50 Watts was increased by 50 Watts every two minutes if the heart rate was less than $60 \%$ of the predicted maximum and by 25 Watts if it was between $60 \%$ and $70 \%$. After attaining the target heart rate, all patients continued exercising at the same exercise load level for at least two additional minutes until steady-state heart rate was reached. In the last two minutes the range in heart rate had to be less than five beats per minute to end the test. Each patient's maximal oxygen uptake capacity (VO2max in $\mathrm{mL}$ of oxygen per kilogram per minute) was estimated according to the equations of Siconolfi (1982) and the Astrand nomogram (Astrand and Ryhming; 1954). The cycle ergometer' was calibrated prior to the testing. Pedalling rate was kept constant at $50 \mathrm{rpm}$. During the test patients were verbally encouraged to give their best effort.

\section{Body composition}

As to body composition the percentage of body fat was estimated. Calculations of body fat percentage were performed based on the summed thickness of four subcutaneous fat folds (triceps, biceps, subscapular and suprailiac) according to the procedure of Durnin and Womersly (1974). Fat folds were measured with a Servier skinfold calliper (Biersteker et al, 1983). Body weight was obtained using an electronic balance. Weight, height and percentage of body fat were all measured twice and mean scores were calculated. 


\section{Data analysis}

Results for groups were expressed as a mean score and standard deviation combined with the range of scores. In case of a normal distribution of the data comparisons between two groups were performed using the Student T-test $(\alpha=0.05)$. In case of a non-normal distribution of the data the Mann-Whitney $U$ test for unpaired observations $(\alpha=0.05)$ was used. Bivariate correlations were evaluated using Spearman's rank order correlation ( $\left.\mathrm{r}_{\mathrm{s}}\right)$. Three multiple regression analyses were performed with the consecutive criterion variables disability, level of aerobic fitness and depression. In all three analyses the predictor variables were gender, catastrophizing and fear of injury. The variables, which were introduced in the multiple regression models, were chosen based on their hypothesized role as a predictor in the fear avoidance model (fear of injury and catastrophizing) as presented in figure 1. To evaluate the interdependency berween disability and the level of aerobic fitness, a multiple regression analysis was performed with disability as criterion variable and level of aerobic the fitness and depression as predictor variables. All statistical analyses were performed using SPSS software. 


\section{RESULTS}

40 patients, 28 males and 12 females, participated in the study. Three patients, two males and one female, were excluded from further analysis, because they did not perform the exercise test according the protocol. One patient had to quit because of knee complaints. A second patient did not manage to follow the test procedure, even after two attempts, and a third patient decided to end the test prematurely because of increasing back pain complaints, which were unbearable according to this patient. Of the 37 resulting patients mean age was $45.2 \pm 8.2$ years. Patients had non-specific low back pain with a mean duration of $11.7 \pm 8.5$ years. 26 participants $(70 \%)$ had a paid job. 6 patients of those with a paid job $(23 \%)$ were currently on sick leave because of their back pain. 9 patients ( $24 \%$ of all patients) were declared fully or partially disabled and received disability payment. In table 1 additional demographics are presented for males and females separately.

\begin{tabular}{|c|c|c|c|}
\hline & Total $(n=37)$ & Male $(n-26)$ & Female $(n=11)$ \\
\hline \multirow[t]{2}{*}{ Age (years) } & $45.2 \pm 8.2$ & $44.8+6.9$ & $46.1 * 9.9$ \\
\hline & $25-61$ & $30-61$ & 25.61 \\
\hline \multirow[t]{2}{*}{ Pain duration (years) } & $11.7 \pm 8.5$ & $12.1 \neq 8.6$ & $10.9 * 8.5$ \\
\hline & $1-30$ & 1.30 & $1-24$ \\
\hline \multicolumn{4}{|l|}{ Work status (percentage): } \\
\hline - Paid job & $26(70 \%)$ & $20(77 \%)$ & $6(55 \%)$ \\
\hline - Sick leave & $6(23 \%)$ & $3(15 \%)$ & $3(50 \%)$ \\
\hline - Disability payment & $9(24 \%)$ & $7(27 \%)$ & $2(18 \%)$ \\
\hline
\end{tabular}

Values are means \pm SD and range

Table 1: Demognaphic data of the study population of patients with CLBP $(n=37)$.

As presented in table 2 the mean RDQ score was 11.4 (sd 5.4). Women felt significantly more disabled than men. Although the mean score for depression for females was 14.3 (8.5) and for males was 8.2 (4.6), this difference did not reach statistical significance. However, women did report higher levels of catastrophizing than men did. 


\begin{tabular}{lllll}
\hline & Total & Male & Female & $\begin{array}{l}\text { Total number } \\
\text { and M/F }\end{array}$ \\
& & & & \\
\hline Perceived disability & $11.4 \pm 5.4$ & $9.9 \pm 5.1$ & $14.9 \pm 4.5^{*}$ & $\mathrm{n}=37$ \\
(RDQ) & $0-21$ & $0-21$ & $6-19$ & $\mathrm{M} / \mathrm{F}=26 / 11$ \\
Fear of injury & $39.1=7.0$ & $38.4=5.8$ & $40.6 \pm 9.4$ & $\mathrm{n}=37$ \\
(TSK) & $27-57$ & $28-52$ & $27-57$ & $\mathrm{M} / \mathrm{F}=26 / 11$ \\
Depression & $9.9=6.4$ & $8.2 \pm 4.6$ & $14.3 \pm 8.5$ & $\mathrm{n}=25$ \\
(BDI) & $1-26$ & $1-19$ & $3-26$ & $\mathrm{M} / \mathrm{F}=18 / 7$ \\
Catastrophixing & $20.3=11.9$ & $16.1=7.6$ & $30.4=14.8 *$ & $\mathrm{n}=25$ \\
(PCS) & $4=48$ & $4-30$ & $15-48$ & $\mathrm{M} / \mathrm{F}=18 / 7$ \\
\hline
\end{tabular}

Values are means $t$ SD and range

- gender-related difference $\mathrm{p} \quad 0.05 ; \mathrm{M} / \mathrm{F}=\mathrm{Male} / \mathrm{Female}$ ratio

Table 2: Scores on psychosocial variables for males and females $(n=37)$.

In table 3 anthropometric variables are presented.

\begin{tabular}{lccc}
\hline & Total $(\mathrm{N}=37)$ & Male $(\mathrm{N}=26)$ & Female $(\mathrm{N}=11)$ \\
\hline Weight $(\mathrm{kg})$ & $82.0 \pm 16.5$ & $86.3 \pm 15.8$ & $71.7 \pm 13.8^{*}$ \\
& $51-128$ & $61-128$ & $51-96$ \\
Height $(\mathbf{m})$ & $1.74 \pm 0.09$ & $1.79 \pm 0.06$ & $1.65 \pm 0.06^{\circ}$ \\
& $1.52-1.96$ & $1.66-1.96$ & $1.52-1.73$ \\
Percentage of body fat (\%) & $30.9 \pm 8.5$ & $27.7 \pm 6.8$ & $39.1 \pm 6.8^{*}$ \\
& $14-50$ & $14-42$ & $24-50$ \\
Lean Body Mass $(\mathrm{kg})$ & $56.9 \pm 10.7$ & $61.7 \pm 8.0$ & $44.5 \pm 5.9^{*}$ \\
& $37.3-74.5$ & $47.6-74.5$ & $37.3-57.9$ \\
VO2 max (L.min $)$ & $2.43 \pm 0.65$ & $2.78 \pm 0.49$ & $1.60 \pm 0.24^{*}$ \\
& $1.28-3.70$ & $1.94-3.70$ & $1.28-2.08$ \\
\hline
\end{tabular}

Values are means $\pm S D$ and range

- gender-related difference $p<0.05$

Table 3: Scons on anthropometric wariables for males and females. 
Lean body mass was calculated as (100-pbf) 'w whereby pbf stands for percentage of body fat and $\mathrm{w}$ stands for weight. Lean body mass represents the weight of bodily tissues (particularly existing of water, muscles and bones) minus the weight of body fat. In table 4 Spearman correlation coefficients are presented.

\begin{tabular}{|c|c|c|c|}
\hline & $\begin{array}{c}\text { Disability } \\
\text { (RDQ) }\end{array}$ & VO2 $2 \max$ & $\begin{array}{c}\text { Depression } \\
\text { (BDI) }\end{array}$ \\
\hline Gender & $0,43^{\cdots}$ & $-0.79 \cdots$ & 0.34 \\
\hline Age & -0.15 & $-0.44^{*}$ & -0.20 \\
\hline \multicolumn{4}{|l|}{ Pyybologically oriented } \\
\hline Catastrophizing (PCS) & $0.45^{\circ}$ & -0.14 & $0.56 \cdots$ \\
\hline Fear of injury (TSK) & $0.44 *$ & -0.17 & $0.57 *$ \\
\hline \multicolumn{4}{|l|}{ Pbysically ariented } \\
\hline Percentage of body fat & 0.25 & $-0.59 *$ & -0.03 \\
\hline Body weight (kg) & 0.18 & $0.45^{\circ}$ & -0.16 \\
\hline Lean Body Mass (kg) & -0.32 & $0.79 \cdots$ & 0.20 \\
\hline
\end{tabular}

$* p<0.05 * p<0.01$

Table 4: Spearman Correlation Coefficient of psychological variables with disability, aenobic fimess and depression.

Both fear of injury and catastrophizing were significantly correlated to disability and depression. However, neither fear of injury nor catastrophizing correlated significantly with aerobic fitness or with the percentage of body fat representing another domain of physical fitness. Although aerobic fitness was not statistically significant related to the psychosocial variables, it was, however, significantly related to demographic variables such as gender and age and to physical variables concerning body weight and body composition. In table 5 results of multiple regression analyses are presented concerning the criterion variables disability and $\mathrm{VO} 2 \mathrm{max}$. 


\begin{tabular}{|c|c|c|c|c|}
\hline & $\begin{array}{l}\text { Independent } \\
\text { variables }\end{array}$ & $\mathbf{R}^{2}$ & Adjusted $\mathbf{R}^{2}$ & $\begin{array}{c}\text { Standardized } \\
\text { B }\end{array}$ \\
\hline \multirow[t]{3}{*}{ Disability } & Gender & $0.37^{\circ}$ & 0.28 & 0.21 \\
\hline & Fear of injury & & & 0.33 \\
\hline & Catastrophizing & & & 0.22 \\
\hline$V O 2 \max$ & Gender & $0.68 *$ & 0.63 & $-0.86 \cdots$ \\
\hline \multirow[t]{2}{*}{ (L.min ') } & Fear of injury & & & 0.00 \\
\hline & Catastrophizing & & & 0.06 \\
\hline
\end{tabular}

${ }_{p}<0.05 * p<0.01$

Table 5: Multiple Linear Regression analyses for disability and VO2max as criterion variables and gender, fear of injury and catastrophizing as predictor variables.

'Gender' was added to 'catastrophizing' and 'fear of injury' as a predictor variable in the regression equation, based on its significant correlation with disability and VO2max as presented in table 4 . The percentage explained variance ranged from $37 \%$ for disability to $68 \%$ for $\mathrm{VO} 2 \mathrm{max}$. In the model for $\mathrm{VO} 2 \mathrm{max}$ the best predictor was gender with a $\beta$ of -0.86 . In a multiple regression analysis with disability as a criterion variable and depression and aerobic fitness as predictor variables the percentage of variance explained by depression and aerobic fitness was $30 \%$. Depression appeared to be a significant predictor for disability $(\beta=0,41 ; p=0.04)$ in contrast to aerobic fitness $(\beta=-$ $0.25 ; p=0.21$ ).

Of all patients $52 \%$ performed sports activities on a regular basis. This percentage was comparable between patients with a paid job and those on disability payment. Half of these patients even participated in more than one sports activity. 


\section{Discussion}

The first aim of the present study was to determine whether high levels of catastrophizing and fear of injury negatively affect physical fitness (expressed as aerobic fitness). In the present study no statistically significant association was found between catastrophizing and fear of injury on the one hand and aerobic fitness on the other hand. This means that patients in our study who have more fear of injury or catastrophize more do not have a lower physical fitness level. Furthermore, our study could not demonstrate a statistically significant relationship between aerobic fitness, disability and depression in patients with in CLBP, which was the third aim of this study. These findings are not in accordance with the presentation of disuse and related deconditioning in the fear avoidance model (Vlacyen and Linton, 2000).

In total 40 patients entered the study. To evaluate possible discrepancies in demographic variables of patients that entered the study in 1998 and 2000 mean age, mean pain duration and the male/female ratio were compared. On these variables no differences were found. Seemingly more patients entering the study in 2000 received full or partial disability payment $(30 \%)$ compared to patients entering the study in 1998 (15\%). However, this difference was not statistically significant. This finding together with the fact that all patients participating in 2000 were on a waiting list for rehabilitation training could probably indicate that patients entering in 2000 perceived more functional problems in daily life compared to the patients of 1998. This supposition, however, was not confirmed by a difference in the level of perceived disability (RDQ) in both groups. For further analysis data of both patients groups were used as derived from one sample. The data of 37 patients were used for the final analyses. The mean RDQ score of all patients in this study (11.4 \pm 5.4 ) was comparable to the RDQ scores $(9.5 \pm 5.8)$ in a population of 338 persons with chronic low back pain in a study of Gommans et al (1997). In addition, the mean TSK score $(39.1 \pm 7.0)$ was equivalent to the TSK score $(38.4 \pm 7.8)$ in a study of Vlaeyen et al, in which a comparable population of CLBP patients on a waiting list for a rehabiltation program participated (Vlaeyen et al, 1995). These findings support the generalization of our research results to the overall CLBP population. $70 \%$ of participants were male. The low number of women that entered the study impel to interpret group results on women with caution. Since, in the interpretation of anthropometrical data, gender plays an important role, the results of men and women were stratified by gender. Also in the multiple regression analysis we controlled for gender.

In this study no significant association between fear of injury and physical fitness (expressed by aerobic fitness) was found. In contrast to our findings, in other studies in which physical fitness was expressed as muscle strength (Vlaeyen et al 1995; Crombez 
et al, 1996 and 1999; Al-Obaidi et al, 2000) this negative relationship between physical fitness and fear of injury was found, which is in agreement with the suggested pathway of disuse and physical deconditioning as presented in the fear avoidance model. Another explanation for the discrepancy between our findings, based on aerobic fitness and findings of studies on muscle strength, is also possible. Most tests on muscle strength are based on the performance of a maximal voluntary muscle contraction, in which patients are asked to maximally contract their muscle during a period of about 5 seconds. If a person is afraid of injury it is possible that he unintentionally will avoid a maximal contraction of his muscle to prevent an feared injury. In this situation the assessment of strength as an indicator of physical fitness is confounded by fear of injury, leading to an underestimation of real performance (Watson, 1999). Decreased muscle strength therefore has to be interpreted not merely as the result of physical deconditioning but at least by a combination of physical deconditioning and submaximal performance or even as a result of submaximal performance alone. During aerobic fitness testing, in contrast to muscle testing, no sudden maximum effort is asked but the load is only slowly increased. This load increase will stop at a submaximal level at the end of the assessment period. Patients are probably less afraid to become injured during a slowly increase in loading in aerobic firness testing compared to the short intensive activity during muscle testing. This would imply that aerobic fitness testing is to be favoured over maximal muscle testing to measure physical fitness in patients with CLBP.

In this study, fear of injury and catastrophizing were not statistically significant related to aerobic fitness or to the percentage of body fat. However, a significant association was found between fear of injury and disability and between fear of injury and depression. The finding that fearful parients feel more disabled and depressed in daily life is in accordance with results of other studies (disability (Riley et al, 1988; Waddell et al, 1993; Vlaeyen et al, 1995; Klenerman et al, 1995; McCracken et al, 1996; Crombez et al, 1999), and depression (Dionne et al, 1997)). Although patients with CLBP feel disabled, it could be that they try to stay physically active in spite of their perceived disability. Knibbe et al suggested that patients with CLBP are probably aware of the importance of staying active (1999). In their study on self care in a group of persons with low back pain, derived for a sample of the general Dutch population, about $59 \%$ of the participants reported that they tried to maintain the same level of physical activities in daily life as before the back pain started. This finding was independent of the level of pain perceived. In a previous study on physical activities in daily life in patients with CLBP Verbunt et al did not find a significant correlation between physical activities in daily life and disability (Verbunt et al, 2001). In the present study $52 \%$ of the patients participated in one or more sports activities. In the general population this amounts to $65 \%$. This active behaviour may have prevented a 
decrease in the level of physical fitness. However, it still is possible that feared activities were avoided. But, by replacing these feared activities by alternative less feared activities the level of physical fitness may probably have been less affected than expected.

The results of this study are based on a rather small sample size and thus have to be interpreted with caution. Associations between variables were calculated based on correlation coefficients. As to the statistics and methodology of the present study the regression analyses maximally contained three variables. Methodologically, in a study involving a larger study population it is possible to enter more variables into the regression model. This will result in a more precise prediction of the criterion variable based on the model. Therefore, in future research, a larger population is needed to determine the replicability of the results found in this study. It is also important to realise that in this study, mean aerobic fitness levels are presented, in contrast to individual fitness levels over time. A change in a patient's fitness level is probably even more appropriate when investigating deconditioning. However, to measure fitness changes over time, a longitudinal study is needed instead of the cross-sectional design as was used in this study. In this study an indication is given on the relation of disuserelated variables with psychosocial variables in the fear avoidance model. We conclude that the presence of disability and depression in the fear-avoidance model was supported, whereas the presence of disuse-related physical deconditioning could not be confirmed.

Acknowledgements: The authors thank P. de Vos and the physiatrists of the Pain department of the Hoensbroeck Rehabilitation Centre in Hoensbroek and the department of Rehabilitation Medicine of the Atrium Medical Centre in Heerlen for their co-operation in this study. 


\section{REFERENCES}

- Al-Obaidi SM, Nelson RM, Al-Awadhi S, Al-Shuwaie N. The role of anticipation and fear of pain in the persistence of avoidance behavior in patients with chronic low back pain. Spine 2000;25(9):1126-1131.

- Astrand P, Ryhming. A nomogram for calculation of aerobic capacity (physical fitness) from the pulse rate during submaximal work. J Appl Physiol 1954;7:218.

- Astrand P, Rodahl K. Textbook of work physiology, Physiological bases of exercise. 3rd edition. New York, NY: McGraw-Hill, Inc., 1986.

- Battie M, Bigos SJ, Fisher LD, Hansson TH, Nachemson AL, Spengler DM et al. A prospective study of the role of cardiovascular risk factors and fitness in industrial back pain complaints. Spine 1989;14:141-147.

- Beck AT, Rush AJ, Shaw BF, Emmery G. Cognitive therapy of depression. John Wiley, New York 1979.

- Biersteker MWA, Broere F and Biersteker PA. Het schatten van een gewichtspercentage lichaamsvet met eenvoudige hulpmiddelen. Geneesk Sport 1983:16:29-32.

- Crombez G, Vervaet L, Lysens R, Eelen P, Baeyens F. Do pain expectancies cause pain in chronic low back patients? A clinical investigation. Behav Res Ther 1996;34:919925.

- Crombez G, Vlaeyen JWS, Heuts PHTG, Lysens R. Fear of pain is more disabling than pain itself. Evidence on the role of pain-related fear in chronic back pain disability. Pain 1999;80:329-340.

- Van Damme S, Crombez G, Vlaeyen JWS, Van den Broeck A, Van Houdenhove B. De Pain Catastrophizing Scale: Psychometrische karakteristieken en normering [The Pain Catastrophizing Scale: Psychometric characteristics and norms]. Gedragstherapie 2000.

- Dionne CE, Koepsell TD, Von Korff M, Deyo RA, Barlow WE, Checkoway H. Predicting long-term functional limitations among back pain patients in primary care settings. J Clin Epidemiol 1997:50:31-43.

- Durnin JGVA and Womersly J. Body fat assessed from total body density and its estimation from skinfold thickness: measurements on 481 mean and women aged 16 to 72 years. Brit J Nutr 1974;32:77-97.

- Gommans JH, Koes BW, Tulder MW van. Validiteit en responsiviteit Nederlandstalige Roland Disability Questionnaire. Vragenlijst naar functionele status bij patiënten met lage rugpijn. Ned Tijdschr Fys 1997;107(2):28-33.

- Goubert L, Crombez G, Vlaeyen JWS, Van Damme S, Van den Broeck A, Van Houdenhove B. De Tampa schaal voor Kinesiofobie: Psychometrische karakteristieken en normering [The Tampa scale for Kinesiophoba: Psychometric properties and norms]. Gedrag en Gezondheid 2000;28: 54-62. 
- Hurri H, Mellin G, Korhonen O, Harjula R, Harkapaa K, Luamo J. Acrobic capacity among chronic low back pain patients. J Spinal Disord 1991;4:34-38.

- Kellett KM, Kellett DA, Nordholm LA. Effects of an exercise program on sick leave due to back pain. Phys Ther 1991;71:283-290.

- Klenerman L, Slade PD, Stanley M, Pennie B, Reilly JP. The prediction of chronicity in patients with an acute attack of low back pain in a general practice setting. Spine 1995;20:478-484.

- Knibbe H, Straten G, Friele R. Zelfzorg bij rugpijn: Wat doen mensen met rugpijn om hun klachten te beperken? Tijdschr Oefenth Mensendieck 1999;4:48-51.

- McArdle WD, Katch Fl, Katch VI. Physical activity, health and aging. Exercise physiology. Energy, nutrition and human performance. 4th edition Baltimore, Maryland: Williams\&Wilkins 1996;635-655.

- McCracken LM, Gross RT, Aikens J, Carnkike JCLM. The assessment of anxiety and fear in persons with chronic pain : a comparison of instruments. Beh Res Ther 1996:34:927- 933 .

- McQuade KJ, Turner MPH, Buchner DM. Physical fitness and chronic low back pain. Clin Orthop 1988;233:198-204.

- Osman A, Barrios FX, Gutierrez PM, Kopper BA, Merrifield T, Grittmann L. The Pain Catastrophizing Scale: further psychometric evaluation with adults samples. J Behav Med 2000;23: 351-165.

- Park RJ. Measurement of physical fitness: a Historical Perspective. Office of Disease Prevention and Health Promotion Monograph Series. Washington, D.C.: U.S. Department of Health and Human Services, Public Health Service, 1-35,1989.

- Pope MH, Rosen JC, Wilder DG, Frymoyer JW. The relation between biomechanical and psychological factors in patients with low-back pain. Spine 1979;5:173-178.

- Riley JF, Ahern DK, Follick MJ. Chronic pain and functional impairment: assessing beliefs about their relationship. Arch Phys Med Rehabil 1988;69:579-582.

- Siconolfi SF, Cullinane EM, Carleton RA, Thompson PD. Assessing VO2max in epidemiology studies: modification of the Astrand-Ryhming test. Med Sci Sports Exer 1982:335-338.

- Verbunt JA, Westerterp KR, van der Heijden GJ, Seelen HA, Vlacyen JW, Knottnerus JA. Physical activity in daily life in parients with chronic low back pain. Arch Phys Med Rehab 2001:82;726-730.

- Vlaeyen JWS, Kole-Snijders AM, Rotteveel AR, Ruesink R, Heuts PH. The role of fear of movement/(re)injury in pain disability. J Occup Rehabil 1995;5(4): 235-52. 
- Vlaeyen JWS, Kole-Snijders AMJ, Boeren RGB, Eek H van. Fear of movement/ (re)injury in chronic low back pain and its relation to behavioural performance. Pain 1995;62: 363- 372.

- Vlaeyen JWS, Linton SJ. Fear-avoidance and its consequences in chronic musculoskeletal pain: a state of the art. Pain 2000;85:317-332.

- Waddell G, Newton M, Henderson I, Somerville D, Main C. A Fear-Avoidance Beliefs Questionnaire (FABQ) and the role of fear-avoidance beliefs in chronic low back pain and disability. Pain 1993;52:157-168.

- Watson PJ. Non-psychological determinants of physical performance in musculoskeletal pain, In Mitchell, M. et al, Pain 1999 an updated review; refresher course syllabus 9th World Congress on Pain, Seattle: IASP press 1999:153-158.

- Wittink H. Acrobic fitness, Pain, function and disability in chronic low back pain parients. Thesis Ann Arbor: Bell\&Howell 1998.

- Wittink H. Physical fitness, function and physical therapy in patients with pain: clinical measures of aerobic fitness and performance in patients with chronic low back pain. In Mitchell, M. et al, Pain 1999 an updated review; refresher course syllabus 9th World Congress on Pain, Seattle: LASP press 1999:137-144.

- Zitman FG, Griez EJL, Hooijer C. Standaardisering depressie-vragenlijsten. Tijdschr Psychiatr 1989;31:114-135.

Suppliers:

a. heart rate monitor: Polar, Professorintie 5 FIN-90440 Kempele, Finland

b. cycle ergometer: ER800 Jaeger, Leibnizstrasse 7 D-97204 Hochberg

c. SPSS : SPSS Inc, 233 S. Wacker Drive, 11th floor Chicago, IL 60606-6307 
$\frac{5}{\frac{5}{5}}$ 


\section{Chapter five}

PAIN-RELATED FACTORS CONTRIBUTING TO MUSCLE INHIBITION IN PATIENTS WITH CHRONIC LOW BACK PAIN: AN EXPERIMENTAL INVESTIGATION BASED ON SUPERIMPOSED ELECTRICAL STIMULATION

Jeanine A. Verbunt, Henk A. Seelen, Johan W. Vlaeyen, Eric J. Bousema, Geert J. van der Heijden, Peter H. Heuts, J. André Knottnerus

In press: Clinical Journal of Pain 


\section{ABSTRACT}

\section{Aim of investigation:}

(1) To evaluate muscle strength, as a component of physical deconditioning, and central activation ratio (CAR), representing the performance level during testing, in patients with chronic low back pain (CLBP) as compared to healthy controls. (2) To evaluate the contribution of cognitive behavioural and pain-related factors to the CAR of CLBP patients.

\section{Methods:}

25 patients with CLBP and 25 age and gender-matched controls participated. Muscle strength, i.e. peak torque $(\mathrm{T})$ of the quadriceps muscle, was measured on a Cybex dynamometer. During $\mathrm{T}$ the quadriceps muscle was percutaneously stimulated using superimposed electrical stimulation, generating an additional twitch torque (Ttwitch) in case of submaximal performance. CAR was calculated as $T /(T+T$ twitch). To evaluate cognitive behavioural and pain-related factors influencing CAR, measures of fear of injury (TSK), pain catastrophizing (PCS), psychological distress (SCL90) and pain intensity (VAS) were used. Differences between groups were tested using either T-tests or Mann-Whitney U tests. Associations were tested by partial correlation coefficients controlling for gender.

\section{Results:}

The male/female ratio was 15/10. Mean age and CLBP duration were $42.7( \pm 9.5)$ and $9.9( \pm 8.3)$ years respectively. Mean muscle torque (per kg lean body mass) in patients $(1.95 \mathrm{Nm} / \mathrm{kg} \pm 0.8)$ was less than in controls $(3.16 \mathrm{Nm} / \mathrm{kg} \pm 0.7)(\mathrm{p}<0.01)$. Median CAR was lower in patients $(\mathrm{p}<0.05)$. Patients experiencing increased psychological distress and patients with a higher current pain level showed a lower CAR $(\mathrm{p}<0.05)$.

\section{Conclusions:}

When interpreting decreased muscle strength in terms of physical deconditioning in patients with CLBP, submaximal performance has to be taken into account. The results suggest that CLBP patients who report increased psychological distress and a higher level of current pain tend to show increased inhibition of muscle activity, leading to submaximal performance. 
For years, physical deconditioning has been thought to be both a cause and a result of back pain (Waddell, 1998). As a consequence in clinical practice physical reconditioning has been proposed to be a goal for treatment in patients with chronic low back pain (CLBP). Based on this multidimensional phenomenon of physical deconditioning, which negatively influences acrobic fitness, muscle strength, muscle endurance and body composition, a variety of rehabilitation programs appeared. The effectiveness of these interventions in changing a patient's level of physical fitness is often tested using muscle strength or muscle endurance tests (Hazard et al, 1989; Lindstrom et al, 1992; Kankaanpaa et al, 1999; Mannion et al, 1999; Mannion et al, 2001). The significant post-treatment increase in muscle strength, which has been confirmed in several studies, has often been suggested to confirm pre-treatment physical deconditioning in CLBP patients. However, whether a significant increase in muscle strength is solely based on physical changes can be questioned. In a study of Mannion et al (2001a) patients with CLBP participated in one out of three common reconditioning programmes: active physiotherapy, reconditioning based on muscle strength training or low impact aerobic fitness. All groups improved significantly in back muscle performance (increased strength and endurance) and perceived disability level after three months. However, these alterations in muscle performance could not be explained on the basis of structural changes within the muscle as evaluated by MRI imaging (muscle cross sectional area) and muscle biopsy (fiber type proportion and distribution) (Kaser et al, 2001). On the other hand, the change in perceived disability level after therapy was best explained by pain, psychological distress and fear avoidance beliefs (Mannion et al, 2001b).

Could it be possible that these psychological and pain related-factors not only influence disability, but also physical performance? In patients with CLBP fear of movement/(re)injury and pain are assumed to limit the performance of daily life activities, eventually leading to avoidance of these feared physical activities (Vlaeyen and Linton, 2000). One could hypothesize that the same avoidance-generating factor exerts its influence during muscle strength testing, thereby reducing test validity. Since in most protocols on muscle testing a fast maximum (voluntary) muscle contraction is required, this sudden increase in load could be feared by patients with pain. In contrast in protocols on aerobic testing, load is only slowly increasing during the test and the influence of fear of injury or fear of pain may therefore be less prominent. The association between fear of injury and muscle strength has already been demonstrated in several studies (Vlaeyen et al, 1995b; Crombez et al, 1996 and 1999; Al-Obaidi et al, 2000). If muscle strength testing in pain patients is influenced more by behavioural or pain-related factors, such as fear or pain, avoidance behaviour will lead to 
submaximal performance during the test (Watson, 1999; Rutherford, 1986). The lower level of muscle strength in patients with CLBP compared to healthy controls (Hultman et al, 1993; Lee et al, 1995; Gibbons et al, 1997) may therefore not only be caused by a different level of physical deconditioning but also by a more prominent role of behavioural factors influencing the test. The interpretation of muscle strength as a measure for physical deconditioning in chronic pain would therefore only be valid in those conditions in which submaximal performance during the test is prevented, which, in patients with pain, is practically impossible. A combination of muscle strength testing and a measure to reveal submaximal performance during the test is needed to make valid inferences from muscle strength testing.

One way to obtain a better representation of muscle strength is by controlling whether the muscle is indeed fully contracted during the test. A technique which has been used for this purpose in healthy controls is the superimposed electrical stimulation technique (Rutherford et al, 1986; Mc Kenzie et al, 1992; Nørregaard et al, 1997). A submaximal contraction of the muscle, due to incomplete central nervous system recruitment or submaximal activation of the muscle, will be revealed. Until now superimposed electrical stimulation has especially been used in neuromuscular disorders (Allen et al, 1994), in muscle fatigue (Lloyd et al, 1991) and in fibromyalgia (Norregaard et al, 1994 and 1995; Rutherford 1986). Application of this technique during a isometric muscle strength test implies that during a maximal voluntary contraction the muscle is simultaneously stimulated percutaneously. The stimulus unmasks a sub-maximal contraction of the muscle by generating an additional torque. If, on the other hand, a muscle is already maximally contracted, the stimulation will not lead to any increase in torque. Based on the superimposed electrical stimulation the Central Activation Ratio (CAR) can be calculated reflecting the percentage of the muscle activation during the muscle strength effort (Stackhouse et al, 2000).

Suter and Lindsay (2001) used superimposed electrical stimulation in persons with CLBP. They studied inhibition of the quadriceps muscle in 25 golfers with back pain and found an association between inhibition of the quadriceps and back muscle endurance measured using surface electromyography (EMG). They suggested that changes in muscular control take place with the manifestation of low back dysfunction leading to inhibition of the quadriceps muscles. They also measured pain and disability but they did not find a relation between these pain-related variables and muscle inhibition or back muscle endurance. However, their population differed from CLBP patients attending medical care as they used only sportsmen with and without back pain. The differences between participants as to pain and disability scores were small. In our opinion cognitions on pain and related behavioural changes can attribute to muscle inhibition in patients with chronic pain. Assuming that patients with non- 
specific chronic pain have an intact nervous system, submaximal performance in this group, as measured by the superimposed electrical stimulation technique, may be explained by the influence of behavioural and pain-related factors during testing. Superimposed electrical stimulation therefore seems a promising instrument in detecting and quantifying submaximal performance during muscle testing in patients with CLBP. And, in addition, by relating the performance level of patients with CLBP to hypothesized pain-related factors, such as present pain, catastrophizing, fear of injury and psychological distress, interference of such factors during muscle testing may be identified.

In view of the above mentioned, three questions were raised in the present study:

1. Is muscle strength of the quadriceps muscle of patients with CLBP impaired as compared to healthy controls?

2. Is the muscle strength performance of patients with CLBP submaximal as compared to healthy controls?

3. Is submaximal performance in patients related to pain-related factors such as current pain, fear of (re)injury, catastrophizing and psychological distress during muscle strength testing? 


\section{Subjects AND Methods}

\section{Subjects}

\section{Patients}

Patients were referred to the study by the physiatrist of the Pain Department of the Hoensbroeck Rehabilitation Centre, Hoensbroek, The Netherlands. Inclusion criteria were: non-specific low back pain of at least three months and age between 18 and 65 years. Exclusion criteria were: lumbar disc herniation with neurological complications, major structural back abnormality, evidence of inflammatory, systemic or neoplastic disease, major psychiatric illness, muscle diseases and presence of a cardiac pacemaker. All patients gave their written informed consent to participate in the study. The experimental protocol was approved by the Ethics Committee of the Rehabilitation Foundation Limburg in Hoensbroek, The Netherlands.

\section{Controls}

Control subjects were selected among employees of the Maastricht University, the Rehabilitation Foundation Limburg and the Institute for Rehabilitation Research in the Netherlands. An exclusion criterion for controls was having current back pain. Controls were individually matched to a patient regarding gender and age ( \pm 3 years).

\section{Methods}

Self-report measures

\section{Psychological distress}

The Dutch Version of the Symptom Checklist (SCL-90) was used to rate psychological distress. The SCL-90 is a multidimensional state measure of psychopathology and it consists of eight dimensions: anxiety, agoraphobia, depression, somatic symptoms, distrust and interpersonal sensitivity, anger hostility as well as sleeping disorders. The total SCL-90 score reflects general psychoneurotiscism or psychological distress. Reliability and validity of the Dutch version of the SCL-90 have been reported to be adequate (Derogatis, 1983; Arrindell and Ettema, 1986).

\section{Low Back Disability}

The Dutch version of the Roland Disability Questionnaire (RDQ; Roland and Morris, 1983) was used to measure perceived disability due to low back pain. This questionnaire consists of 24 items. The RDQ has been reported to be a valid, reliable and responsive measure of physical disability in patients with chronic low back pain 


\section{Fear of movement/(re)injury}

The Dutch version of the Tampa scale for kinesiophobia (TSK) measures fear of movement. This questionnaire contains 17 items and is aimed at the assessment of fear of (re)injury due to movement. The Dutch version of the TSK has been reported to be reliable and valid (Vlacyen et al, 1995b, Goubert et al, 2000).

\section{Pain Catastrophizing}

Pain Catastrophizing was measured using the factor "catastrophizing" from the Pain Cognition List that measures the verbal-cognitive response system for chronic pain and consists of five factors: pain impact, catastrophizing, outcome efficacy, acquiescence and reliance on health care. The PCL is reported to be reliable and valid (Vlacyen et al, 1990).

\section{Physical Activity Rating Scale (PARS)}

In the PARS 20 different regular daily activities were presented. For each activity patients were asked to indicate how frequently they had performed the specified activity in the last two weeks. Examples of activities were: one hour walking, four hours working, climbing two stairs and one hour shopping. Categories were: never, rarely, now and then, often and very often. The unweighted mean score of the 20 items was calculated (Vercoulen et al, 1997).

\section{Pain intensity}

Immediately prior to the first muscle strength effort, when the patient was already sitting on the Cybex equipment, current pain intensity was rated verbally on a numerical rating scale with extremes of 0 (no pain) and 100 (unbearable pain) (Bolton, 1999).

\section{Physical measures}

\section{Body composition, body weight}

Body weight and body composition are both representative parameters for physical deconditioning. The percentage of body fat was used as an index for body composition. Due to physical inactivity body weight as well as the percentage of body fat will increase (McArdle et al, 1996). Fat folds were measured with a Servier skinfold calliper (Biersteker et al, 1983). Calculations of the percentage of body fat were performed based on a sum of four subcutaneous fat folds according the procedure of Durnin and Womersly (1974). Body weight was measured with a mechanical balance. All 
measurements were performed twice and mean scores were calculated. Lean body mass was calculated as weight - (percentage of body fat " weight).

\section{Muscle strength}

Isometric muscle strength of the quadriceps muscle was measured on a Cybex (Cybex II isokinetic dynamometer, Cybex, Ronkonkoma, NY). Measurement was performed unilaterally on the preferred leg of the subject. The lateral epicondyle of the femur was aligned with the axis of rotation of the dynamometer. The subject was seated in a standardised position with a hip and knee angle of 90 degrees flexion. During testing the pelvis was restrained with an adjustable belt to maintain position. The end of the Cybex moment lever was positioned over the tibia at a distance of two third of the distance between the apex patella and the malleolus lateralis. Subjects were asked to gradually build up force to a maximal level and then hold the maximum contraction for 5 seconds. During the attempt subjects received visual feedback as to their produced torque but there was no verbal encouragement. Muscle strength was measured as the maximum isometric peak torque ( $\mathrm{T}$ ) of two efforts. To compare groups $\mathrm{T}$ was standardised to torque per kilogram lean body mass. The Cybex was calibrated prior to testing.

\section{Voluntary Muscle Activation}

To assess the central activation ratio (CAR), or the level of muscle contraction during a voluntary muscle contraction, superimposed electrical stimulation was used. If muscle activation was not $100 \%$, the electrical stimulus produced an increase in torque. An aluminum electrode (anode; sized $12 \times 12 \mathrm{~cm}$ ) enveloped by a sponge tissue was placed on the thigh at one third of the distance between the anterior superior iliac spine and the upper border of the patella (SIAS-P) and the second electrode (cathode; sized $10 \times 10 \mathrm{~cm})$ was placed at two third of the SIAS-P distance. Electrical stimuli were generated using a stimulator (Model DS7A Digitimer Led., Welwyn Garden City, Hertfordshire, UK) which was governed by a Compaq Deskpro 386SX computer (Compaq Computer Co., Houston, TX). Unidirectional square-wave pulses of $50 \mathrm{~ms}$. duration were used on a constant voltage of 80 Volts. As the individual amperage level is also influenced by the percentage of body fat, for every person an individual amperage level for muscle stimulation was identified, based on a set of stimuli (1 second, $30 \mathrm{~Hz}$ ) in gradually increasing intensity, delivered to the muscle at rest. This individual amperage level was equal to the amperage level at which a muscle stimulation on a resting muscle elicited at least $25 \%$ of the subjects' maximum voluntary torque (25\%amp). This individual amperage level was eventually used during the whole test procedure. The individual amperage level ranged from 165 to maximum $300 \mathrm{~mA}$. The mean amperage level was 251 (sd 37) $\mathrm{mA}$ for patients and 259 (sd 38) $\mathrm{mA}$ for controls. 


\section{Test procedure}

The protocol started with a warming up period of 2 minutes on an ergo meter bicycle with a load of about 50 Watts. Next, when the person had taken position on the Cybex machine, current pain intensity was scored. Two muscle strength efforts of the quadriceps muscles were performed with a pause of two minutes in between to avoid fatigue. Then the individual amperage level for stimulation $(25 \% \mathrm{amp})$ was determined. A new set of two muscle strength efforts followed during which the quadriceps muscle was stimulated. The moment the subject reached the plateau phase during the maximum voluntary torque production a stimulation with a voltage of 100 $\mathrm{V}$ and an amperage of $25 \%$ amp (duration: $40 \mathrm{~ms}$; frequency: $100 \mathrm{~Hz}$ ) was delivered. Again there was a pause of about two minutes between the efforts.

Torque signals were A/D converted and stored on a second 386 computer using a DT2824 PGL data acquisition board (Data Translations, Marlboro, Mass.) via a 2 channel single ended registration. Sample time was 5 seconds with a sample frequency of $1000 \mathrm{~Hz}$. Signal analysis was performed off-line using MATLAB software (The Math Works Inc., Natick, Mass.). Maximum torque was calculated for each effort of each subject using a windowing technique. The activation level of the muscle or the central activation ratio (CAR) was calculated as the torque divided by the increment in torque produced by stimulation of the quadriceps muscle added to the torque (Stackhouse et al, 2000) (as presented in figure 1). A CAR of 100\% indicates that the muscle was fully contracted, whereas a CAR below $100 \%$ indicates that during the attempt the voluntary contraction of the muscle was not maximal. CAR was measured as the maximum CAR of two muscle strength efforts.
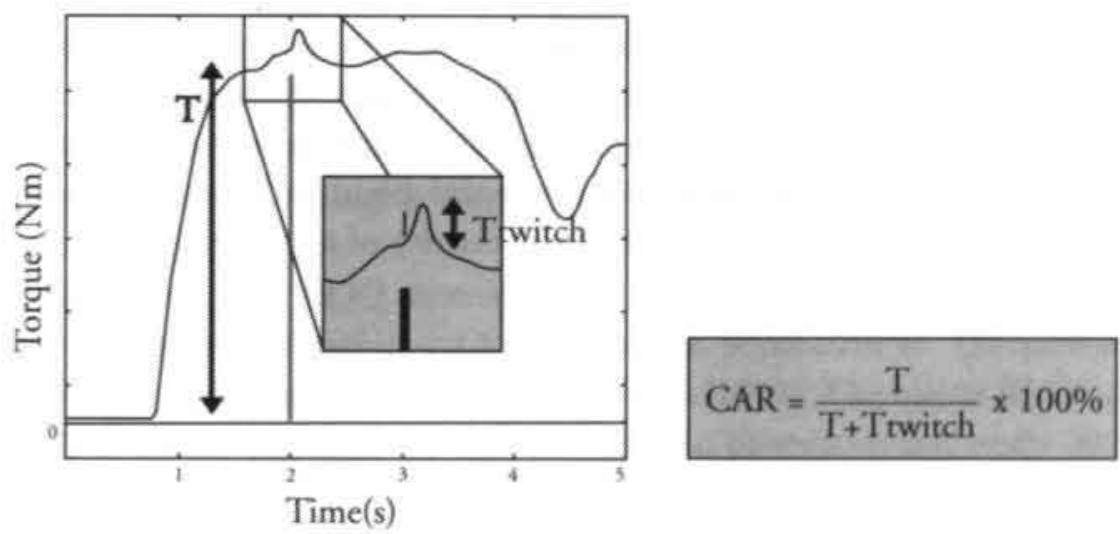

Figure 1: Calculation of the Central Activation Ratio (CAR) based on the produced torque (T) and the additional twitch torque (Ttwitch) as generated by the superimposed electrical stimulation. (The gray line indicates the moment of stimulation) 


\section{Data analysis}

Results for groups were expressed as a mean score and standard deviation combined with the range of scores. Comparisons between two groups were performed using the Student T-test for unpaired observations in case of a normal distribution of the data $(\alpha=0.05)$. In case of a non-normal distributions of the data the Mann-Whitney $U$ test for unpaired observations was used. Since gender is an important factor influencing physical variables, partial correlations coefficients were calculated controlling for gender. All statistical analyses were performed using SPSS software (SPSS Inc,, Chicago, III.)

\section{RESUlts}

\section{Demographics}

In total, 25 patients and 25 controls entered the study. The mean age of patients was $42.7( \pm 9.5)$ years ranging from 24 to 63 years. The mean age of controls was 42.3 $( \pm 10.2)$ years ranging from 21 to 61 years. In both groups 15 males and 10 females participated. Patients had non-specific low back pain with a mean duration of 9.9 $( \pm 8.3)$ years ranging from 0.4 to 32 years. Eight patients $(32 \%)$ had undergone back surgery in the past. Of the 25 participating patients $15(60 \%)$ had a paid job and were currently on sick leave for their back pain in order to attend a rehabilitation programme, two patients $(8 \%)$ were unemployed, one was a student and three $(12 \%)$ had other day activities. Of all patients $4(16 \%)$ were declared fully disabled and therefore received disability compensation. Data concerning CAR scores were missing for two patients (one male and one female) and three controls (two males and one female). In the data of these five persons the electrical stimulation was, in both assessments, not situated in the plateau phase of the voluntary torque production, which made it impossible to calculate a CAR. Although all persons were asked to maintain their maximum force effort for five seconds, these persons did not manage to do this. Data of one control subject were excluded from further analysis because of current back pain complaints of the subject on the day of measurement. 
Mean scores for patients on self-report measures are presented in table 1.

\begin{tabular}{|c|c|c|c|}
\hline & Total & Male & Female \\
\hline & $(n=25)$ & $(n=15)$ & $(n=10)$ \\
\hline \multirow[t]{2}{*}{ Current pain (VAS) } & $42.8 \div 25.5$ & $35.0 \div 22.4$ & $54.5=26.5^{\circ}$ \\
\hline & $0-80$ & $0-70$ & $5-80$ \\
\hline Perceived disability & $15.3 * 4.5$ & $13.7 \pm 4.9$ & $17,6 \pm 2.4^{*}$ \\
\hline (RDQ) & $4-22$ & $4-22$ & $12 \cdot 21$ \\
\hline Fear of injury & $39.9+6.5$ & $41.4 \times 6.5$ & $37.9,6.2$ \\
\hline (TSK) & 23.52 & $31 \cdot 52$ & 23.45 \\
\hline Pyych. distreas & $154.5 \times 43.8$ & $148.7=34.7$ & $162.1 * 54.5$ \\
\hline (SCI.90) & $96-249$ & $106-206$ & $96-249$ \\
\hline Catastrophizing & $42.3 \pm 11.8$ & $38.3=12.8$ & $47.9 \div 7.8$ \\
\hline (PCL) & $21-59$ & $21 \cdot 58$ & $37-59$ \\
\hline
\end{tabular}

Values are means \pm SD and range:" gender related difference $p<0.05$

Table I: Scores on psychosocial variables for all patients.

Females perceived a significantly higher current pain level and a higher level of disability compared to males. The mean scores for pain catastrophizing and psychological distress were higher for women compared to men, though the difference did not reach significance.

According to the mean RDQ score the patients in this study were somewhat more disabled compared to those in a Dutch reference population of 338 persons with chronic low back pain in a study of Gommans et al (1997). The higher RDQ scores in this study could be explained by the fact that the patients in our study all sought medical assistance, as they probably felt more disabled in daily life. 


\section{Physical measures}

Physical characteristics of patients and controls are presented in table 2 .

\begin{tabular}{|c|c|c|c|c|}
\hline & \multicolumn{2}{|c|}{ Patients } & \multicolumn{2}{|c|}{ Controls } \\
\hline & Male (n-15) & Female $(n=10)$ & Male (n=14) & Female $(n=10)$ \\
\hline \multirow[t]{2}{*}{ Weight (kg) } & $88.5 \neq 12.0$ & $77.0 \pm 11.7$ & $73.7=9.3 *$ & $58.8 \pm 11.1^{*}$ \\
\hline & $74 \cdot-108$ & $58-99$ & $62-95$ & $49-88$ \\
\hline \multirow[t]{2}{*}{ Height (m) } & $1.79 \pm 0.05$ & $1.66 \pm 0.04$ & $1.81 \pm 0.06$ & $1.66 \pm 0.06$ \\
\hline & $1.72-1.88$ & $1.58-1.73$ & $1.66-1.90$ & $1.58-1.78$ \\
\hline \multirow[t]{2}{*}{ PARS } & $2.09 \div 0.41$ & $2.11 \pm 0.54$ & $2.64 \pm 0.58 *$ & $2.59 \div 0.30^{\circ}$ \\
\hline & $1.15-2.75$ & $1.45-3.20$ & $2.00-4.00$ & $2.05-2.90$ \\
\hline \multirow[t]{2}{*}{ Percentage of body fat (\%) } & $29.7 \div 6.8$ & $37.3+3.5$ & $21.5 \pm 4.6^{* *}$ & $30.2+5.7^{* *}$ \\
\hline & $13-42.4$ & $33.1-42.5$ & $14.6-29.5$ & $23.0-38.1$ \\
\hline Muscle torque per kilogram & $2.31 \div 0.58$ & $1.34 \div 0.68$ & $3.42 \pm 0.68 *$ & $2.78 \pm 0.56 *$ \\
\hline lean body mass $(\mathrm{Nm} / \mathrm{kg})$ & $1.21-3.71$ & $0.37 \cdot 3.31$ & $2.34-4.51$ & $1.99-3.76$ \\
\hline
\end{tabular}

Values are means $* \mathrm{SD}$ and range

Patient compared to control by gender: ${ }^{*}$ difference $p<0.05 *$ difference $p<0.01$

Table 2: Scores on physical variables for patients and controls, presented by gender.

Since patients were matched as to age and gender in both groups combined data of males and females are given. Patients scored a significantly lower peak torque (113.8 $\mathrm{Nm} \pm 56.4)$ during the muscle strength test compared to controls $(165.0 \mathrm{Nm} \pm 54.3)$. When $T$ was standardised to kilogram lean body mass, the difference was also significant $(\mathrm{p}<0.01)$, as presented in table 2 . Patients reported being less active in daily life in comparison to controls as was scored on the PARS. As to anthropometrical variables, patients had a significant higher body weight and percentage of body fat, whereas height in both groups was comparable. 
However, next to the above mentioned differences in muscle torque, also the CAR of patients was significantly less compared to controls (as is presented in figure 2).

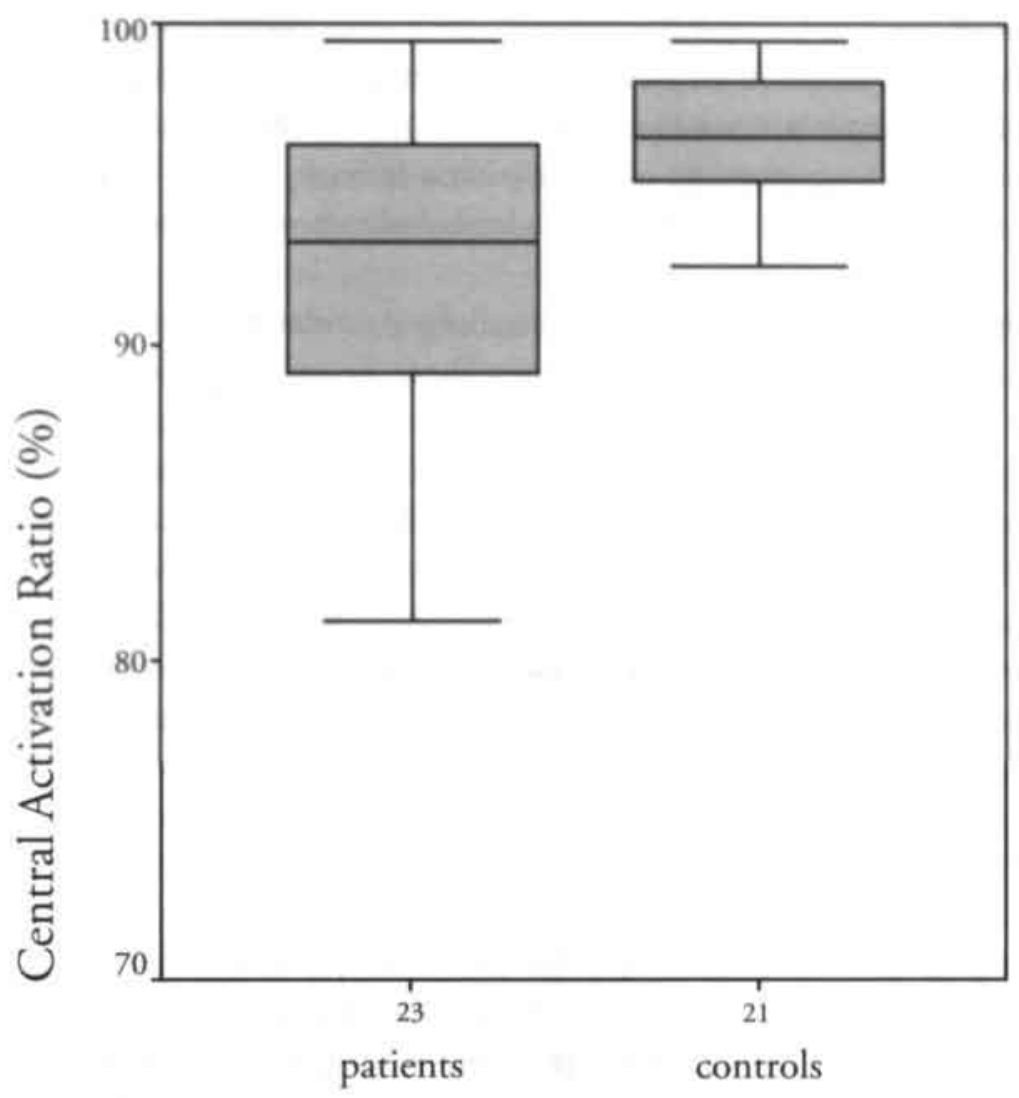

Figure 2: Central activation natio (CAR) in patients and controls. Median scores combined with interguartile ranges are presented. Patients had a lower CAR compared to controls $(p<0.05)$.

The interquartiles (25-75\%) range of CAR scores was higher for patients (88.9-96.3) as compared to controls (94.8-98.4) indicating a larger variability in CAR scores between patients. As presented in table 3, partial correlation coefficients were calculated between CAR and the pain related variables in patients controlling for gender. CAR had a significantly negative correlation with pain intensity $(-0.47 \mathrm{p}<0.05)$ and the level of psychological distress $(-0.49 \mathrm{p}<0.05)$. CAR was not related to either fear of injury or catastrophizing. Muscle torque per kilogram lean body mass was significantly related to PARS $(0.68 \mathrm{p}<0.01)$, physical activity in daily life, but not to pain-related variables like fear of injury, catastrophizing and pain intensity. 


\begin{tabular}{|c|c|c|}
\hline $\begin{array}{l}\text { Physical activity } \\
\text { (PARS) }\end{array}$ & $0.68 \cdots$ & 0.22 \\
\hline $\begin{array}{l}\text { Current pain intensity } \\
\text { (VAS) }\end{array}$ & -0.22 & $-0.47^{\circ}$ \\
\hline $\begin{array}{l}\text { Fear of injury } \\
\text { (TSK) }\end{array}$ & 0.16 & 0.31 \\
\hline $\begin{array}{l}\text { Psych. distress } \\
\text { (SCL.90) }\end{array}$ & -0.37 & $-0.49^{\circ}$ \\
\hline $\begin{array}{l}\text { Perceived disability } \\
\text { (RDQ) }\end{array}$ & -0.25 & -0.17 \\
\hline $\begin{array}{l}\text { Catastrophizing } \\
\text { (PCL) }\end{array}$ & -0.20 & -0.02 \\
\hline${ }^{*} p<0.05 \cdots p<0.01$ & & \\
\hline
\end{tabular}

Table 3: Partial correlation coefficients (controlling for gender) in patients $(n=23)$.

\section{Discussion}

This study investigated differences in quadriceps muscle strength and level of muscle performance in CLBP patients as compared to healthy controls. Associations between pain- related factors and muscle performance level were explored. The results of this study show that the muscle torque and central activation ratio (CAR) of the quadriceps muscle during a maximal voluntary contraction in patients with CLBP were lower than in healthy controls. Furthermore, an association was found between CAR and painrelated factors such as pain intensity and psychological distress, but not with pain catastrophizing and fear of injury.

The finding that patients had a lower torque of their quadriceps muscle than controls is in accordance with results from Lee et al (1995) who found lower knee extensor strength and lower back muscle strength for patients with CLBP as compared to healthy controls. Research on deconditioning is focused on altered function of the back muscles most of the time. However, if the concept of chronicity of pain, as presented in the fear avoidance model (Vlaeyen and Linton, 2000), is correct, low back pain influences total physical performance and not solely back muscle function. If a person's 
daily activity level is decreased as a result of back pain problems this will result in disuse-related changes in the whole body, especially influencing antigravity muscles, which are controlling upright posture in humans. The quadriceps muscle is, similar to the back extensor muscles, an important antigravity muscle and therefore changes due to inactivity may be expected. In this study physical activity in daily life as measured with the PARS was significantly lower in patients compared to controls, whereas PARS scores for controls were comparable with PARS scores of healthy persons in a study of Vercoulen $(2.7 \pm 0.5)(1997)$. In this study a lower muscle strength, a higher percentage of body fat and a lower physical activity score in patients suggest that deconditioning might be present in the musculoskeletal and circulatory system of patients with CLBP.

Besides lower strength also a significant difference in CAR between patients and healthy controls was found, indicating that patients performed submaximally compared to controls.

This is in agreement with results of Hutten et al (1999) who also found a submaximal performance in patients with CLBP. They expressed submaximal performance in muscle strength testing in patients with CLBP as a higher variability (coefficient of variation or $\mathrm{CV}$ ) in a set of consecutive muscle strength attempts. When comparing two groups with a different mean strength (such as patients with CLBP and controls) it is important to realise that, merely due to the nature of the statistic itself, not only a different score between attempts but also a lower mean strength can result in a higher $\mathrm{CV}$. Conclusions as to the $\mathrm{CV}$ as a differentiating measure of variability between groups with unequal mean force strength therefore have to be drawn with caution (Lechner et al, 1998). The calculation of CAR on the other hand is not solely based on the results of strength measurement, but additional information on muscle performance is checked by a external stimulation. CAR therefore seems a more objective measure. Nørregaard et al (1997) even used the CAR for evaluating muscle strength corrected for submaximal performance. They calculated "true muscle strength" based on extrapolation of the produced torque during testing to a torque which would be produced if CAR was $100 \%$, under the assumption that within a person the relation muscle torque and CAR is linear. Based on our results, true muscle torque in patients with CLBP would be still significantly less than muscle torque of healthy controls. This finding, again, underlines the effect of physical deconditioning. Summarizing, both physical deconditioning as well as submaximal performance during testing contribute to the explanation of a lower muscle torque in patients with CLBP compared to controls.

How can we explain this submaximal performance in patients with CLBP as compared to controls? As suggested by Suter et al (2001), in patients with CLBP muscle inhibition during an intended maximal muscle contraction could be a result of 
and pain intensity and psychological distress. More information on factors influencing CAR simultaneously would be available with calculations based on regression analysis. In this study, however, due to the small number of patients this statistical method could not be applied. In further research, regression analysis, in which CAR can be expressed as dependent factor and pain-related as well as physical factors as independent factors, can provide the possibility to evaluate the contribution of all factors and their interdependency to submaximal performance in patients with CLBP. This may, eventually, result in more comprehensive knowledge on reasons for submaximal performance in patients with CLBP during testing and in activities of daily living and the related mechanism.

\section{Conclusion}

In patients with CLBP physical deconditioning once more proves to be a general disuse-related problem instead of a problem solely affecting the back muscle. The results suggest that CLBP patients who report increased psychological distress or a higher level of pain intensity tend to show increased inhibition of muscle activity, leading to submaximal performance. When interpreting decreased muscle strength in terms of physical deconditioning in patients with CLBP, submaximal performance has to be taken into account. 


\section{REFERENCES}

- Al-Obaidi SM, Nelson RM, Al-Awadhi S, Al-Shuwaie N. The role of anticipation and fear of pain in the persistence of avoidance behaviour in parients with chronic low back pain. Spine 2000;25(9):1126-1131.

- Allen GM, Gandevia SC, Neering IR, Hickie I, Jones R, Middleton J. Muscle performance, voluntary activation and perceived effort in normal subjects and patients with prior poliomyelitis. Brain 1994;117:661-670.

- Arendt-Nielsen L, Graven-Nielsen T, Svarrer H, Svensson P. The influence of low back pain on muscle activity and coordination during gait: a clinical and experimental study. Pain 1995;64:231-240.

- Arrindell WA, Ettema JHM. Handleiding bij een Multidimensionele Psychopathologie-indicator. Lisse the Netherlands; Swets\&ZZitlinger, 1986.

- Biersteker MWA, Broere F and Biersteker PA. Het schatten van een gewichtspercentage lichaamsvet met eenvoudige hulpmiddelen. Geneeskunde en Sport 1983;16:29-32.

- Bolton JE. Accuracy of recall of usual pain intensity in back pain patients. Pain 1999;533-539.

- Beurskens AJ, de Vet HC, Köke AJ. Responsiveness of functional status in low back pain: a comparison of different instruments. Pain 1996;65(1):71-76.

- Crombez G, Vervaet L, Lysens R, Eelen P, Baeyens E. Do pain expectancies cause pain in chronic low back patients? A clinical investigation. Behav Res ther 1996;34:919925.

- Crombez G, Vlaeyen JWS, Heuts PHTG, Lysens R. Fear of pain is more disabling than pain itself. Evidence on the role of pain-related fear in chronic back pain disability. Pain 1999;80:329-340.

- Derogatis LR. SCL90R Manual II. Clinical psychometric research. Maryland 1983.

- Estlander AM, Vanharanta H, Moneta GB, Kaivanto K. Anthropometric variables, self-efficacy beliefs, and pain and disability ratins on the isokinetic performance of low back pain patients. Spine 1994;19(8):941-947.

- Gibbons LE, Videman T and Crites Battié M. Isokinetic and psychophysical lifting strength, static back muscle endurance, and magnetic resonance imaging of the paraspinal muscles as predictors of low back pain in men. Scand J Rehabil Med 1997;29:187-191.

- Gommans JH, Koes BW, Tulder MW van. Validiteit en responsiviteit Nederlandstalige Roland Disability Questionnaire. Vragenlijst naar functionele status bij patienten mer lage Rugpijn. Ned Tijdschr Fysioth 1997;107(2):28-33. 
- Goubert L, Crombez G, Vlaeyen JWS, Van Damme S, Van den Broeck A, Van Houdenhove B. De Tampa schaal voor Kinesiofobie: Psychometrische karakteristieken en normering [The Tampa scale for Kinesiophoba: Psychometric properties and norms]. Gedrag en Gezondheid 2000;28:54-62.

- Gronblad M, Hurri H, Kouri JP. Relationships between spinal mobility, physical performance tests, pain intensity and disability assessment in chronic low back pain patients. Scan J Rehabil Med 1997;29:17-24.

- Hazard RG, Fenwick JW, Kalisch SM, Redmond J, Reeves V, Reid S, Frymoyer JW. Functional restoration with behavioural support; a one-year prospective study of patients with chronic low back pain. Spine 1989;14(2):157-161.

- Hultman G, Nordin M, Saraste H, Ohlsen H. Body composition, endurance, strength, cross sectional area and density of MM Erector spinae in men with and without low back pain. J Spinal Disord 1993;6:114-123.

- Hirsch G, Beach G, Cooke C, Menard M, Locke S. Relationship between performance on lumbar dynamometry and Waddell score in a population with chronic low back pain. Spine 1991;16:1039-1043.

- Hutten MMR, Muller MTH, Hermens HJ. Discrimination between maximal and submaximal effort in lumbar dynamometry. Clin Biomechanics 1998;13(1):27-35.

- Hutten MMR, Hermens HJ, Lousberg R, Zilvold G. Distribution of psychological aspects in subgroups of chronic low back pain patients divided on the score of physical performance. Int J Rehabil Res 1999;22(4):261-268.

- Kankaanpaa M, Tailema S, Airaksinen O, Hanninen O. The efficacy of active rehabilitation in chronic low back pain: Effect on pain intensity, self-experienced disability, and lumbar fatigability. Spine 1999:24;1034-1042.

- Kaser L, Mannion AF, Rhyner A, Weber E, Dvorak J, Muntener M. Active therapy for chronic low back pain. Part 2: Effects on paraspinal muscle cross-sectional area, fiber type size and distribution. Spine 2001;26(8):909-919.

- Lechner DE, Bradbury SF, Bradley LA. Detecting sincerity of effort : a summary of methods and approaches. Phys Ther 1998;78 (8):867-888.

- Lee JH, Ooi Y, Nakamura K. Measurement of muscle strength of the trunk and the lower extremities in subjects with history of low back pain. Spine 1995;18:19941996.

- Lindstrom I, Ohlund C, Eek C, Wallin L, Peterson LE, Nachemson A. Mobility, strength, and fitness after a graded activity program for patients with subacute low back pain. Spine 1992;17(6):641-649.

- Lloyd AR, Gandevia SC, Hales JP. Muscle performance, voluntary activation, twitch properties and perceived effort in normal subjects and patients with chronic fatigue syndrome. Brain 1991;114:85-98. 
- Lund JP, Widmer CG, Schwartz G. The pain modulation model : a discussion of the relationship between musculoskeletal pain and motor activity. Can J Physiol Pharmacol 1989;69:683-694.

- Mannion AF, Muntener M, Taimela S, Dvorak J. A randomised clinical trial of three active therapies for chronic low back pain. Spine 1999;24:2435-2448.

- Mannion AF, Junge A, Taimela S, Muntener M, Dvorak J. Active therapy for chronic low back pain. Part 1: Effects on back muscle activation, fatigability, and strength. Spine 2001a;26(8):897-908.

- Mannion AF, Junge A, Taimela S, Muntener M, Lorenzo K, Dvorak J. Active therapy for chronic low back pain. Part 3: factors influencing self-rated disability and its change following therapy. Spine 2001b;26(8):920-929.

- McArdle WD, Katch FI, Katch VI. Physical activity, health and aging. Exercise physiology. Energy, nutrition and human performance. 4th edition Baltimore, Maryland: Williams \& Wilkins 1996;635-655.

- McKenzie DK, Bigland-Ritchie B, Gorman RB, Gandevia SC. Central and peripheral fatigue of human diaphragm and limb assessed by twitch interpolation. J Physiol 1992;454:643-656.

- Nørregaard J, Bülow PM, Danneskiold-Samsøe B. Muscle strength, voluntary activation, twitch properties, and endurance in patients with fibromyalgia. J Neurol Neurosurg Psychiatry 1994:57:1106-1111.

- Nørregaard J, Bülow PM, Vestergaard-Poulsen P, Thomsen C, Danneskiold-Samsee B. Muscle strength, voluntary activation and cross-sectional area in patients with fibromyalgia. Br J Rheumatol 1995;34:925-931.

- Nørregaard J, Lykkegaard JJ, Bülow PM, Danneskiold-Samsøe B. The twitch interpolation technique for the estimation of true quadriceps muscle strength. Clin Psychol 1997;17: 523-532.

- Rutherford OM, Jones DA, and Newham DJ. Clinical experimental application of the percutaneous twitch superimposition technique for the study of human muscle activation. J Neurol Neurosurg Psychiatry 1986;49:1288-1291.

- Roland M and Morris R. A study of the natural history of back pain. Part I: development of a reliable and sensitive measure of disability in low-back pain. Spine 1983;8(2):141-144.

- Stakhouse SK, Dean JC, Lee SCK, Binder-Macleod A. Measurement of central activation failure of the quadriceps femoris in healthy adults. Muscle Nerve 2000;23:1706-1712.

- Suter E, Lindsay D. Back muscle fatigability is associated with knee extensor inhibition in subjects with low back pain. Spine 2001;26(16):E361-E366.

- Vercoulen JH, Bazelmans E, Swanink CM, Galama JM, Jongen PJ, Hommes O, Van der Meer JW, Bleijenberg G. Physical activity in chronic fatigue syndrome: assessment and its role in fatigue. J Psychiatr Res 1997;31(6):661-73. 
- Vlacyen JW, Geurts SM, Kole Snijders AM et al. What do chronic pain patients think of their pain? Towards a pain cognition questionnaire. $\mathrm{Br} \mathrm{J}$ Clin Psychol 1990:187-188

- Vlaeyen JW, Kole-Snijders AM, Rotteveel AR, Ruesink R, Heuts PH. The role of fear of movement/(re)injury in pain disability. J Occup Rehabil 1995a;5(4):235-52.

- Vlacyen JWS, Kole-Snijders AMJ, Boeren RGB, Eek H van. Fear of movement/ (re)injury in chronic low back pain and its relation to behavioural performance. Pain 1995b;62:363-372.

- Vlacyen JWS and Linton SJ. Fear-avoidance and its consequences in chronic musculoskeletal pain : a state of the art. Pain 2000;85:317-332.

- Waddell G. The physical basis of back pain. In: Waddell G, The back pain revolution. London Chirchill Livingstone 1998:135-154.

- Watson PJ, Booker CK, Main CJ. Evidence for the role of psychological paraspinal activity in patients with chronic low back pain. J Musculoskeletal Pain 1997;5(4):4157.

- Watson PJ. Non-psychological determinants of physical performance in musculoskeletal pain, In Mitchell, M. et al, Pain 1999 an updated review; refresher course syllabus 9th World Congress on Pain, Seattle: LASP press 1999:153-158. 
Chapter SIX

DECLINE IN PHYSICAL ACTIVITY, DISABILITY AND PAIN RELATED FEAR IN SUB-ACUTE LOW BACK PAIN

Jeanine A. Verbunt, Judith M. Sieben, Henk A. Seelen, Johan W. Vlaeyen, Eric J. Bousema, Geert J. van der Heijden, J. André Knottnerus

submitted 
Aim of investigation: (1) To evaluate whether a decline in the level of physical activity (PAD) is more appropriate in the explanation of disability as compared to the actual level of physical activity (PAL) in patients with subacute back pain.

Methods: Patients with 4 to 7 weeks of non-specific low back pain (LBP) participated in this study. Their habitual level of physical activity before the back pain started $(\mathrm{H}$ PAL), their actual level of physical activity (PAL) and the reported decline in the level of physical activity after the onset of pain (PAD) were assessed. The interrelation of these physical activity related variables with perceived disability (QBPDS), fear of injury (TSK), pain catastrophizing (PCS) and pain intensity (VAS) was examined. Based on a set of three linear regression analyses the role of PAD as a mediator in the association berween fear of movement/(re)injury and disability was examined.

Results: 123 patients with sub-acute low back pain ( 66 male and 57 female) with a mean age of 44.1 years $(S D=10.3)$ participated in this study. PAD rather than PAL and H-PAL was significantly correlated with disability, fear of movement/(re)injury, pain catastrophizing and pain intensity. PAD and PAL appeared more important in the explanation of disability in the subgroup of patients who were physically active before their back pain started. Generally, PAD indeed mediated the association between fear of movement/(re)injury and disability.

Conclusions: The perceived decline in physical activity, rather than the current physical activity itself is important in the evaluation of the impact of activity related changes on disability in low back pain. 


\section{INTRODUCTION}

Activity intolerance is a problem which is often reported by patients with chronic low back pain (CLBP). As a result of their back pain, they perceive a disabling reduction of their level of physical activity. Fear of movement/(re)injury has been reported to be strongly associated with activity restrictions, often stronger than pain severity (Vlaeyen et al, 1995; Crombez et al, 1999). The fear-avoidance model predicts that when patients with an acute back pain problem, interpret their pain as threatening (they catastrophize about their pain), fear of movement/(re)injury emerges. The expectation of adverse consequences of increasing their physical activity level (1 may end up in a wheelchair) may be the reason to avoid physical activities. In the long run, long-lasting avoidance behaviour can result in both disability and disuse. The latter has been defined as performing at a reduced level of physical activity in daily life (Verbunt et al. 2003).

In contrast to the influence of pain-related fear on the perceived disability level, which has been reported frequently (Vlaeyen et al, 1995. Klenerman et al, 1995; Mc Cracken et al, 1996; Crombez et al, 1999; Linton, 2000; Fritz et al, 2001) the presumed negative influence of pain-related fear on the actual level of physical activity in daily life (PAL) and accompanying disuse has received less attention in the pain literature. In this area, most of the studies have focused on the difference between the PAL or physical fitness level of patients with CLBP as compared to those of healthy individuals. Moreover, these studies are unequivocal, and reveal that levels of PAL or physical fitness for patients with CLBP were either lower (Schmidt 1985; Davis et al, 1992; Brennan et al,1987; Van der Velde and Mierau, 2000; Nielens and Plaghki, 2001) or comparable (Battie et al, 1989; Hurri et al, 1991; Kellet et al, 1991; Protas 1999; Wittink et al, 2000; Verbunt et al, 2001) to scores of healthy subjects. Based on these data, the conclusion seems justified that physical activity plays a rather limited role in the explanation of disability of CLBP patients. Some authors have even questioned the presence of disuse or physical deconditioning in patients with CLBP (e.g. Wittink et al, 2000).

However, if patients report activity intolerance and associated disability, it is unlikely that they compare their PAL to the PAL of others. It seems more likely that their evaluation is based on a comparison between their actual PAL in reference to their habitual PAL before their back pain started. In making such a comparison, their judgement is likely to be based on decline in the level of their daily activities (PAD= physical activity decline) rather than on their actual PAL. This would imply that PAD, would be more strongly associated with self-reported disability than PAL. Therefore, research on the role of physical activity and disability in back pain, might benefit from 
the assessment of the individual's decline in the level of physical activity over time (PAD) as a reaction on a pain problem instead of his or her actual level of physical activity. Until now, however, only the latter has been the subject of research in most studies. In contrast to former studies, in the current study we will therefore focus on the disabling role of PAD.

Following the fear-avoidance model, fearful patients will avoid physical activities which are expected to produce adverse consequences when performed. Such avoidance behaviour can then result in a PAD, leading to a higher interference in daily life activities and participation, and on the long run to physical deconditioning. Following this line of reasoning, PAD would act as a mediator in both the association between fear and disability, as well as in the relation between pain catastrophizing and disability. If the association between fear and PAD can be demonstrated, this will also underscore the potential role of physical deconditioning as a long term consequence of pain related fear as suggested by the fear avoidance model. As we know from research in the exercise physiology in healthy individuals, that a decline in one's level of PAL might result in a worsening of physical deconditioning; including changes in aerobic fitness, muscle strength, muscle coordination and weight (Convertino et al, 1997), it can be hypothesized that PAD is also related to fitness related changes as a result of back pain.

It is also important to consider that not all patients with CLBP report activity intolerance. PAD is not the only factor causing disability in back pain. It can be hypothesized that activity-related restrictions can probably be more disabling for patients who were used to an active lifestyle before their back pain started as compared to formerly sedentary patients. Simply because they used to perform more activities, more activities can be restricted, resulting in more influence on a patients daily activity schedule. In this study, a discrepancy between the role of PAD in active as compared to sedentary patients will be studied.

In view of the above mentioned, in this study, three hypotheses will be tested:

1. A decline in the level of physical activity (PAD) is more strongly associated with the level of perceived disability than the actual level of physical activity (PAL).

2. A decline in the level of physical activity $(\mathrm{PAD})$ plays a mediating role in the association between fear of movement/(re)injury and disability.

3. The disabling role of a decline in the level of physical activity (PAD) is more pronounced in patients with a formerly active lifestyle as compared to formerly sedentary patients. 


\section{METHODS}

\section{Patients}

In this study, 123 patients, with subacute low back pain participated. Pain was localised below the scapulae and above the gluteal folds (following LASP taxonomy) (Merskey and Bogduk, 1994). At the moment of inclusion, patients suffered low back pain for 4 to 7 weeks (sub-acute phase) due to either a first or new episode of pain. In the last three months before the actual episode started, there were no significant activity limitations due to back pain. Additional selection criteria were: (1) age between 18 and 60 years (2) no specific cause or strong suspicion of a specific cause, such as lumbar disc herniation with neurological complications, major structural back abnormality, evidence of inflammatory, systemic or neoplastic disease (3) no pregnancy (4) no major psychiatric illness (5) no muscle diseases (6) not having a cardiac pacemaker and (7) sufficient knowledge of the Dutch language. Patients were included in two different ways: They were referred by their general practitioner or they reacted on an advertisement in a local newspaper. Inclusion criteria were either checked by the referring general practitioner or, when a patient replied on the advertisement, criteria were checked by a physician in rehabilitation medicine. Both physicians performed a medical screening according the guideline low back pain of the Dutch Society of General Practitioners (Faas et al, 1996). All patients gave their written informed consent to participate in the study. The experimental protocol was approved by the Medical Ethics Committee of the Rehabilitation Foundation Limburg and the Institute for Rehabilitation Research, Hoensbroek, the Netherlands.

\section{Measures}

\section{Physical activity}

Physical activity in daily life before the onset of pain (H-PAL)

To score the habitual physical activity level, which reflects the level of daily life activities before the back pain started, the Baecke Physical Activity Questionnaire (BPAQ) was used. To be able to score activities in the past, the BPAQ was transformed in the past tense. Patients had to recall their physical activity level during the last year before the back pain started. The BPAQ consists of three indices of habitual physical activity : the occupational activity index; sport activity index and the leisure time activity index. The reliability (Baecke et al, 1982) and validity (Philippaerts et al,1999) of the questionnaire in a healthy population appear to be good. The reliability of the BPAQ 
in a population patients with LBP appear to be sufficient (Jacob et al, 2001).

\section{Physical activity in daily life after the onset of pain (PAL)}

To measure PAL a triaxial accelerometer (RT3; Stayhealthy Inc., Monrovia, USA ); consisting of three uniaxial piezo-resistive accelerometers was used to record the amount of body movement. Acceleration signals from the three measurement directions (the posterior, the mediolateral and the longitudinal axes of the trunk) were amplified and filtered. The rectified and integrated acceleration from all three directions over a time-period of one minute was calculated. The number of occasions on which this signal exceeded a predefined threshold was calculated. The data is the output of the accelerometer and is expressed in counts per minute. Data collection continued uninterrupted for seven days. Output was stored in a data memory chip within the accelerometer and was read out by a computer after one week. Patients attached the RT3 with a clip on their waist. They were instructed to wear the RT3 during waking hours, for 7 days except during bathing, taking a shower or swimming. In addition, they recorded in a diary the moment of attaching the RT3 to the body in the morning and the moment of taking it off in the evening. In case they had to remove the RT3 during the day, the reason and the exact rime-period had to be registered also. Physical activity in daily life was expressed as the total sum of counts registered per day. The validity of a tri-axial accelerometer for the measurement of physical activity in daily life appeared to be acceptable (Verbunt et al, 2001).

\section{Physical Activity Decline (PAD)}

For the measurement of PAD the Physical Activity Rating Scale (PARS; Vercoulen et al, 1997) was used. In the PARS, 20 different regular daily activities are presented. For each activity patients are asked to indicate how frequently they had performed the specified activity in the last two weeks using the following response categories: never, rarely, now and then, often and very often. Examples of activities are: one hour walking, four hours working, climbing two stairs and one hour shopping. After they rated their activity level per item, patients were asked if they would have performed this specific activity more often if they would not have back pain. The total sum score resulted in a score for PAD. Internal consistency of this measure of PAD is adequate (Cronbach's alpha $=0.92)$.

\section{Muscle strength}

As a representation of the level of physical fitness, isometric muscle strength of the quadriceps muscle was measured on a Cybex (Cybex II isokinetic dynamometer, Cybex, Ronkonkoma, NY) according to the protocol as described by Verbunt et al (in press, 2003). Muscle strength was measured as the maximum isometric peak torque ( $T$ ) of two efforts. Torque was standardised to torque per kilogram lean body mass (lean 
body mass was calculated as weight - (percentage of body fat " weight). Calculations of the percentage of body fat were performed based on a sum of four subcutaneous fat folds according the procedure of Durnin and Womersly (1974). Fat folds were measured with a Servier skinfold calliper (Biersteker et al, 1983). To control for submaximal performance, the interpolated twitch technique was used during muscle strength testing (Rutherford et al, 1986). Signal analysis was performed off-line using MATLAB software (The Math Works Inc., Natick, Mass.).

\section{Pain}

\section{Pain intensity}

Current pain intensity was rated on a visual analogue scale (VAS) with extremes of 0 (no pain) and 100 (unbearable pain) (Bolton, 1999). Information related to the current and former pain episodes was collected based on questions derived from the McGill Pain questionnaire (Vanderiet et al, 1987). All questions were dichotomous and consisted of the following items: episodes of pain in history (yes/no), radiation of back pain (yes/no), the onset of pain (sudden/gradual).

\section{Perceived Disability}

Low back disability was assessed using the Quebec Back Pain Disability Scale (QBPDS). The QBPDS contains 20 items. Each item is scored from 0 (No difficulty performing this activity) to 5 (Impossible to perform this activity) and the final QBPDS score is expressed with a higher number indicating greater disability. The QBPDS appeared to be valid and reliable both in the original version (Kopec et al, 1995), as well as in the Dutch version (Schoppink et al, 1996).

\section{Psychological characteristics}

\section{Fear of movement/(re)injury}

The Tampa scale for Kinesiophobia (TSK) is a 17-item questionnaire aimed at the assessment of fear of movement/(re)injury. The Dutch version of the TSK has been reported to be reliable and valid (Vlaeyen et al, 1995b, Goubert et al, 2000).

\section{Pain catastrophizing}

The Pain Catastrophizing Scale (PCS) consists of three subscales focused on rumination, magnification and helplessness. The psychometric properties of the PCS, as tested in a population of patients with CLBP, appeared to be good (Osman et al, 2000; Van Damme et al, 2000). 


\section{Depression}

The Dutch version of the Beck Depression Inventory (BDI) scores depression. It is a 21 -item self-report questionnaire designed to measure the severity of depression and was proposed by the Dutch Committee for the Standardization of Depression Questionnaires (Beck et al, 1979; Zitman et al, 1989).

\section{STATISTICAL ANALYSES}

Spearman rank correlation coefficients were calculated to observe the association between pain disability and physical activity related variables. Since in physical performance gender and age are important characteristics, for the association between activity related variables and muscle strength, a partial correlation coefficient was used, corrected for age and gender. Results for groups were expressed as a mean score and standard deviation combined with the range of scores. Comparisons between two groups were performed using the Student T-test for unpaired observations in case of a normal distribution of the data $(\alpha=0.05)$. In case of a non-normal distributions of the data the Mann-Whitney $U$ test for unpaired observations was used.

To evaluate the role of PAD as a mediator in the relation of fear of injury and disability three linear regression analyses were performed according to Baron and Kenny (1986). In the first analysis disability was the dependent variable and gender, age, pain intensity and fear of injury were the independent variables. In the second analysis, PAD was introduced as dependent variable and the independent variables were identical to those in the first analysis. In the third analysis disability was again the dependent variable in the equation and PAD was added to the set of independent variables. If PAD acts as a mediator in the relation fear of injury and disability, the contribution of fear of injury in the first and the second model should be statistically significant, whereas its influence should decrease in the third model after the introduction of PAD. Since the data were collected in a cross sectional design, hypothetical inverse relations were also tested. Again with the three regression analyses as presented above, it was checked whether disability acted as a mediator in the relation between fear of injury and PAD and whether fear of movement/(re)injury acted as a mediator in the association between PAD and disability.

To evaluate whether the role of PAD in the explanation of disability differed in patients with a sedentary lifestyle as compared to patients with an active lifestyle, patients were categorized in two groups based on the median split of their Baecke score. In both groups a linear regression analysis was performed to identify variables significantly 
contributing to the explanation of disability. Independent variables were pain intensity, depression, PAD and PAL.

For all linear regression analyses standardized beta coefficients and their significance were tested under the null hypothesis that the coefficient differed from zero. To control for co-linearity, variable inflation factors (VIF) were checked and had to be below 10. Outliers, if any, with a Cook distance above 1 were removed from the model. All statistical analyses were performed using SPSS software (SPSS Inc., Chicago, III.)

\section{RESULTS}

\section{Demographic and pain related chanacteristic}

This study included 123 patients ( 66 male and $57 \mathrm{female}$ ) with a mean age of 44.1 years $(S D=10.3)$. Main characteristics of the current pain episode were the following: A sudden onset of the pain was reported by $50 \%$, radiating pain into the legs by $68 \%$, and an earlier episode of back pain by $76 \%$ of the participants. Mean duration of complaints on the day of measurement was 38.5 days $(\mathrm{SD}=8.3$ ). Eighteen of the 86 patients with a paid job $(21 \%)$ were still on sick leave at the time of measurement. Mean pain intensity was 42.1 ( $\mathrm{SD}=21.9$ ), with no gender differences. Mean TSK score for all patients was $36.0(\mathrm{SD}=7.4)$. On average men had a significantly higher TSK scores of $(M=37.2 ; S D=6.9)$ as compared to women $(M=34.5 ; S D=7.8$; $\mathrm{p}=0.05)$. Mean scores for PCS and BDI were $16.5(\mathrm{SD}=9.8)$ and $7.5(\mathrm{SD}=5.5)$ respectively, with no gender differences.

\section{Physical activity}

Mean BPAQ scores of male and female patients were $8.50(\mathrm{SD}=1.40)$ and $8.27(\mathrm{SD}=$ 1.14) respectively. These scores were comparable with scores of healthy Dutch individuals, with $\mathrm{M}=8.2(\mathrm{sem}=0.1)$ and $\mathrm{M}=8.4(\mathrm{sem}=0.1)$ for males and females respectively (Baecke,1982). This would imply that the persons in this study were, before their back pain started, as active as a general Dutch population. As to physical fitness-related characteristics in this subacute phase of back pain, on average male patients scored $2.44 \mathrm{Nm} / \mathrm{kg}(\mathrm{SD}=0.98)$ on the muscle strength test. They weighed $83.4 \mathrm{~kg}(\mathrm{SD}=15.6)$ and their mean length was $1.79(\mathrm{SD}=0.06) \mathrm{m}$. Men had a mean percentage of body fat of $23.8(\mathrm{SD}=5.7)$. The mean score of women on the muscle strength test was $2.01 \mathrm{Nm} / \mathrm{kg}(\mathrm{SD}=0.75)$. They had a mean weight of $72.7 \mathrm{~kg}$ (SD $=15.0)$ and a mean length of $1.68(S D=0.11)$. Their mean percentage of body fat was $37.2(\mathrm{SD}=5.3)$. Table 1 displays the associations between physical activity related variables (H-PAL, PAD and PAL) and pain disability related variables using spearman 


\section{Pain disability related variables}

$\begin{array}{lccc}\text { Disability } & -0.10 & 0.47 * & -0.19 \\ \text { Fear of injury } & 0.06 & 0.34 * & 0.06 \\ \text { Catastrophizing } & 0.13 & 0.31 * & -0.03 \\ \text { Depression } & -0.02 & 0.30 * & -0.17 \\ \text { Pain intensity } & -0.02 & 0.27 \cdots & 0.07\end{array}$

\section{Physical activity related wariables}

$\begin{array}{lccc}\text { Muscle strength: } & 0.15 & -0.17 & 0.20 \\ \text { H.PAL } & & 0.18 & 0.25^{*} \\ \text { PAD } & & -0.05\end{array}$

H-PAl physical activity level before the onset of back pain:

PAL: physical activity in daily life after the onset of pain

* $0.05 *$ pe0.01

* partial correlation coefficients corrected for age and gender are presented

Table I: Pain disability and physical activity related variables (Spearman nank correlation coefficients are presented).

\begin{tabular}{|c|c|c|c|c|c|}
\hline Dependent variable & Independent variables & $\mathbf{R}^{2}$ & Adj $\mathbf{R}^{2}$ & Standardized B & p-value \\
\hline \multirow[t]{4}{*}{ Disability } & Gender & 0.46 & 0.44 & -0.08 & 0.24 \\
\hline & Age & & & 0.14 & 0.04 \\
\hline & Pain intensity & & & 0.57 & $<0.01$ \\
\hline & Fear of injury & & & 0.19 & 0.01 \\
\hline Physical Activity & Gender & 0.22 & 0.20 & -0.20 & 0.02 \\
\hline \multirow[t]{3}{*}{ Decline (PAD) } & Age & & & -0.04 & 0.65 \\
\hline & Pain intensity & & & 0.20 & 0.03 \\
\hline & Fear of injury & & & 0.38 & $<0.01$ \\
\hline \multirow[t]{5}{*}{ Disability } & Gender & 0,48 & 0.46 & -0.05 & 0.46 \\
\hline & Age & & & 0.15 & 0.04 \\
\hline & Pain intensity & & & 0.52 & $<0.01$ \\
\hline & Fear of injury & & & 0.10 & 0.19 \\
\hline & PAD & & & 0.23 & $<0.01$ \\
\hline
\end{tabular}

Table 2: PAD as a mediator in the relation foar of injury and disability. 
rank correlation coefficients. H-PAL did not relate significantly to any of the pain disability related variables. In contrast, PAD was significantly associated with disability, fear of injury, catastrophizing, depression and pain intensity. PAL was only interrelated with H-PAL. No relations with disability related variables were found.

\section{$P A D$ as a mediator}

In table 2 results of three linear regression analyses are presented.

For all analyses VIFs were low (with a maximum of 1.324 in the third analysis) suggesting that there is no problem of colinearity. In all analyses, Cook's distances did not exceed 1 . In the first analysis with disability as a dependent variable the percentage explained variance appeared to be $44 \%$. In the first model pain intensity proved to be an important variable in the explanation of disability. But also fear of injury contributed significantly with a standardized $B$ of 0.19 . In the second analysis, in which PAD was introduced as the dependent variable, $19.5 \%$ of the variance in PAD could significantly be explained. Fear of movement/(re)injury was the most important variable in the explanation of $\mathrm{PAD}$, with a standardized $\mathrm{B}$ of 0.38 . In the third model. disability was the dependent variable, which was in accordance with the first model. PAD was introduced as an independent variable in the equation. $46 \%$ of the variance in disability could be explained by this model, but after the introduction of PAD, fear of movement/(re)injury no longer contributed significantly. In the analyses focussing on an inverse association, where disability was tested as a mediator in the association between fear of movement/(re)injury and PAD, fear of movement/(re)injury showed a significant contribution to the explanation of PAD, which lasted after the introduction of disability in the model. Also in the analyses on the mediating role of fear of movement/(re)injury in the association between PAD and disability, the significant contribution of PAD to the explanation of disability lasted after the introduction of fear of movement/(re)injury in the model. In other words, support was exclusively found for the mediating role of PAD in the association between fear of movement/(re)injury and disability, and not for other mediation models.

In addition, from identical analyses a mediating role for PAD in the association between catastrophizing and disability was also confirmed.

\section{Lifestyle related differences}

In table 3, activity related scores of formerly sedentary and formerly active patients are presented. Groups were categorized based on the median split of their Baecke-score ( $\mathrm{H}$ PAL), which was 8.4 . In table 4 , results of regression analyses indicated that in the sedentary group $52 \%$ of the variance could be explained by the model. VIFs ranged from 1.088 to 1.158 showing that there was no colinearity. Both PAD and PAL did not significantly contribute to the explanation of disability. In the active group the 


\section{H-PAL}

$$
\begin{aligned}
& 7.4=0.8 \\
& (5.8-8.3)
\end{aligned}
$$$$
9.4 \times 0.9
$$

PAD*

PAL.

$$
\begin{gathered}
191812+72894 \\
(59893-360803)
\end{gathered}
$$

\section{Disability}

$$
\begin{gathered}
40.3+19.1 \\
(1-83)
\end{gathered}
$$

Values are means $*$ SD and ranges

- as PAD was not normally distributed the median score combined with ranges is presented

Table 3: Mean scores on activity related tariables for patients with an active lifostyle as compared to patients with a formerly sedentary liforte.

\begin{tabular}{lllll}
\hline Dependent variable Independent variables & $\mathbf{R}^{2}$ & Adj $\mathbf{R}^{2}$ & Standandized $\mathbf{B}$ & p-value
\end{tabular}

\section{Sedentary (H-PAL $\leq 8.4)$}

Disability

Pain intensity

0.57

0.52

0.64

$<0.01$

Depression

PAD

PAL

Active $(H-P A L>8.4)$

Disability

Pain intensicy
Depression
PAD

0.47

0.42

0.24

0.04

0.07

0.55

$-0.16$

0.16

PAL.

Table 4: Lineair mgression analysis with disability as dependent variable in two groups based on the median split of H-PAL (Baecke). 
percentage explained variance was $42 \%$. In contrary to the sedentary group, in patients who were active before their back pain started, both PAD and PAL contributed significantly in the explanation of disability,

\section{Error analysis}

12 patients $(10 \%)$ had an invalid score on PAL and their score was not used in the calculations. Their registered period of physical activity in daily life as measured with the RT3 was less than 5 days, which was the minimum time period acceptable to express PAL (Gretebeck and Montoye, 1992). This deficient data registration of PAL was most of the time based on insufficient battery charge of the RT3. $16 \%$ of all patients had an incomplete score and for H-PAL. For these patients the total Baecke score could not be calculated. Most incomplete Beacke scores ( 16 of 20) were based on the absence of the work-index, which is an essential part to calculate the total Baecke score. 14 persons of the 16 with an incomplete work-index score were women with full time house keeping activities. They did not significantly differ in age, disability level, level of physical activity or physical performance compared to women with full time housekeeping who had a complete work-index.

\section{Discussion}

In this sample of low back pain patients PAD, in contrast to PAL, was significantly related to disability in patients with sub-acute low back pain. In addition, PAD acted as a mediator in the relation between fear and disability and between the relation of catastrophizing and disability. It appeared that for patients with an active lifestyle before the pain started, PAD was significantly contributing in the explanation of disability, whereas this was not the case for patients with a formerly sedentary lifestyle.

\section{$\mathrm{PAD}$ as a mediator}

Based on table 1 it appeared that disability related variables were related to PAD and not to H-PAL and PAL. These data support the hypothesis that changes in the level of physical activity are more disabling then the actual level of physical activity.

Fearful patients with sub-acute back pain, experience a fear-induced activity decline, which they perceive as disabling. Results from the analyses regarding the association 
between catastrophizing and disability, showed an identical role for PAD as a mediating factor in this association. The apparent interrelation of fear of injury, catastrophizing, a change in physical activity and disability could also be suggested based on the results of a study on graded exposure in chronic pain (Vlaeyen et al, 2002). In this study improvements in pain-related fear and pain catastrophizing were shown, based on exposure in vivo. As a result, on a very short term disability decreased and PAL, which was measured using accelerometry, increased. This rapid increase in activity seems to support the role of behavioural factors in changes in activity levels in pain. Because, if PAL was limited by physiological factors (like physical deconditioning), changes in PAL were not to be expected on such a short term. An improvement of PAL based on an increase in physical fitness would necessitate an intensive physical training programme (McArdle et al, 1996). Based on the results of our study, it can be hypothesized that for an optimal result of graded exposure in vivo, expressed as a high increase in PAL after treatment, not only fear and catastrophizing, but also PAD can be taken into account in the selection of patients.

Pain intensity appeared to be the most disabling factor in patients with sub-acute LBP. This important role for pain intensity in the first phase of LBP was already reported by others (Sieben et al, 2002; Fritz et al, 2001). In the study of Sieben et al in patients with acute back pain, pain intensity was, in accordance with our findings, even more important than fear of injury in the explanation of disability. However, in the explanation of PAD, pain intensity seemed less important as compared to pain-related fear and catastrophizing. In a sub-acute phase of back pain, the disabling role of pain intensity is therefore probably less based on a pain induced activity decline, but will mainly be based on other mechanisms. It is however beyond the scope of this article to explore this alternative routes of the influence of pain intensity on the level of perceived disability in patients with sub-acute low back pain.

\section{The disabling role of PAD and PAL}

The levels of perceived disability for both formerly active and formerly sedentary patients were comparable. However, in the explanation of disability, PAD and PAL seemed important factors in patients with a formerly active lifestyle, but they did not contribute in formerly sedentary patients. In the active group, even after correction for the actual level of activities (PAL), PAD was still significantly related to disability. In these patients, PAL was significantly related to disability. This disabling effect of activity in this active subgroup is even more interesting, given the fact that the mean PAL for this group was still higher (although not significant) as compared to the formerly sedentary group. In contrast, for patients with a sedentary lifestyle before the 
pain started the impact of both PAD and PAL seemed less important in the explanation of disability. Although this pain episode has an impact on their daily life, since they report a level of disability comparable to the active group, their daily physical activity schedule is probably less influenced after the onset of pain. Other factors, such as depression and pain intensity appeared to be more disabling. Keefe and co-workers (2001) reported that a negative emotional state increases the risk of the onset of pain or the exacerbation of pain. It could be hypothesized that in the group with a sedentary lifestyle, mood was already a contributing factor in a patients health status before the back pain started. A negative mood may also negatively influence reported pain intensity, as was shown in an experiment based on a cold-pressor pain tolerance task (Salovey and Birnbaum, 1989). This could explain the high impact of pain intensity in the sedentary group. Although our data support this hypothesis, some caution is justified, since the mean score on the BDI for the sedentary group was only 7.2 (SD= 5.8). This is still rather low for making inferences about the clinical implications associated with depression.

This discrepancy in both activity groups in the relation between a disability related PAD and the actual level of PAL is important to consider in both clinical practice and research. Regarding clinical practice, for patients with a formerly active lifestyle, their daily physical activity schedule seemed more interfered due to pain related factors. They probably report disabling activity restrictions. Notwithstanding, when measuring PAL or level of physical fitness, these will not necessarily be low as compared to the mean levels of the population. On the other hand, sedentary patients will probably report a disabling pain instead of activity restrictions, even although there PAL and level of physical fitness is probably low compared to the mean level of the population. In research, this discrepancy between the reported reason for disability and the actual PAL or level of physical fitness could be an explanation for the absence of an evident association between disability and PAL or disability and physical fitness, which appeared in studies in a cross sectional design (Wittink et al, 2000; Verbunt et al, 2001).

\section{$\mathrm{PAD}$ and disability}

Although the constructs of PAD and disability share many similarities, the data of the sedentary group, as presented in table 4, indicated already, that these constructs are not identical. PAD is not related to disability in this model. Disability has been defined by the World Health Organisation (WHO) as any restriction or lack of ability to perform an activity in the manner or within the range considered normal for a human being (1980). Pain-related disability questionnaires focus therefore on both a decrease in 
capacity in the performance and altered performance of regular activities of daily living in patients with pain. Physical Activity Decline (PAD) is defined as a decrease in the level of physical activity relative to a person's activity level before the onset of pain. PAD is therefore only focused on an individual change in the intensity of PAL. If, for example, an activity can still be performed despite great difficulties due to back pain, this will influence a disability score but will not influence PAD. Compromised performance of an activity can be disabling but not necessary influences PAD. Items featuring the Roland Disability Questionnaire (Gommans et al, 1997) like: 'Because of my back, I use a handrail to get upstairs'; 'My back is painful most of the time'; 'I sleep less well because of my back', do not represent the concept of PAD, which refers to a change in physical activities, and its measure needs to be based on changes in physical activity instead of performance difficulties.

\section{Methodological issues}

In this study H-PAL and PAL, although they representing PAL, were measured using different assessment methods. H-PAL was based on self report (Baecke questionnaire), whereas PAL was obtained by accelerometry. In research on chronic pain, the use of objective methods to measure physical activity instead of self-report is advised in order to avoid the influence of a patients' perception or interpretation of the variable of interest, which can harm test validity (Verbunt et al, 2001). However, information on physical activities as performed in the past can only be obtained based on self-report. In order to measure activities before the back pain started, the Baecke questionnaire was translated in the past tense. To reduce the influence of information bias, the interval between the moment of measurement and the time period the Baecke questionnaire was aimed at (i.e. one year before the back pain started), was chosen to be only 4 to 7 weeks. As H-PAL, also PAD was based on self-report. At this moment, no other assessment method for measuring activity decline is available. However, when in future research the inter-correlation between Beacke and the accelerometer (RT3) is found to be high, computation of PAD scores based on the substraction of Z-scores of Baecke-Z-score of PAL might be an option. In healthy subjects, Philipaerts and coworkers (1999) found that the Baecke questionnaire correlated well with the Tracmor accelerometer, which like the RT3, a triaxial is a accelerometer. However, similar findings in a patient sample is lacking.

This study was based on a cross-sectional design, which implies that the possibility to collect information on causal relationships is limited. Therefore besides the mediating role of PAD in the association fear of injury and disability, also two other associations between the three variables were checked. Firstly it was checked whether disability 
acted as a mediator in the association between fear of movement/(re)injury and secondly if fear acted as a mediator in the relation PAD and disability. In both analyses, no mediating role for either disability or fear of injury was found, which strengthen the finding that PAD had a mediating role in the association fear and disability.

\section{Physical deconditioning}

This study was mainly focussed on PAL and the disabling effect of changes in PAL. But based on the fact that a decrease in one's level of physical activity in daily life leads to physical deconditioning, it can be hypothesized that PAD is also associated with reduced fitness. In this study, muscle strength, representing the actual level of physical fitness, showed no relation with the actual level of physical activity nor with a decline in activities. But as it appeared for PAD, also for physical fitness are changes in fitness probably more disabling than the actual fitness level. At the present, a longitudinal study covering a period of one year after the acute onset of pain, originating from the present study, is underway, investigating fitness related changes and their association with disability. Knowledge on this association would open the prospect for more patient specified interventions directed towards positive changes in disability and physical activity.

Summarizing, in this study a decline in the level of physical activities seemed more disabling as compared to the actual level of activities. An activity decline appeared to play a mediating role in both the association between fear of movement/(re)injury and disability. Both the level of physical activity and a decline in activity seemed more important in the explanation of disability in patients with an active lifestyle before their back pain started as compared with patients with a formerly sedentary lifestyle. Research on the disabling role of physical activity restrictions in back pain should be focussed on PAD instead of PAL.

\section{Acknowledgements}

The authors want to thank Sita van Riet and Piet Portegijs for their cooperation in the inclusion of patients in this study and the participating general practitioners for the reference of the patients. They also want to thank the Department of Movements Sciences of the Maastricht University for the use of the Cybex-equipment in their laboratory. This study was supported by the Council for Medical and Health Research of the Netherlands (NWOMW), grant nr. 904-65-090 and Zorgonderzoek Nederland (ZON) grant nr. 96-06-006. 


\section{REFERENCES}

- Baecke JA, Burema J, Frijters JE. A short questionnaire for the measurement of habitual physical activity in epidemiological studies. Am J Clin Nutr 1982;36:936942.

- Baron RM and Kenny DA. The moderator-mediator variable distinction in social psychological research: conceptual, strategic, and statistical considerations, J of Pers and Soc Psychol 1986;51:1173-1182.

- Battie M, Bigos SJ, Fisher LD, Hansson TH, Nachemson AL, Spengler DM, Wortley $\mathrm{MD}$, Zeh J. A prospective study of the role of cardiovascular risk factors and fitness in industrial back pain complaints. Spine 1989;14:141-147.

- Beck AT, Rush AJ, Shaw BF, Emmery G. Cognitive therapy of depression. John Wiley, New York 1979.

- Biersteker MWA, Broere F, Biersteker PA. Het schatten van een gewichtspercentage lichaamsvet met eenvoudige hulpmiddelen. Geneeskunde en Sport 1983;16:29-32.

- Bolton JE. Accuracy of recall of usual pain intensity in back pain patients. Pain 1999:533-539.

- Bortz WM. The disuse syndrome. West J Med 1984;141:691-694.

- Brennan GP, Ruhling RO, Hood RS et al. Physical characteristics of patients with herniated intervertebral lumbar discs. Spine 1987;12:699-702.

- Convertino VA, Bloomfield SA, Greenleaf JE. An overview of the issues: physiological effects of bed rest and restricted activity. Med Sci Sports Exerc 1997;29:187-90.

- Crombez G, Vlaeyen JWS, Heuts PHTG, Lysens R. Fear of pain is more disabling than pain itself. Evidence on the role of pain-related fear in chronic back pain disability. Pain 1999;80:329-340.

- Davis VP, Fillingin RB, Doleys DM, Davis MP. Assessment of aerobic power in chronic pain patients before and after a multi-disciplinary treatment program. Arch Phys Med Rehabil 1992;73:726-729.

- Durnin JGVA and Womersly J. Body fat assessed from total body density and its estimation from skinfold thickness: measurements on 481 mean and women aged 16 to 72 years. Brit J Nutr 1974:32:77-97.

- Faas A, Chavannes AW, Koes AW, Van den Hoogen JMM, Mens JMA, Smeele I, Romeijnders ACM, van der Laan JR. Practice Guideline "Low Back Pain" (translation) Utrecht, 1996.

- Fritz JM, George SZ, Delitto A. The role of fear-avoidance beliefs in acute low back pain: relationships with current and future disability and work status. Pain 2001;94:7-15. 
- Gommans JH, Koes BW, Tulder MW van. Validiteit en responsiviteit Nederlandstalige Roland Disability Questionnaire. Vragenlijst naar functionele status bij patienten met lage rugpijn. Ned T fysiotherapie 1997;107(2):28-33.

- Goubert L, Crombez G, Vlaeyen JWS, Van Damme S, Van den Broeck A, Van Houdenhove B. De Tampa schaal voor Kinesiofobie: Psychometrische karakteristieken en normering [The Tampa scale for Kinesiophoba: Psychometric properties and norms]. Gedrag en Gezondheid 2000:28:54-62.

- Gretebeck RJ and Montoye HJ. Variability of some objective measures of physical activity. Med Sci Sports Exerc 1992;24:1167-1172.

- Hurri H, Mellin G, Korhonen O, Harjula R, Harkapaa K, Luamo J. Acrobic capacity among chronic low back pain patients. J spinal Disord 1991:4:34-38.

- Jacob T, Baras M, Zeev A, Epstein L. Low back pain: reliability of a set of pain measurement tools. Arch Phys Med Rehabil 2001;82:735-742.

- Keefe FJ, Lumley M, Anderson T, Lynch T, Carson KL. Pain and emotion: new research directions. J Clin Psychol 2001;57:587-607.

- Kellett KM, Kellett DA, Nordholm LA. Effects of an exercise program on sick leave due to back pain. Phys Ther 1991;71:283-290.

- Klenerman L, Slade PD, Stanley IM, Pennie B, Reilly JP, Atchison LE, Troup JDG. Rose MJ. The prediction of chronicity in patients with an acute attack of low back pain in a general practice setting. Spine 1995;20:478-484.

- Kopec J, Esdaile J, Abrahamowitz M, Abenhaim L, Wood-Dauphines S, Lamping D, Williams J. The Quebec Back Pain Disability Scale. Measurement properties. Spine 1995;20(3):341-352.

- Linton SJ. A review of psychological risk factors in back and neck pain. Spine 2000;25:9:1148-1156.

- McArdle WD, Katch FI, Katch VI. Physical activity, health and aging. Exercise physiology. Energy, nutrition and human performance. 4th edition Baltimore, Maryland:Williams\&Wilkins 1996;635-655.

- McCracken LM, Gross RT, Aikens J, Carnkike JCLM. The assessment of anxiety and fear in persons with chronic pain: a comparison of instruments. Beh Res Ther 1996;34:927-933.

- Merskey H and Bogduk N. Classification of chronic pain. Second edition, IASP Task force on taxonomy. LASP press, Seattle, 1994.

- Nielens H and Plaghki L. Cardiorespiratory fitness, physical activity level, and chronic pain: are men more affected than women? Clin J Pain 2001;17:129-137.

- Osman A, Barrios FX, Gutierrez PM, Kopper BA, Merrifield T, Grittmann L. The Pain Catastrophizing Scale: further psychometric evaluation with adults samples. J Behav Med 2000;23:351-165. 
- Philippaerts RM, Westerterp KR, Lefevre J. Comparison of two questionnaires with a tri-axial accelerometer to assess physical activity patterns. Int J Sports Med. 2001;22(1):34-39.

- Philippaerts RM, Westerterp KR, Lefevre J. Doubly labelled water validation of three physical activity questionnaires. Int J Sports Med 1999;20(5):284-289.

- Pincus T, Burton K, Vogel S, Field AP. A systematic review of psychological factors as predictors of chronicity/disability in prospective cohorts of low back pain. Spine 2002;27:E109-E120.

- Protas EJ. Physical activity and low back pain, In Mitchell, M. et al., Pain 1999 an updated review; refresher course syllabus 9th World Congress on Pain, Seattle: IASP press, 1999:145-152.

- Rutherford OM, Jones DA, Newham DJ. Clinical experimental application of the percutaneous twitch superimposition technique for the study of human muscle activation. J Neurol Neurosurg Psychiatry 1986;49:1288-1291.

- Salovey P, Birnhaum D. Influence of mood on health-relevant cognitions. J Pers Soc Psychol 1989;57:539-551.

- Schoppink LM, van Tulder MW, Koes BW, Beurskens AJ, de Bie RA. Reliability and validity of the Dutch adaptation of the Quebec Back Pain Disability Scale. Phys Ther 1996;76:268-275.

- Schmidt AJ. Performance level of chronic low back pain patients in different treadmill test conditions. J Psychosom Res 1985;29:639-645.

- Sieben JM, Vlacyen JW, Tuerlinkx S, Portegijs PJ. Pain-related fear in acute low back pain: the first two weeks of a new episode. Eur J Pain 2002;6(3):229-37.

- Van Damme S, Crombez G, Vlaeyen JWS, Van den Broeck A, Van Houdenhove B. De Pain Catastrophizing Scale: Psychometrische karakteristieken en normering [The Pain Catastrophizing Scale: Psychometric characteristics and norms]. Gedragstherapie 2000.

- Vanderiet K, Adriaensen H, Carton H, Vertommen H. The McGill Pain Questionnaire constructed for the Dutch language (MPQ-DV). Preliminary data concerning reliability and validity. Pain 1987 Sep;30(3):395-408.

- Velde G van der and Mierau D. The effect of exercise on percentile rank aerobic capacity, pain, and self-rated disability in patients with chronic low back pain: a retrospective chart review. Arch Phys Med Rehabil 2000;81:1457-1463.

- Verbunt J, Westerterp K, van der Heijden G, Seelen H, Vlaeyen J, Knottnerus A. Physical activity in daily life in patients with chronic low back pain. Arch Phys Med Rehabil 2001;82:726-730.

- Verbunt JA, Seelen HA, Vlaeyen JW, van der Heijden GJ, Heuts PH, Pons K, Knottnerus JA. Disuse and Deconditioning in Chronic Low Back Pain; Concepts and Hypotheses on Contributing Mechanisms. Eur J Pain 2003;7:9-21. 
- Verbunt JA, Seelen HA, Vlacyen JW, Bousema EJ, van der Heijden GJ, Heuts PH, Knottnerus JA. Pain-related factors contributing to muscle inhibition in patients with chronic low back pain: An experimental investigation based on superimposed electrical stimulation. Clin J Pain (in press).

- Vercoulen JH, Bazelmans E, Swanink CM, Galama JM, Jongen PJ, Hommes O, Van der Meer JW, Bleijenberg G. Physical activity in chronic fatigue syndrome: assessment and its role in fatigue. J Psychiatr Res 1997 ;31(6):661-73.

- Vlacyen JWS, Kole-Snijders AM, Rotteveel AR, Ruesink R, Heuts PH. The role of fear of movement / (re)injury in pain disability. J Occup Rehabil 1995a:5(4): 23552.

- Vlaeyen JWS, Kole-Snijders AMJ, Boeren RGB, Eek H van. Fear of movement/ (re)injury in chronic low back pain and its relation to behavioural performance. Pain 1995b;62:363-372.

- Vlacyen JWS, de Jong J, Geilen M, Heuts PH, van Breukelen G. The treatment of fear of movement/(re)injury in chronic low back pain: further evidence on the effectiveness of exposure in vivo. Clin J Pain 2002;18(4):251-61.

- Westerterp K. Physical activity assessment with accelerometers. Int J Obes Relat Metab Disord 1999;23:3:S45-49.

- World Health Organization, International Classification of impairments, disabilities and handicaps. Geneva 1980.

- Wittink H, Hoskins Michel T, Wagner A, Sukiennik A, Rogers W. Deconditioning in patients with chronic low back pain. Fact or fiction? Spine 2000;25(17)22212228.

- Zitman FG, Griez EJL, Hooijer C. Standaardisering depressie-vragenlijsten. Tijdschr Psychiatr 1989;31:114-135. 
5
$\frac{5}{5}$
$\frac{5}{3}$ 
Chapter 7

General Discussion 


\section{INTRODUCTION}

This thesis is focused on physical functioning of patients with subacute and chronic low back pain.

The main topics are:

- the level of physical activity in daily life (PAL) in patients with chronic low back pain (CLBP),

- the level of physical fitness in patients with CLBP,

- decline of the level of physical activity (PAD) in patients with sub-acute low back pain,

- the association between physical activity in daily life and disability,

- sub-maximal physical performance in patients with chronic pain.

This chapter starts with an overview of the main results of this thesis. Next methodological and practical considerations are discussed. Finally, the conclusions of the study together with recommendations for future research are presented.

\section{Expectations before the start of the study}

It was expected that patients with chronic low back pain were less physically fit as compared to healthy controls. This expectation was based on the fear avoidance model in which it is hypothesized that fear of injury influences physical functioning of patients with chronic low back pain. Avoidance behaviour, as a reaction to fear, influences both the quantity and the quality of physical activities performed. Changes in quantity lead to a lower level of physical activities, the latter being defined as disuse (chapter 2), whereas changes in quality lead to altered movement. In this thesis especially the first hypothesized effect, i.e. changes in quantity of activities, is addressed. Long term avoidance of physical activities will eventually lead to physical deconditioning. In addition, it was expected that patients with a lower level of physical activity in daily life would feel more disabled. 


\section{Are patients with CLBP less physically active as compared to healthy controls?}

Whether the PAL of patients is indeed lower as compared to healthy controls is addressed in chapter 3 and 5. Both chapters present studies in which the PAL of patients and healthy persons matched for age and gender is compared. The results of the study presented in chapter 3 showed no significant difference in PAL between patients and controls. In the study presented in chapter 5, however, a significant lower level of PAL for patients as compared to controls was found. This disagreement between outcomes of both studies could be explained in two ways: firstly by a difference in the method of measurement and secondly by a difference in the participating patients between both studies.

\section{Regarding the first explanation:}

In the study presented in chapter 5, in accordance with other articles discussing PAL in CLBP (Protas, 1999; Nielens and Plagki; 2001), self report was used to measure PAL. However, in studies of Kremer et al (1981) and Schmidt (1986) it was shown that patients in pain were less capable in judging their own physical performance as compared to healthy persons. Self report may contain a discrepancy between how patients function and how they believe they function, which may result in a different reported PAL compared to the actually observed behaviour, thus negatively affecting validity of self report on PAL. In the study presented in chapter 3 this disadvantage of self report does not play a part. In this study the double labelled water technique and accelerometry, which are methods providing data on physiological processes, were used to measure PAL. Both physiological methods are based on activity registration, and their final outcomes were not biased by interpretations of the patient. For this reason, the results based on doubly labelled water technique and accelerometry are preferred over the results based on self report.

\section{Regarding the second explanation:}

A difference in outcome between both studies based on a difference in the participating patients: There was no difference between patients in both studies based on main characteristics such as age, gender and duration of complaints. However, fact was that they attended different health care services, which probably may explain some of the variance in outcome of both studies. Most patients in the study presented in chapter 3 were either visiting primary or secondary care institutes or did not attend medical care at all, whereas all patients participaring in the study presented in chapter 5 were on a waiting list for a rehabilitation program in a tertiary care centre for rehabilitation. This 
could suggest that the impact of the pain problem differed between both patient groups. On the other hand, a finding contrary to this supposition is the fact that both groups reported a disability level which was above the main level for patients with CLBP as reported in the literature (Gommans et al, 1997). Also the percentage of patients with a paid job in both studies, which was $77 \%$ and $60 \%$ respectively, differed only slightly. In summary, the difference in outcome between both studies seems not based on a discrepancy of either demographic or disability related scores. Patients with CLBP seem to be less to equally physically active in daily life as compared to healthy controls.

\section{Are patients with CLBP less physically fit as compared to healthy controls?}

The level of physical fitness of patients with CLBP is reported in the studies presented in chapter 4 and 5. In both studies different aspects of the multidimensional phenomenon physical fitness (including muscle strength, muscle endurance, muscle power, joint flexibility, aerobic fitness, speed, reaction time, balance and body composition) are addressed. In chapter 4 physical fitness was measured as aerobic fitness and in chapter 5 as muscle strength. In chapter 4 aerobic fitness was assessed using a submaximal ergometer test. In this study no controls participated. However, when scores of patients were related to scores of healthy individuals as presented in the literature, the level of aerobic fitness indicated that patients were equally fit as compared to healthy controls. In study 5 muscle strength was measured based on the isometric strength of the quadriceps muscles. Results indicate that patients had significantly lower muscle strength compared to healthy controls. At the same time, patients performed submaximally during muscle strength testing compared to healthy controls as was shown by the lower muscle activation ratio. The lower score during muscle strength testing for patients was based both on a lower level of physical fitness in patients with CLBP and submaximal performance during the test. Patients seemed less fit as compared to controls. The different outcome between both studies may again be explained in two ways: Firstly by the fact that two different components of fitness were evaluated: aerobic fitness in the study in chapter 4 and muscle strength in the study in chapter 5. And secondly, again, a difference regarding the participating patients has to be taken in account. As reported, patients participating in the study presented in chapter 5 were on a waiting list for a rehabilitation program in a tertiary care centre for rehabilitation and patients participating in the study in chapter 4 visited secondary care institutes. However, again in both studies main characteristics like age, gender and duration of complaints were comparable. In both studies patients reported to be disabled based on an above average mean disability score. The percentage patients 
with a paid job was $70 \%$ in chapter 4 and $60 \%$ in chapter 5 respectively, which seemed to differ only slightly. Therefore, the different results in fitness between both studies seems not to be based on a discrepancy in demographic or disability scores. In conclusion, based on the studies in this thesis, patients with CL.BP seemed to be less to equally fit as compared to healthy controls.

Summarizing, relative to healthy controls, patients with CLBP showed low to equal levels of PAL and low to equal levels of fitness. These conclusions are in line with results from other studies, as presented in the review in chapter 3. Based on these findings, it can be concluded that physical changes in CLBP, when present, seem to be more closely related to bodily changes as a result of physical inactivity than to physical immobility. This is important to consider since many articles discussing disuse related changes in patients with CLBP refer to studies from exercise physiology on bodily changes due to immobility as a result of bed rest (Bortz, 1984). In CLBP, functional changes may occur, but the extent of such changes is not equivalent to bodily changes of persons who are immobilized.

\section{Is either a low level of physical activity or a low level of physical fitness disabling?}

To evaluate the impact of the level of physical activity on daily life for patients with CLBP, in all our studies the disabling role of PAL and physical fitness was tested. However, in none of them PAL was related to the level of disability. This suggests that patients with a low PAL not necessarily felt disabled and that similarly, patients who feel very disabled did not necessarily have a low PAL. Also fitness related parameters like aerobic fitness (chapter 4), muscle strength (chapter 5), body weight (chapter 3,4 and 5) and percentage of body fat (chapter 3, 4 and 5) seemed not related to disability. This would suggest that being inactive or unfit is not disabling in CLBP. In chapter 6 , on the other hand, it was shown that PAD was related to disability. A negative change in the level of PAL seems more disabling than being inactive or being unfit. Or in other words, the fact that one's usual activity level is reduced due to the onset of pain is more disabling than eventually having a low level of activity. In chapter 6 it was shown, that in patients who already had a low activity level before the onset of pain a decline in activities, if any, seemed less disabling. In conclusion, a low level of physical activities or a low level of physical fitness are not necessarily disabling, whereas a high decline in physical activities after the onset of back pain is disabling. 


\section{Is muscle strength a representation of the level of physical fitness in patients with CLBP?}

In the study presented in chapter 5 it appeared that patients with CLBP performed submaximally during a maximum isometric muscle strength test as compared to healthy individuals. Evidence for this submaximal performance was found in a decrease in the muscle activation ratio measured using the interpolated twitch technique. In this study, the muscle activation ratio was negatively influenced by a higher score on pain intensity and more psychological distress, which implies a role for behavioural factors influencing muscle inhibition during muscle strength testing. Watson (1999) already mentioned the importance of evaluating non-physical contributing factors during performance tests in CLBP. Non-physical factors can influence performance assessment indicating that the validity of the test may be biased by these pain-related variables. As a consequence for research and clinical practice, in the interpretation of results based on strength measurement in patients with low back pain, submaximal performance has to be taken in account.

\section{Methodological considerations}

\section{Cross-sectional design}

The studies in this thesis are all based on a cross-sectional design. In the studies presented in chapter 3 and 5 patients were compared to healthy controls, whereas in the studies in chapter 4 and 6 within-patient associations of physical and psychosocial variables were explored. However, in an observational study in a cross-sectional design transversal and partly retrospective associations can be tested. The possibilities to make conclusions on causal relationships are limited. For this reason in observational research a study in a longitudinal design is preferred, and this has been prepared by initiating the cohort study of which this thesis analysed the baseline data. Accordingly, patients participating in the study presented in chapter 6 will be followed for one year after the onset of their back pain. The results of this study in a longitudinal design will give more insight in the interrelation between psychosocial variables and variables related to physical activity and there mutual influence over time. These results are, however, not presented in this thesis.

\section{Methods of measurement}

In several studies in this thesis, measurement instruments were used, of which the usage was not yet very common in studies on patients with back pain. We chose these relatively new measures in the research on CLBP, because they fitted our hypothetical concept better in comparison to more traditional techniques. For example, in chapter 
5, the interpolated twitch technique was used to measure submaximal performance based on the muscle activation ratio during muscle strength testing. This method was used before in healthy subjects, in research on neuromuscular disorders and muscle fatigue. A few studies applied this technique in patients with chronic pain (Norregaard et al, 1994 and 1995, Rutherford 1986, Suter and Lindsay 2001 and our study presented in chapter 5). The reliability and validity of this technique in patients with pain has to be further explored. A totally new instrument, based on a new concept was presented in chapter 6: i.e. PAD or physical activity decline. PAD seems to be a promising concept in the search for the role of physical activity in disability in back pain. In chapter $6 \mathrm{PAD}$ was assessed based on self report. At this moment, no other assessment method for measuring activity decline is available. Also for this assessment method validity and reliability are not yet determined. Both instruments need further evaluation in patients with CLBP.

\section{Implications for clinical practice; suggestions for further research}

\section{Increasing physical activities or fimess?}

In this thesis evidence has been presented supporting the hypothesis that patients with CLBP had a lower or equal activity level compared to healthy controls. From research on healthy individuals, it can be shown that already 21 to $53 \%$ of the Dutch population is inactive according to the recommendations for physical activity in daily life (Schuit et al, 1999; Hildebrandt et al, 1999). The latter include 30 minutes or more of moderate intensity physical activity on at least five, but preferable all days of the week (Kemper et al, 2000). For both healthy persons and patients with CLBP long term inactivity results in physical deconditioning (Convertino, 1997). Based on the studies in this thesis, physical deconditioning in CLBP was suggested to be a result of inactivity instead of a result of immobility.

As in healthy individuals, in patients with CLBP an increase in the level of physical activity in daily life will result in a positive change of the level physical fitness. In inactive healthy individuals it appeared that, for the achievement of long term changes in activity and fitness, a focus on a change in behaviour regarding physical activity is favoured over increasing one's level of physical fitness (Baranowski et al, 1998). A primary goal for treatment of inactive patients with CLBP seems therefore analogous to the approach regarding inactive healthy persons, increasing one's physical activity level in daily life. Increasing physical activity levels in patients with CLBP is hypothesized to decrease the level of low back pain disability (chapter 6) and, as in inactive healthy persons (Sparling et al, 2000; Crespo et al, 2002; Elley et al, 2003), it is assumed to lead to multiple beneficial health effects, such as reducing the risk for coronary heart disease and type 2 diabetes. In conclusion, to achieve long term effects, 
programmes focusing on changing the level of activity in daily life in patients with CLBP seems more promising and are favoured over programmes focusing on reconditioning.

\section{What should be the goal for activity treatment in chronic low back pain?}

In healthy individuals, physical activity in daily life has been presented as healthy behaviour (Sparling et al, 2000). Confidence in one's ability to engage in regular activities, enjoyment in physical activity, support from others, positive beliefs concerning benefits of physical activity, and a lack of perceived barriers to being active were reported to be consistent influences on physical activity patterns among adults in the US (USDHHS, 1996). To change activity related behaviour in healthy but inactive persons, individually-adopted healthy behaviour change programs were recommended (Task force, 2000). In such a programme, for each individual person possible limiting factors regarding physical activity are identified. In the attempt to achieve long term positive changes in the level of physical activity in patients with CLBP, identification of factors, which influence activities in daily life negatively are important too. It can be hypothesized, that in patients with CLBP, in order to achieve a positive change in activity related behaviour, individual counselling for limiting factors in activity related behaviour is useful.

However, in patients with CLBP the level of physical activity will be especially interfered by by back pain related factors. Therefore especially these factors should to be explored as limiting factors for one's enhancement in physical activity. As presented in chapter 6 in this thesis, fear of injury, catastrophizing, pain and depression appear to be activity limiting factors, which was shown by their association with the decline in physical activity in patients with subacute low back pain. Evaluation of these factors as a limiting factor for the activity level of the individual patient seems therefore a important. Specified intervention programmes to reduce the influence of this individual activity limiting factor can subsequently be applied. In favour of this supposition are the results of Vlaeyen et al (2002). In their study, in which they treated fearful patients with graded exposure to reduce fear for injury, a long term increase in the level of physical activity was achieved. As presented in chapter 6 , for a subgroup of patients with CLBP a decline in the level of activity was not disabling. For these patients, participating in a programme focused on the increment of activities seems currently not the right moment for achieving activity related behavioural changes.

Individual counselling for patients with back pain could be implemented by a structured anamnesis supported by a screening list for physicians. Screening items are the actual physical activity level, the presence of a decline in activities, the patient specified reason for his/her activity decline, the patient's motivation to change the 
actual situation. Subsequently, results of this screening may lead to an advice for a specified intervention changing activity behaviour. In rehabilitation medicine such an intervention directed to changes in physical activity behaviour can be a part of a rehabilitation treatment focusing on coping with pain. In conclusion, in order to achieve long term changes in the activity level of patients with CLBP, an individual counselling programme focused on determining personal limiting factors in the increment of the level of physical activity in daily life, followed by a patient specific intervention may be promising. To investigate the hypothesized effect of individual screening programmes on the change in activity related behaviour in patients with back pain further research is needed.

\section{Further Recommendations for future research}

\section{Presenting information of studies regarding physical fitness in low back pain}

Similar to the heterogeneity in the activity level of healthy persons, there is also heterogeneity in the activity level of patients with CLBP. In research on physical activity in CLBP, patients are nearly always included by the fact that they were having back pain. As a result of that in articles pain related characteristics are presented. However. in order to be able to compare results of different studies on PAL in patients with CLBP, it is necessary to describe the participating patient population in the study accurately. As was advocated in chapter 2, especially information on work status and information on the way patients were referred to the study seem important. In conclusion, in articles presenting a study on PAL in CLBP, the presentation of work status and the way of reference to the study is needed.

\section{Decline in physical fitness}

As presented in chapter 6 , a decline in the activity level acts as a mediator in the relation between fear and disability. As fear is related to a decline in activities it can also be hypothesized that a decline in activities is also a mediator in the relation between fear and decline in physical fitness. From exercise physiology we know that a decrease in daily activities will lead to a decrease in the level of physical fitness. To study a decline in the level of physical fitness, all patients participating in the study as described in chapter 6 will be followed for one year. If this relation can be confirmed, the role of disuse in the fear avoidance model is also confirmed for a subgroup of patients with CLBP.

\section{Subgroups of activity related behaviour}

In this thesis daily activities are characterized as PAL, which was measured as the intensity of activities in daily life. Based on a difference between groups we were able 
to detect whether patients did less or did more than healthy persons. For a subgroup of patients we were able to confirm that an activity decline based on avoidance behaviour led to disability. This could, however, not explain the disability level of all patients. Apparently not all patients use the same behavioural coping strategies. In chapter 2 it was already suggested that, besides avoidance behaviour as a reaction to pain, also suppressive behaviour is present. The physical activity level of patients coping with suppressive behaviour seem to be characterized based on fluctuations in their activity level instead of a low activity level. These patients ignore pain and overload their muscles, followed by a periodical forced rest, which again is followed by an uncontrolled restart of activities. In the further unravelling of the role of activity related disability research on activity patterns rather than research on a reduced level of activities is needed. By detecting subgroups of patients with different activity related coping strategies, treatment can become more individually focused and therefore will be more effective.

Summarizing, in this thesis the level of physical activity and physical fitness of patients with CLBP seemed less to equal as compared to healthy individuals. A decline in the level of activities seemed more disabling then the actual level of activities in CLBP. Patients with CLBP performed submaximally during performance testing as compared to healthy individuals. To achieve long term changes in the level of physical activity in patients with back pain, an individual counselling programme in determining patient specific limiting factors for enhancement of physical activity is advocated. Further research is needed to distinguish subgroups of patients with different styles of activity related behaviour and to develop specific interventions to change activity related behaviour. 


\section{REFERENCES}

- Baranowski T, Anderson C, Carmack C. Mediating variable framework in physical activity interventions. How are we doing? How might we do better? Am J Prev Med 1998;15(4):266-97.

- Bortz WM. The disuse syndrome. West J Med 1984;141:691-694.

- Convertino VA, Bloomfield SA, Greenleaf JF. An overview of the issues: physiological effects of bed rest and restricted activity. Med Sci Sports Exerc 1997;29:187-90.

- Crespo CJ, Palmieri MR, Perdomo RP, Mcgee DL, Smit E, Sempos CT, I-Min, Sorlic PD. The relationship of physical activity and body weight with all-cause mortality: results from the Puerto Rico Heart Health Program. Ann Epidemiol 2002;12(8):543-52.

- Elley CR, Kerse N, Arroll B, Robinson E. Effectiveness of counselling patients on physical activity in general practice: cluster randomised controlled trial. BMJ 2003:12:326(7393):793.

- Gommans JH, Koes BW, Tulder MW van. Validiteit en responsiviteit Nederlandstalige Roland Disability Questionnaire. Vragenlijst naar functionele status bij patienten met lage rugpijn. Ned Tijdschr Fysioth 1997;107(2):28-33.

- Hildebrandt VH, Urlings IJM, Proper KI, Ooijendijk WTM, Stiggelhout M. Are the Dutch still sufficiently physically active? (Bewegen Nederlanders nog wel voldoende?) In Hildebrandt VH, Ooijendijk WTM, Stiggelhout M. Trendrapport Bewegen en Gezondheid 1998-1999. Koninklijke Vermande, Lelystad,1999;23-52.

- Kemper HCG, Ooijendijk WTM, Stiggelhout M. Consensus about the Dutch recommendation for physical activity to promote health (Consensus over de nederlandse norm gezond bewegen) Tijdschr Gezondheidsw 2000;78:180-183.

- Kremer EF, Block A, Gaylor M. Behavioral approaches to treatment of chronic pain: The inaccuracy of patient self-report measures. Arch Phys Med Rehab 1981;62:188191.

- Malkia E, Ljunggren AE. Exercise programs for subjects with low back disorders. Scand J Med Sci Sports 1996 Apr;6(2):73-81.

- McCracken LM, Gross RT, Eccleston C. Multimethod assessment of treatment process in chronic low back pain: comparison of reported pain-related anxiety with directly measured physical capacity. Beh Res and Ther 2002;40:585-594.

- Nielens H, Plaghki L. Cardiorespiratory fitness, physical activity level, and chronic pain: are men more affected than women? Clin J Pain 2001;17:129-137.

- Nørregaard J, Bülow PM, Danneskiold-Samsøe B. Muscle strength, voluntary activation, twitch properties, and endurance in patients with fibromyalgia. J Neurol Neurosurg Psychiatry 1994;57:1106-1111. 
- Nørregaard J, Bülow PM, Vestergaard-Poulsen P, Thomsen C, Danneskiold-Samsøe B. Muscle strength, voluntary activation and cross-sectional area in patients with fibromyalgia. Br J Rheumatol 1995;34:925-931.

- Protas EJ. Physical activity and low back pain, In Mitchell, M. et al, Pain 1999 an updated review; refresher course syllabus 9th World Congress on Pain, Seattle: IASP press, 1999:145-152.

- Rutherford OM, Jones DA and Newham DJ. Clinical experimental application of the percutaneous twitch superimposition technique for the study of human muscle activation. J Neurol Neurosurg Psychiatry 1986;49:1288-1291.

- Schmidt AJ. Persistence behaviour of chronic low back pain patients in treadmill test with false and adequate feedback. Thesis 1986.

- Schuit AJ, Feskens EJM, Seidell JC. Lichamelijke activiteit in samenhang met sociaal-demografische determinanten en gezondheidskenmerken bij volwassen mannen en vrouwen in Amsterdam, Doetichem en Maastricht. Ned Tijdschr Gencesk 1999;143(30):1559-1564.

- Sparling PB, Owen N, Lambert EV, Haskell WL. Promoting physical activity; the new imperative for public health. Health Educ Res 2000;15:367-376.

- Suter E, Lindsay D. Back muscle fatigability is associated with knee extensor inhibition in subjects with low back pain. Spine 2001;26(16):E361-E366.

- Task Force on Community Preventive Services. Recommendations to increase physical activity in communities. Am J Prev Med 2002;22:67-72.

- van Tulder M, Malmivaara A, Esmail R, Koes B. Exercise therapy for low back pain: a systematic review within the framework of the cochrane collaboration back review group. Spine 2000 1;25(21):2784-96.

- US Department of Health and Human Services, Physical Activity and Health: a Report of the Surgeon General. Department of health and human services, Centers for Disease Control and Prevention, National Center for Chronic Disease Prevention and Health Promotion, Atlanta,1996:3-8.

- Vlaeyen JW, de Jong J, Geilen M, Heuts PH, van Breukelen G. The treatment of fear of movement/(re)injury in chronic low back pain: further evidence on the effectiveness of exposure in vivo. Clin J Pain 2002;18(4):251-61.

- Watson PJ. Non-psychological determinants of physical performance in musculoskeletal pain, In Mitchell, M. et al, Pain 1999 an updated review; refresher course syllabus 9th World Congress on Pain, Seattle: LASP press 1999:153-158. 
$\frac{8}{3}$ 
Chapter eight

SUMMARY 


\section{SUMMARY}

Epidemiological studies in western countries have reported a life time incidence of low back pain ranging from 49 to $70 \%$. Six weeks after an acute onset of low back pain 75 to $90 \%$ of patients is recovered. For the majority of low back pain patients the pathophysiologic mechanism of low back pain is unknown. About $10 \%$ of patients with acute back pain without a known specific cause, eventually develop chronic low back pain (CLBP). However, this group accounts for $75 \%$ to $90 \%$ of the societal costs of back pain. Because of these huge social and financial consequences research in pain has, for several decades, been focussed on causal biomedical models for the transition from acute to chronic low back pain. In recent years, however, the emphasis has shifted from biomedical models to biopsychosocial models. One of the latest biopsychosocial models is the fear avoidance model. According to this model, fear of pain/(re)injury plays an important role in the transition from acute to chronic pain in a subgroup of patients with low back pain. Patients may fear an increase of pain or re-injury if they perform physical activities, which, to their opinion, will harm them. As a result, they avoid these activities. In the long run, this avoidance behaviour can result in a combination of negative health consequences: disability, depression and disuse. The latter may be defined as a decreased level of physical activities in daily life and will result in physical deconditioning. In contrast to the influence of fear on the perceived disability level, the presumed negative influence of fear on the level of physical activity in daily life leading to disuse and accompanying physical deconditioning still lacks a firm scientific base. In this thesis the role of disuse and physical deconditioning in CLBP is investigated. Firstly, an extensive review of the literature concerning the role of physical activity and physical fitness in CLBP was performed (chapter 2). Secondly, three studies were performed to investigate the presence of disuse (chapter 3 ) and physical deconditioning (chapter 4 and 5) in patients with CLBP. Subsequently, the last study focuses on patients with sub-acute low back pain and in this study the decline in physical activities after the onset of pain instead of the actual level of activities is the central theme of research (chapter 6).

In chapter $\mathbf{2}$ an overview of the literature concerning disuse and physical deconditioning in both healthy individuals and patients with CLBP was presented. The phenomenon "disuse" was described as performing at a reduced level of physical activity in daily life. The construct of "physical deconditioning" was described as a decreased level of physical fitness with emphasis on both negative physiological consequences, muscle atrophy, osteoporosis, and changes in metabolism as well as negative functional consequences, such as a decrease in muscle strength, a decrease in aerobic capacity and impaired motor control. In this chapter, two explanatory models for chronicity in low back pain, both based on physical performance, are discussed, i.e. 
the fear avoidance model and the avoidance endurance model. In accordance with the fear-avoidance model as described earlier, the avoidance endurance model also describes a subgroup of patients with low back pain who avoid activities and develop deconditioning and CLBP. But, in addition to this subgroup of patients with avoidance strategies as a coping mechanism, the avoidance endurance model also identifies a second subgroup of patients who cope with pain using endurance strategies. These patients appear to ignore the pain, and, by their suppressive behaviour, overload their muscles (overuse), which leads to muscular hyper-reactivity. This long-term muscular hyper-reactivity can, eventually, cause disability in CLBP. Furthermore chapter 2 includes an overview of studies regarding physical activity in daily life (PAL) and physical fitness of patients with CLBP as compared to healthy individuals. Published studies indicate that PAL of patients is either lower or comparable to PAL of healthy subjects. Also the level of physical fitness of CLBP patients appeared to be lower or comparable to the fitness level of healthy persons. These findings may partly be explained by different measurement methods used in research on PAL and physical fitness in chronic pain within and between studies. However, unfit patients with back pain are more likely to be unemployed and thereby may show less physical activity, and reduced PAL, while fit persons are more frequently employed, and may be involved more in physical activity. In summary, based on this review of the literature, both the presence of disuse or physical deconditioning in CLBP could not be confirmed.

In chapter 3 the hypothesis, based on the fear avoidance model, that patients with CLBP are less physically active as compared to healthy individuals of the same age and gender, was tested. As a second objective in this study the construct validity of accelerometry as a measurement method for physical activity in daily life was investigated. To address the second objective, two measurement methods for physical activity in daily life were used; i.e. accelerometry and the doubly labeled water technique. By means of a tri-axial accelerometer the amount of body movement during daily physical activities in three directions was assessed and the total day-score was presented as PAL. Based on the doubly labeled water technique, PAL was computed as the ratio between average daily metabolic rate (ADMR) and resting metabolic rate (RMR). The latter was measured by the ventilated hood method. Both accelerometry and the doubly labeled water technique were used simultaneously during fourteen days. The level of physical activities (PAL) of patients with CLBP and healthy controls did not differ significantly. Therefore, in this study the presence of disuse in this sample of CLBP patients was not confirmed. The tri-axial accelerometer appeared to be a valid instrument for measuring daily activity in patients with CLBP. 
Chapter 4 focused on the result of disuse: physical deconditioning, which was operationalized as cardiovascular capacity. The hypothesis, derived from the fear avoidance model, that fear of injury leads to disability and physical deconditioning in patients with CLBP was tested in this study. 40 patients with chronic non-specific LBP performed a submaximal exercise test according the protocol of Siconolfi. In addition, their level of perceived disability (Roland Disability Questionnaire) and fear of injury (Tampa-scale) were measured. A significant association was found between fear of injury and disability, which was in agreement with other studies. However, no association between fear of injury and physical deconditioning was found. The results of this study again confirm that patients with more fear of injury feel more disabled but do not necessarily have a lower level of physical fitness. The assumption that fear of injury leads to physical deconditioning was not confirmed in this sample of patients with CLBP.

In chapter 5, physical deconditioning was again addressed. In the study presented in this chapter, physical deconditioning was operationalized as muscle strength. This study was aimed at the evaluation of muscle strength, as a component of physical deconditioning, and central activation ratio (CAR), representing the performance level during testing, in patients with CLBP as compared to healthy controls. In addition, the contribution of cognitive behavioural and pain-related factors to the CAR of CLBP patients was evaluated. Twenty-five patients with CLBP and 25 age and gendermatched controls participated. Muscle strength, i.e. peak torque of the quadriceps muscle, was measured on a Cybex dynamometer. During peak torque (T) the quadriceps muscle was percutaneously stimulated using superimposed electrical stimulation, generating an additional twitch torque (Ttwitch) in case of submaximal performance. CAR was calculated as $\mathrm{T} /(\mathrm{T}+\mathrm{T}$ twitch). To evaluate cognitive behavioural and pain-related factors influencing CAR, measures of fear of injury (TSK), pain catastrophizing (PCS), psychological distress (SCL90) and pain intensity (VAS) were used. Mean muscle torque (per $\mathrm{kg}$ lean body mass) in patients was significantly less than in controls. Median CAR was significantly lower in patients. Patients experiencing increased psychological distress and patients with a higher current pain level showed a lower CAR. In conclusion, results in this study support the presence of physical deconditioning in CLBP. However, it also appeared that in the interpretation of decreased muscle strength, in terms of physical deconditioning, in patients with CLBP, submaximal performance has to be taken into account. In addition, CLBP patients who report increased psychological distress and a higher level of current pain tend to show increased inhibition of muscle activity, leading to submaximal performance. 
In chapter 6, the hypothesis was tested whether a decline in the level of physical activity (PAD) is more appropriate in the explanation of disability in patients with subacute back pain as compared to the actual level of physical activity (PAL). Also the hypothesis that PAD acted as a mediator in the association between fear of injury and disability was tested. In this study, patients with sub-acute low back pain ( 4 to 7 weeks of non-specific low back pain) participated. Their habitual level of physical activity before the back pain started (H-PAL) and the reported decline in the level of physical activity after the onset of pain (PAD) were assessed by means of a questionnaire. The actual level of physical activity (PAL) was assessed using accelerometry. The interrelation of these physical activity-related variables with perceived disability (QBPDS), fear of injury (TSK), pain catastrophizing (PCS) and pain intensity (VAS) was examined. Based on a set of three linear regression analyses the role of PAD as a mediator in the association between fear of movement/(re)injury and disability was examined. In total, 123 patients with sub-acute low back pain, i.e. 66 men and 57 women, participated. PAD rather than PAL and H-PAL was significantly correlated with disability, fear of movement/(re)injury, pain catastrophizing and pain intensity. PAD and PAL appeared more important in the explanation of disability in the subgroup of patients who were physically active before their back pain started as compared to formerly sedentary people. Generally, PAD indeed seems to mediate the association between fear of movement/(re)injury and disability. Results of this study indicate that the perceived decline in physical activity rather than the current physical activity itself is important in the evaluation of the impact of activity-related changes on disability in low back pain.

Chapter 7 comprises the general discussion. In the studies presented in this thesis, in agreement with other studies, the level of physical activity in daily life of patients with CLBP appeared to be lower to comparable with healthy controls. The level of physical fitness for patients proved to be lower or comparable to healthy controls. A decrease in physical fitness seemed better explained as the result of physical inactivity instead of the result of physical immobility. Not in all patients their low level of physical activities or low level of physical fitness was disabling. In a subgroup of patients it was confirmed that not a low level of physical activities but rather a decline in activities was perceived as being disabling. Since the association of disability and physical activity differed for individual patients, it was suggested that treatment concerning activity increase should also be more individualized. It is suggested that in patients with a decline in the level of activities after the onset of back pain, a change of behaviour towards physical activity instead of physical reconditioning may favour a long term activity increase. For clinical practice an individual screenings programme concerning the level of physical activity and the decline in activities is suggested. In addition, personal limiting factors for an activity increase have to be identified. Several goals for future research were identified, 
notably: a. a further evaluation of measurement methods for assessing physical activity in patients with CLBP; and b. the identification of subgroups regarding physical activity behaviour in patients with CLBP, in order to be able to further individualize treatment. 


\section{SAMENVATting}

Gedurende hun leven ervaart 49 tot $70 \%$ van de mensen op enig moment hinder van lage rugklachten. $\mathrm{Na} 6$ weken is de pijn bij 75 tot $90 \%$ van de patiènten met acute pijn echter verdwenen. Bij een groot deel van de patiënten met acute pijn in de rug is de pijn niet verklaarbaar door een organisch lijden. Bij $10 \%$ van de patiènten, waarbij geen organische oorzaak voor hun klachten wordt gevonden, wordt de pijn uiteindelijk chronisch. Alhoewel deze groep klein is, is het maatschappelijke probleem van aspecifieke lage rugpijn anzienlijk. Van alle kosten met betrekking tot rugpijn gaat 75 tot $90 \%$ naar deze groep. Het vinden van verklaringsmodellen en behandelingsmogelijkheden voor aspecifieke lage rugpijn is dan ook een belangrijk aandachtspunt in het wetenschappelijk onderzoek gericht op pijn. In de loop der jaren is het accent in onderzock naar pijn van somatische gerichte verklaringsmodellen naar biopsychosociale verklaringmodellen verschoven. Een van de biopsychosociale verklaringsmodellen is het fear avoidance model. Volgens dit model zal een subgroep patiènten na een acuut probleem aan de lage rug angst hebben om tijdens bewegen een nieuw letsel op te lopen en/of een verergering van de pijn te krijgen, waardoor ze activiteiten gaan vermijden. Langdurig vermijden van lichamelijke activiteit kan vervolgens leiden tot een toename in ervaren beperkingen, verminderde lichamelijke activiteit in het dagelijks leven (disuse) en depressic. In tegenstelling tot de relatic angst en ervaren beperkingen is de relatie angst en disuse onvoldoende wetenschappelijk onderbouwd. Dit proefschrift richt zich daarom ten eerste op disuse en zijn consequenties voor de lichamelijke conditie in chronische rugpijn, en ten tweede op de relatie tussen angst en disuse bij patiënten met chronische rugpijn. Bij aanvang van het project is een literatuurstudie verricht naar bestaande literatuur betreft disuse in chronische lage rugpijn (hoofdstuk 2). Drie deelstudies zijn verricht, met als doel het toetsen van het bestaan van disuse (hoofdstuk 3) en zijn gevolg fysieke deconditionering (hoofdstuk 4 en 5) bij patiënten met chronische lage rugklachten. De laatste deelstudie (hoofdstuk 6) richt zich op patiënten in een subacute fase na het ontstaan van rugklachten. In deze studie staat niet het huidige activiteitenniveau maar het verlies aan activiteiten als een gevolg van pijn centraal. In hoofdstuk 7 volgt uiteindelijk de algehele discussie.

Hoofdstuk 2 beschrijft een overzicht over bestaande literatuur gericht op het bestaan van disuse en fysieke deconditionering in zowel gezonden als in patiënten met chronische lage rugklachten. Disuse wordt omschreven als een verminderd niveau van lichamelijke activiteiten in het dagelijks leven. Het gevolg hiervan is fysieke deconditionering; een vermindering van de lichamelijke conditie, zich uitend in negatieve fysiologische gevolgen, zoals spieratrofie, verandering in het celmetabolisme, osteoporose en obesitas en negatieve functionele gevolgen op het gebied van 
spierkracht, uithoudingsvermogen en coördinatie. Naast het reeds hierboven beschreven fear avoidance model bestaat een tweede gedragsmatig verklaringsmodel voor ervaren beperkingen in chronische lage rugpijn: het avoidance endurance model. Evenals in het fear avoidance model wordt in het avoidance endurance model een groep patiënten onderscheiden die gekarakteriseerd wordt door angst voor bewegen. Daarnaast onderscheidt het avoidance endurance model echter een subgroep patiënten die de pijn negeert en zich te zwaar lichamelijk belast, waardoor pijn persisteert op basis van overbelasting. Ook in dit model leidt de persisterende pijn uiteindelijk tot een toename van ervaren beperkingen. In dit hoofdstuk wordt tevens een overzicht gepresenteerd van artikelen die een vergelijking maken tussen het dagelijks activiteiten niveau en de lichamelijke conditie van patiënten met chronische lage rugklachten en gezonden. Er werden uiteenlopende resultaten beschreven. Patiënten waren minder actief of even actief dan gezonden. Tevens werden resultaten gevonden waarin blijkt dat patiënten minder fit of even fit zijn dan gezonden. Een mogelijke verklaring voor de discrepantic in onderzoeksresultaten was het gebruik van verschillende onderzoeksmethoden om zowel activiteit in het dagelijks leven als lichamelijke conditie te meten. Het nog uitvoeren van betaalde arbeid is mogelijk een bepalende factor voor fitheid van patiënten. Zowel het bestaan van disuse als fysieke deconditionering in chronische lage rugpijn werden in dit literatuur-overzicht niet bevestigd.

In hoofdstuk 3 wordt de eerste deelstudie gepresenteerd. De hypothese, gebaseerd op het fear-avoidance model, dat patiënten met chronische lage rugklachten een lager activiteitenniveau (disuse) hebben in vergelijking met gezonde vrijwilligers van hetzelfde geslacht en dezelfde leeftijd werd hierin getoetst. Tevens werd de validiteit van een accelerometer (Tracmor) voor het meten van de intensiteit van de dagelijkse activiteiten bij patiënten met chronische lage rugklachten gerelateerd aan de dubbel gelabelde watertechniek dat als referentiemaat diende. De tri-axiale accelerometer registreert versnellingen van het lichaam tijdens bewegen in drie richtingen en geeft op basis daarvan een totaalscore over de intensiteit van fysieke activiteit per dag. De dubbel gelabelde watertechniek meet het energieverbruik tijdens de dagelijkse activiteiten op basis van het totale energieverbruik gerelateerd aan het individuele rustmetabolisme. Beide meetinstrumenten registreerden gedurende twee weken de intensiteit van de dagelijkse lichamelijke activiteiten. Het activiteitenniveau van patiënten en gezonden was niet significant verschillend. De hypothese betreffende het bestaan van disuse in chronische lage rugpijn werd in dit onderzoek derhalve niet bevestigd. De validiteit van de accelerometer werd als voldoende beoordeeld $(r=0.72)$.

Hoofdstuk 4 richt zich op de gevolgen van disuse: fysieke deconditionering in chronische lage rugpijn. Aëroob vermogen, als component van lichamelijke conditie, staat in dit hoofdstuk centraal. De hypothese, die gebaseerd is op het fear-avoidance 
model, van de deelstudie beschreven in hoofdstuk 4 luidr: door angst ervaren patiënten met chronische lage rugklachten een hoge mate van beperkingen in het dagelijks leven, die gepaard gaat met een laag niveau van de lichamelijke conditie. In totaal 40 patiënten met chronische lage rugklachten voerden een submaximale fietsergometer test volgens het protocol van Siconolfi uit. Tevens werd het niveau van ervaren beperkingen gemeten met de Roland Disability Questionnaire en de mate van angst voor letsel met de Tampa schaal. Een statistisch significante samenhang werd gevonden tussen angst voor letsel en ervaren beperkingen. E.r werd geen samenhang gevonden tussen angst en de aërobe conditie. De resultaten van deze studie bevestigen opnieuw het verband tussen angst en ervaren beperkingen in chronische lage rugklachten, terwijl de gehypothetiseerde relatie tussen angst en fysieke deconditionering niet werd bevestigd.

Hoofdstuk 5 richt zich, evenals hoofdstuk 4, op fysieke deconditionering. Spierkracht, als component van lichamelijke conditie, staat in dit hoofdstuk centraal. Tevens is het uitvoeren van een fysieke taak, zoals een spierkrachtmeting, een aandachtspunt. De studie, die wordt beschreven in dit hoofdstuk, richtte zich op een vergelijking tussen de uitvoering van een spierkrachtmeting, door patiënten met chronische lage rugklachten en gezonde vrijwilligers. De invloed van cognitief gedragsmatige en pijn gerelateerde factoren tijdens het uitvoeren van deze fysieke taak werd beoordeeld. In totaal 25 pariënten met chronische lage rugklachten en 25 controle personen gematched op leeftijd en geslacht voerden een (submaximale) isometrische spierkrachtmeting van de musculus Quadriceps uit. Om de mate van aanspanning van de spier tijdens het uitvoeren van de taak te bepalen werd deze spier tijdens de meting oppervlakkig elektrisch gestimuleerd. Een onvolledige spieraanspanning werd gezien als een submaximale uitvoering van de test. Als factoren die mogelijk met een submaximale spieraanspanning konden samenhangen werden gemeten: catastroferen, angst voor letsel, ervaren pijn intensiteit en ervaren psychische klachten. Patiënten scoorden lager tijdens de spierkrachtmeting dan gezonden. Dit bleek echter (deels) te verklaren door een significant lager niveau van spieraanspanning bij patiënten, duidend op onvolledige spieraanspanning. Binnen de patiënten groep bleken patiënten met een hogere ervaren pijnintensiteit en/of een hogere mate van ervaren psychische klachten een statistisch significant lager niveau van spieraanspanning te hebben. Deze studie geeft aanwijzingen voor het bestaan van fysieke deconditionering in patiènten met chronische lage rugklachten. Echter met een submaximale uitvoering van spierkrachtmetingen door patiënten ten opzichte van gezonden moet bij deze conclusie rekening worden gehouden.

In hoofdstuk 6 wordt de hypothese getoetst of het beperkingenniveau meer samenhang vertoont met een verlies van activiteiten als gevolg van rugklachten, dan 
met het huidige activiteiten niveau bij het bestaan van rugklachten. Tevens wordt getoetst of het reductie in activiteiten na het ontstaan van rugklachten een mediërende rol speelt in de gepostuleerde relatie tussen angst voor letsel en beperkingen; ofwel dat angst voor letsel bij patiënten tot een verlies van activiteiten in het dagelijks leven leidt, waardoor zij zich vervolgens beperkt voelen. Ook in de relatie catastroferen en beperkingen wordt een mediërende rol van een reductie in activiteiten onderzocht. Aan deze studie namen 123 patiënten met 4 tot 7 weken bestaande aspecifieke lage rugklachten. Het lichamelijke activiteiten niveau voor het ontstaan van rugklachten en het verlies aan activiteiten werden beide gemeten met een vragenlijst. Het huidige activiteitenniveau bij het bestaan van rugklachten werd gemeten met een accelerometer. De resultaten toonden dat het ervaren beperkingen niveau statistisch significant samenhangt met het verlies aan activiteiten en niet met het huidige activiteiten niveau. Op basis van een combinatie van drie regressie analyses werd vervolgens een aanwijzing gevonden voor de mediërende rol van het verlies aan activiteiten in de relatie angst en ervaren beperkingen. Ook voor de relatie catastroferen en ervaren beperkingen werden aanwijzingen gevonden voor de medierende rol van een reductie in activiteiten. Tevens werd op basis van afzonderlijke analyses duidelijk dat de beperkende rol van een activiteitenverlies voor patiënten met een voorheen actieve levensstijl en patiënten met een voorheen passieve levensstijl verschillend was. Door patiënten met een voorheen actieve levensstijl werd pijn en een reductie in activiteiten als beperkend ervaren. Voor patiënten met een voorheen passieve levensstijl bleken pijn en depressie beperkende factoren. De reductie in activiteiten bleek in deze groep niet beperkend. De resultaten van deze studie bevestigen dat niet een laag niveau van dagelijks activiteiten, maar de reductie in activiteiten een beperkende rol speelt bij patiënten met subacute rugklachten. Tevens geeft een reductie in activiteiten in patiënten met een voorheen actieve levensstijl aanwijzingen voor het bestaan van disuse bij een subgroep van patiënten met subacute lage rugklachten.

Tenslotte volgt in hoofdstuk 7 algehele discussie. In dit proefschrift wordt, in overeenstemming met eerdere studies, aangetoond dat het activiteitenniveau van patiënten met CLBP verminderd tot gelijk is ten opzichte van gezonde vrijwilligers. Tevens zijn patiènten met CLBP verminderd tot even fit dan gezonde vrijwilligers. Een verminderde conditie als gevolg van rugklachten zal eerder samenhangen met inactiviteit dan met immobiliteit. Niet voor alle patiënten met een laag niveau aan activiteiten in het dagelijks leven of een laag niveau in lichamelijke conditie is dit een beperkende factor. Bij een subgroep van de patiënten is aangetoond dat met name het verlies aan dagelijkse activiteiten na het ontstaan van rugklachten en niet het huidige niveau van activiteiten beperkend is. Daar de relatie beperkingen en lichamelijke activiteit in het dagelijks leven dus voor individuele patiënten verschillend kan zijn, wordt verdere individualisering van de therapie ten aanzien van activiteitenopbouw 
voorgesteld. Ten behoeve van een activiteitenopbouw bij patiënten met een verlies aan activiteiten na het ontstaan van rugklachten wordt gedragsverandering ten aanzien van lichamelijke activiteit in het dagelijks leven in plaats van fysieke reconditionering voorgesteld. Voor de klinische praktijk wordt een individuele screening gericht op het niveau van lichamelijke activiteiten en een verandering van activiteiten niveau naar aanleiding van de rugklachten voorgesteld. Tevens wordt geadviseerd de persoonlijk belemmerende factor in de opbouw van activiteiten te identificeren. Als doel voor toekomstig wetenschappelijk onderzoek wordt gesuggereerd: 1 het verder evalueren van meetinstrumenten voor lichamelijke activiteit en lichamelijke conditie toegepast in een patiëntengroep met chronische lage rugklachten 2. onderzoek naar subgroepen binnen de patiënten met chronische lage rugklachten gebaseerd op gedrag ten aanzien van lichamelijke activiteit in het dagelijks leven, zodat verdere specificering van behandeling mogelijk is. 


\section{About The author}

Jeanine Verbunt was born August 9, 1969 in Breda, The Netherlands. In 1987 she obtained her VWO diploma at the Schaepmancollege in Dongen and started her study in Health Sciences at the Medical Faculty of the University Nijmegen. She specialized in movement sciences and graduated in 1991. Subsequently, she started her medical training at the same faculty and graduated in 1996. During her medical study she participated in an epidemiological research project focusing on risk factors for typhoid fever in Semarang, Indonesia. In 1997 she was registered as an epidemiologist. In 1996 she started as a trainee (AGIKO) in rehabilitation medicine at the Rehabilitation Foundation Limburg (SRL) and the Institute for Rehabilitation Research (iRv). She combined her training for consultant in rehabilitation medicine, from which she graduated in March 2003, with the preparation of this thesis. At the moment she works both as a consultant in rehabilitation medicine in the Laurentius Hospital of Roermond and as research co-ordinator at the Rehabilitation Foundation Limburg. 


\section{DANKWOORD}

Met dit laatste hoofdstuk in het "bockje" wil ik mijn AGIKO-opleiding revalidatie definitief gaan afsluiten. Deze bladzijden wil ik dan ook graag benutten om een aantal mensen, die gedurende mijn opleidingstijd een belangrijke rol hebben gespeeld, te bedanken.

Als eerste: Henk Seelen. Zonder jou was dit proefschrift er nooit geweest! Ik weet dat je je inbreng zelf soms bagatelliseert, maar zonder jouw kennis over wetenschappelijk onderzoek en je taalkundige kennis was ik nu pas bij hoofdstuk 4 of was ik zelfs nooit tot daar gekomen. Bedankt voor je begeleiding en de prettige samenwerking. Ik hoop dat we in de komende jaren samen nog aan vele onderzoeken kunnen werken. Johan Vlacyen; Van jouw grote expertise op het gebied van onderzoek in de chronisch pijn heb ik veel geleerd. Ook de fijne samenwerking heb ik zeer gewaardeerd. Aan de "discussie-uurtjes op maandag rond zessen" met Henk en jou heb ik veel gehad. Geert van der Heijden; De eerste jaren was je mijn begeleider op het iRv, later toen je in Utrecht ging werken stond je wat meet op de achtergrond. André Knottnerus; Gedurende zeven jaar een promovendus (een soort AIOTHO) begeleiden is een lange rit. Bedankt voor je inzet en begeleiding.

Mijn dank gaat ook uit naar alle opleiders revalidatiegeneeskunde in circuit Limburg, die mij het vak van revalidatiearts hebben geleerd. In het bijzonder wil ik mijn hoofdopleider (dokter) Kees Pons bedanken voor zijn inzet gedurende de afgelopen jaren tijdens mijn opleiding tot revalidatiearts. Ook zijn inbreng en die van Peter Heuts in de projectgroep van mijn onderzoek heb ik zeer gewaardeerd. Alle arts-assistenten, waarmee ik in opleiding was. Gery Bos wil ik bedanken, omdat ze er in de laatste maanden van mijn opleiding voor zorgde dat ik wat meer ruimte kreeg om te schrijven. Bedankt voor je collegialiteit! Martine van Egdom, we hebben gelijktijdig onze opleiding tot revalidatiearts gevolgd. Alhoewel we in werkelijkheid meer dan $200 \mathrm{~km}$ uit elkaar zaten, leek je veel dichterbij. Bedankt voor je vriendschap! Daarnaast wil ik de AGIKO's revalidatie van het eerste uur; Jan-Willem, Leo, Nanne, Tanneke en Mark bedanken voor de onderlinge steun door de jaren heen, die met name in de eerste jaren van de opleiding voor mij heel belangrijk was.

Judith Sieben en Sita van Riet. Samen met Eric vormden we het team van de BackUse studie, waarvan de laatste studie van dit proefschrift een onderdeel was. Bedankt voor de geweldige samenwerking! Sita, je was (en bent) het logistieke brein achter BackUse. Judith, alhoewel het afstemmen van onze studies een hels karwei was, vond ik onze 
afstemming perfect. Bedankt voor je flexibiliteit als ik weer opnieuw voor een half jaar terug ging naar de patiëntenzorg en jij de kar weer meer moest trekken. Piet, als begeleider van Judith was je niet direct betrokken bij mijn studie, maar tijdens ons gezamenlijke overleg inspireerde je me steeds tot nadenken. Ik genoot van de borrels met jullie in de lerse Pub bij iedere 50ste patiënt (of als dat te lang duurde, ter ere van een ter plekke verzonnen te vieren alternatief).

Mijn bijzondere dank gaat ook uit naar alle patiënten en vrijwilligers in de controlegroep, die hebben deel genomen aan een van de deelonderzoeken beschreven in dit proefschrift. Zonder jullie was dit onderzoek nooit mogelijk geweest!!! Ook wil ik de medewerkers van de afdeling Bewegingswetenschappen van de UM bedanken voor hun gastvrijheid en het beschikbaar stellen van de Cybex apparatuur. Tevens dank voor de afdeling fysiotherapie van het AZM, die ons gedurende de verbouwing van het bewegingslab bij BW de mogelijkheid boden, hun Cybex te gebruiken.

Klaas Westerterp en Erwin Meijer van de vakgroep Humane Biologie van de UM; Bedankt voor de begeleiding bij het uitvoeren van de metingen met de gelabelde watertechniek. Pam de Vos, bedankt voor je bijdrage tijdens je wetenschapsstage geneeskunde aan de studie beschreven in hoofdstuk 4.

Ook dank aan de subsidiegevers die dit onderzoek en het drukken van het proefschrift mogelijk hebben gemaakt.

Mijn collega's van (de vroegere) gang twee op het iRv! Yvonne, Roelof, Jolanda, Anja, Caroline, Marielle, Olga, Jos, Marcel, Jeroen, Jacques en Camiel. Ik kwam steeds weer voor ongeveer een half jaar bij jullie binnenvliegen. Het viel niet bij te houden!!! Jolanda; de eerste jaren deelden we samen een kamer op het IRV. Ik heb in die tijd veel "onderzoeksweetjes" van je kunnen afkijken. Bovendien vond ik het heel gezellig. Yvonne, samen met Marion mijn "onderzoeks-steunpilaar". Anja, Marielle en later Jacques; de 'pijn-reisjes' waren heel geslaagd samen met jullie.

Alle onderzockers betrokken bij FADIS en LOBADIS, de onderzoeksprogramma's van NWO en ZON op het gebied van chronische lage rugklachten. De "eerste lichting" Madelon, Jeroen, Jeffrey, Ruud, Marielle, Claudine, Sandra, Rob en Ludwig en iedereen die daarna aansloot. De discussies bij onze gezamenlijke bijeenkomsten gaven steeds stof tot nadenken.

Margot, Nancy, Jolanda, Ellen, Yvonne, Erika en Carine, de vriendenclub uit Nijmegen. Onder andere door jullie onderzoeksverhalen werd ik (opnieuw) aangestoken en ben ik als dokter toch weer op het onderzoekspad terechtgekomen. Ik heb de kunst van het promoveren bij jullie kunnen afkijken. Hopelijk maak ik met dit boekje mijn switch van toen, als bewegingswetenschapper naar de studie geneeskunde 
een beetje goed. Alle kano-, fiets-, wandel- en "bijklets"-weekenden met jullie (met of zonder de steeds groter wordende kroost) in de afgelopen jaren deden me goed. Margot, ik geef het stokje nu aan jou. Zet hem op!

Eric, de laatste jaren van het project was je bijdrage aan het onderzoek onmisbaar. Je hebt heel wat patiënten met een geruststellend woord kunnen overtuigen, dat het allemaal niet zo erg was als het leek. En dat terwijl onze spierkracht-meetopstelling inderdaad wel... een heel klein beetje dan... gelijkenis vertoonde met 'een elektrische stoel'. Daarnaast gaf je blik als fysiotherapeut vaak een extra dimensie aan de discussies. Het sprak vanzelf dat je mijn paranimf zou zijn. Ik hoop dat we in de toekomst onze samenwerking kunnen voortzetten. Marion, je was mijn steun in het leren balanceren met één voet in de wetenschap en de andere in de patiëntenzorg. Je was nooit officiecl mijn opleider, maar je bent voor mij wel heel belangrijk geweest tijdens mijn opleidingsperiode. Bedankt voor al je adviezen en steun. Marion en Eric: Ik ben er trots op dat jullie mijn paranimfen zijn.

Tenslotte wil ik mijn dank richten aan mijn familie. Mijn tante Corrie Verbunt, die helaas in het voorjaar van 2003 overleden is. $\mathrm{Ik}$ wil haar nog bedanken voor haar inbreng in dit onderzoek als "tester" van alweer een nieuwe opstelling, maar meer nog voor het feit dat ze een bijzondere tante was. En vooral wil ik mijn dank richten aan mijn ouders: Mijn pa, die in 1997 is overleden is en mijn ma; Bedankt voor jullie steun door de jaren heen!!!!

En dan zet ik nu, na ruim 7,5 jaar, definitief een punt achter mijn AGIKO-opleiding revalidatie. 


\section{LIST OF ABBREVIATIONS}

$\begin{array}{ll}\text { ADMR } & \text { average daily metabolic rate } \\ \text { AGIKO } & \text { Assistent Geneeskundige in opleiding tot klinisch onderzoeker } \\ \text { BDI } & \text { Beck Depression Inventory } \\ \text { BPAQ } & \text { Baecke Physical Activity Questionnaire } \\ \text { CAR } & \text { central activation ratio } \\ \text { CLBP } & \text { chronic low back pain } \\ \text { CV } & \text { coefficient of variation } \\ \text { EMG } & \text { electromyography } \\ \text { FADIS } & \text { Fear Avoidance Beliefs, Physical Disuse and Pain Disability } \\ & \text { in Low Back Pain (NWO research program) } \\ \text { FCE } & \text { functional capacity evaluation } \\ \text { FRR } & \text { flexion relaxation ratio } \\ \text { FT } & \text { fast twitch } \\ \text { H-PAL } & \text { habitual physical activity level } \\ \text { ICC } & \text { intraclass correlation coefficient } \\ \text { LBM } & \text { lean body mass } \\ \text { LBP } & \text { low back pain } \\ \text { LOBADIS } & \text { Low Back Disability and Rehabilitation Strategy } \\ & \text { (ZON research program) } \\ \text { QBPDS } & \text { Quebec Back Pain Disability Scale } \\ \text { PAD } & \text { physical activity decline } \\ \text { PAL } & \text { physical activity level } \\ \text { PARS } & \text { physical activity rating scale } \\ \text { PCL } & \text { Pain Cognition List } \\ \text { PCS } & \text { Pain Catastrophizing Scale } \\ \text { PBF } & \text { percentage of body fat } \\ \text { RDQ } & \text { Roland Disability Questionnaire } \\ \text { RMR } & \text { resting metabolic rate } \\ \text { SCL90 } & \text { Symptom Check List } \\ \text { SD } & \text { standard deviation } \\ \text { SLBP } & \text { subacute low back pain } \\ \text { ST } & \text { slow twitch } \\ \text { T } & \text { torque } \\ \text { Ttwitch } & \text { twitch torque } \\ \text { TSK } & \text { vampa scale of kinesiophobia analogue scale } \\ \text { VAS } & \end{array}$


$\mathrm{VO} 2 \max$ maximum oxygen uptake

$25 \% a m p$ the individual amperage level resulting in a twitch of $25 \%$ of a subjects' maximum voluntary torque 
